Aus dem Department für Endokrinologie

(Prof. Dr. med. W. Wuttke)

der Medizinischen Fakultät der Universität Göttingen

\title{
Wirkung von selektiven Östrogenrezeptormodulatoren auf die Metaphyse der Tibia ovarektomierter Ratten als Therapiemodell der postmenopausalen Osteoporose der Frau
}

\author{
INAUGURAL-DISSERTATION \\ zur Erlangung des Doktorgrades \\ der Medizinischen Fakultät \\ der Georg-August-Universität zu Göttingen
}

\author{
vorgelegt von \\ Antje Herbst \\ aus \\ Weimar
}

Göttingen 2008 
Dekan:

1. Berichterstatter:

2. Berichterstatter/in:

3. Berichterstatter/in:
Prof. Dr. med. C. Frömmel

Prof. Dr. med. W. Wuttke

Tag der mündlichen Prüfung: 



\section{Inhaltsverzeichnis}

\section{Seite}

Inhaltsverzeichnis

Abkürzungsverzeichnis

\section{Einleitung} Folgen

1.2. Hormone

1.2.1. Die Gruppe der Steroidhormone 11

1.2.2. Die Östrogene 11

1.2.3. Aufbau, Funktionsweise und Verteilung der 12 Östrogenrezeptoren $\alpha$ und $\beta$

1.2.4. Hormonumstellung im weiblichen Organismus in der 14 Perimenopause

1.3. Knochen 15

1.3.1. Der Aufbau von Röhrenknochen $\quad 15$

1.3.2. Die Östrogenrezeptorverteilung im Röhrenknochen 16

$\begin{array}{ll}\text { 1.3.3. Untersuchung der Metaphyse } & 17\end{array}$

1.3.4. Der Knochenstoffwechsel und Stoffwechselmarker 17

1.4. Osteoporose 18

1.4.1. Pathophysiologie der Osteoporose 19

1.4.2. Bedeutung von $\mathrm{ER} \alpha$ und $\mathrm{ER} \beta \quad 20$

$\begin{array}{ll}\text { 1.4.3. Diagnosemöglichkeiten } & 21\end{array}$

1.5. Therapieoptionen 21

1.5.1. Die Hormonersatztherapie (HRT) 22

1.5.2. Die Gruppe der SERMs 23

1.6. Tiermodell und Untersuchungsverfahren 23

1.7. Eingesetzte Substanzen 24

1.7.1. ER $\alpha$ - und ER $\beta$-Agonist 24

1.7.2. 17ß-Östradiol 24

1.7.3. Antiöstrogen ICl 25

1.8. Ziel der vorliegenden Arbeit 25 
2.1. Die Versuchstiere und ihre Haltung 26

2.2. Die Nahrung 26

2.3. Die Identifizierung der Tiere $\quad 27$

2.4. Die Gruppeneinteilung 27

2.5. Die Gewichtsbestimmungen 28

2.6. Die Computertomographie 28

2.7. Die Narkose 29

2.8. Die Ovarektomie 30

2.9. Die Injektionstherapie 30

2.10. Die verabreichten Substanzen 32

2.11. Die Tötung der Tiere und die Probengewinnung 32

2.12. Die standardisierte metaphysäre Tibiafraktur 33

2.13. Die Serumanalyse 34

2.14. Die statistischen Methoden 35

3.2. Körpergewicht 37

3.3. Ergebnisse der Knochendichtemessung in der Metaphyse 38

3.3.1. Spongiosadichte in der Metaphyse der Tibia 39

3.3.2. Kortikalisdichte in der Metaphyse der Tibia 40

3.4. Ergebnisse der Querschnittsflächenmessung in der 41

3.4.1. Endostale Fläche in der Metaphyse der Tibia 42

3.4.2. Kortikalisquerschnittsfläche in der Metaphyse der Tibia 43

3.5. Periostaler Umfang an der Metaphyse der Tibia 44

3.6. Standardisierte metaphysäre Tibiafraktur $\quad 45$

3.6.1. Bruchkraft 46

3.6.2. Maximalkraft 47

3.7. Serumanalyse der Knochenstoffwechselmarker $\quad 48$

$\begin{array}{lll}\text { 3.7.1. } & \text { Rat Laps } & 49\end{array}$

$\begin{array}{lll}\text { 3.7.2. Osteokalzin } & 50\end{array}$ 
4.1.

Futteraufnahme und Körpergewichte

4.2. Knochenarchitektur, Knocheneigenschaften und Knochenstoffwechsel 52

4.3. Kritische Beurteilung des Studienaufbaus 


\section{Abkürzungsverzeichnis}

Abb.

AF-1/AF-2

AS

BAP

BMD

BMI

$\mathrm{cm}^{3}$

CT

DBD

DHT

DNS

DVO

DXA

$\mathrm{E}_{2}$

ER

$\mathrm{ER} \alpha$

ER $\beta$

ERKO

$\alpha$ ERKO

$\beta E R K O$

$\mathrm{FSH}$

$g$

$\mathrm{GnRH}$

HRT

$\mathrm{HVL}$

ICI

IL-1

IL-6

$\mathrm{kDa}$

LBD

$\mathrm{LH}$

LM

$\mu \mathrm{g}$

$\mathrm{mg}$
Abbildung

Transcription Activation Function im ER

Aminosäure

Bonespecific Alcalic Phosphatase

Bone Mineral Density / mineralische Knochendichte

Body Mass Index

Kubikzentimeter

Computertomographie

DNA Binding Domain / DNS-Bindungs-Domäne des ER

Dihydrotestosteron

Desoxyribonukleinsäure

Dachverband Osteologie

Dual-Energy X-ray Absorptiometry

17ß-Östradiol, = E2

Östrogenrezeptor, zwei Subtypen: ER $\alpha$ und ER $\beta$

Östrogenrezeptor $\alpha$

Östrogenrezeptor $\beta$

ER- knock- out- Mäuse

ER $\alpha$ - knock- out- Mäuse

ERß- knock- out- Mäuse

Follikelstimulierendes Hormon

Gramm

Gonadotropin Releasing Hormone (= LHRH =FSHRH)

Hormone Replacement Therapy, Hormonersatztherapie

Hypophysenvorderlappen

Bezeichnung für den verwendeten ER-Antagonisten

Interleukin-1

Interleukin-6

Gewichtseinheit Dalton (Da), $1000 \mathrm{Da}=1 \mathrm{kDA}$

Ligand Binding Domain / Ligandenbindungsdomäne des ER

luteinisierendes Hormon

Lösungsmittel

Mikrogramm

Milligramm 


$\begin{array}{ll}\mathrm{mm}^{2} & \text { Quadratmillimeter } \\ \text { OC } & \text { Osteokalzin, Serumparameter der Osteoblastenaktivität } \\ \text { ovx } & \text { ovarektomiert } \\ \text { qCT } & \text { quantitative Computertomographie } \\ \text { QUS } & \text { quantitativer Ultraschall } \\ \text { Rat Laps } & \text { Serumparameter der Osteoklastenaktivität } \\ \text { RIA } & \text { Radio-Immuno-Assay } \\ \text { s.c. } & \text { subkutan } \\ \text { SERMs } & \text { Selective Estrogen Receptor Modulator, selektiver } \\ & \text { Östrogenrezeptor-Modulator } \\ \text { s.u. } & \text { siehe unten } \\ \text { TGF- } \beta & \text { Transforming Growth Factor }-\beta \\ \text { TNF } \alpha & \text { Tumor-Nekrose-Faktor } \alpha \\ \text { u.a. } & \text { und andere } \\ \text { vs } & \text { versus } \\ \text { WHO } & \text { World Health Organisation }\end{array}$

\section{Symbole}

$\varnothing$

Durchschnitt

C

Grad Celsius

$\%$

Prozent 


\section{Einleitung}

Die durchschnittliche Lebenserwartung der Menschen in den Industrieländern hat sich in den letzten einhundert Jahren verdoppelt und bis heute den Punkt der Stagnation noch nicht erreicht.

Bei Frauen bedeutet dies durch den unveränderten Zeitpunkt der Menopause (Wich und Carnes,1995), dass ein Drittel ihres Lebens postmenopausal stattfindet. Dieser Lebensabschnitt wird durch den Verlust der ovariellen Funktion bestimmt und resultiert daher in einer gravierenden Verschiebung des Hormonhaushaltes. Besondere Konsequenzen resultieren aus der fehlenden Wirkung der Östrogene.

Diese Veränderung zeigt sich in einer Vielzahl von klimakterischen Symptomen. Der empfundene Anteil, wie Hitzewallungen, Schlafstörungen, Unruhe und Abgeschlagenheit, wird von Frau zu Frau sehr individuell erlebt, stellt aber häufig ein behandlungsbedürftiges Problem dar. Die organisch-manifesten Anzeichen hingegen sind Langzeitfolgen des perimenopausalen Hormondefizits und stellen sich gehäuft in Form von urogenitaler Atrophie mit funktionellen Folgen, der Zunahme von kardiovaskulären Krankheitsereignissen und Sterberaten sowie dem Anstieg der Osteoporoserate dar.

Auch gesundheitlich indizierte Ovarektomien führen zu einer Gruppe von behandlungsbedürftigen Frauen, bei welchen durch den abrupten, künstlichen Beginn der Postmenopause gleiche Symptome auftreten.

\subsection{Perimenopause, Hormonumstellung und daraus resultierende Folgen}

Die Perimenopause (Klimakterium) umfasst den Übergang der reproduktionsfähigen Phase einer Frau hin zum Erlöschen der Keimdrüsenfunktion. Diese Veränderungen werden durch typische Umstellungen im hormonellen System hervorgerufen, wobei die Stärke der Symptomausprägung individuell variiert. Veränderungen bezüglich des weiblichen Körpers werden unabhängig von Rasse, Herkunftsland, Kultur, Ernährung und persönlichen Faktoren beobachtet.

Erste Symptome (s. u.) zeigen den Eintritt der Frau in die Prämenopause, den ersten definierten Abschnitt der Perimenopause. Diese umfasst nach WHO-Definition (SeifertKlauss et al.,2005) den Zeitraum vom Auftreten der ersten Zyklusunregelmäßigkeiten bis ein Jahr nach der Menopause. Die Menopause ist die letzte spontane Regelblutung ovariellen Ursprungs und lässt sich nach 12 Monaten retrospektiv datieren. Mit dem Auftreten dieses 
definierten menstruationsfreien Intervalls ist die Perimenopause abgeschlossen und die Postmenopause beginnt. In diesem Lebensabschnitt ist die Frau nicht mehr fortpflanzungsfähig. Ab dem Alter von etwa 65 Jahren schließt sich, bis zum Lebensende andauernd, das Senium an.

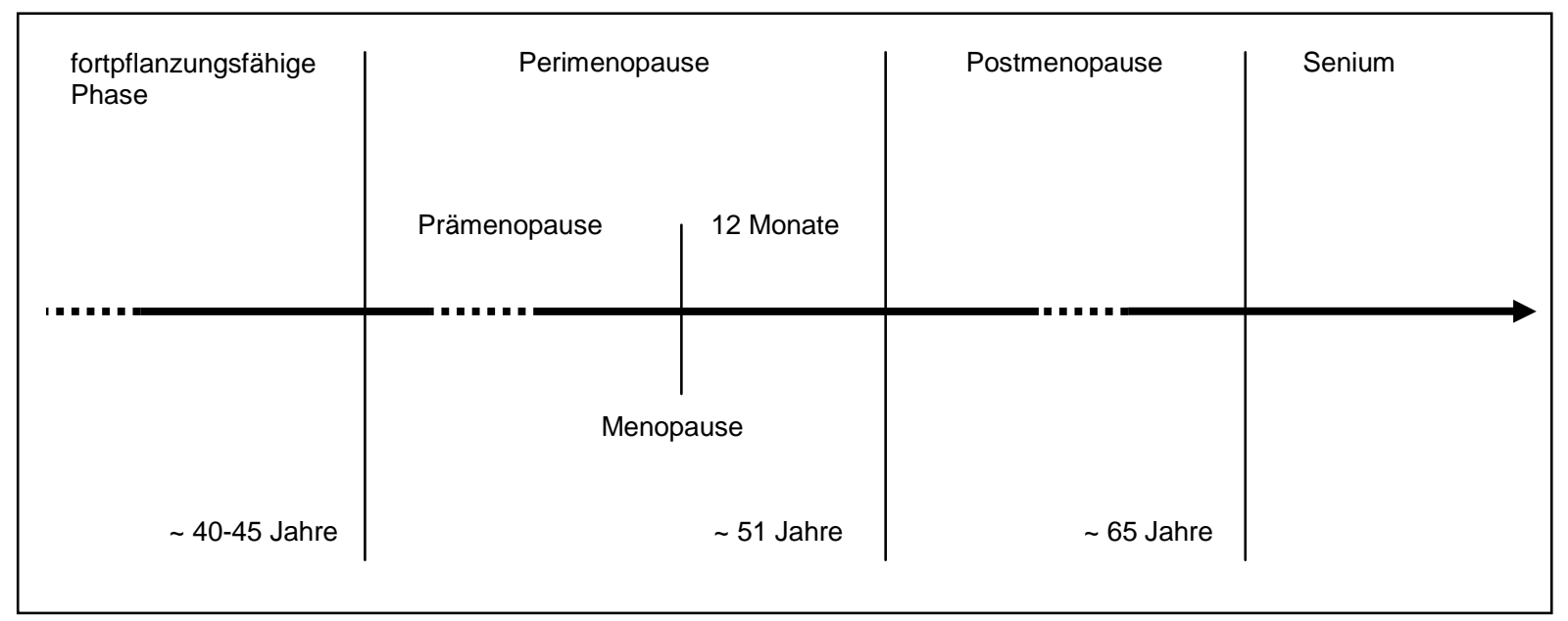

Abb. 1.1. Übersicht über die physiologische Einteilung der zweiten Lebenshälfte der Frau

Die oft ersten Auffälligkeiten sind Unregelmäßigkeiten im menstruellen Zyklus, gefolgt von vasomotorisch bedingten Hitzewallungen, Depressionen und Schlafstörungen. Vaginale Trockenheit und Atrophie (Barrett-Connor,1993; Wich und Carnes,1995), sowie Störungen der Harnwege (Barrett-Connor,1993; Wich und Carnes,1995; Seidlová-Wuttke et al.,2004a) sind häufig dokumentierte Probleme. Als Langzeitfolge erhöht sich die kardiovaskuläre Morbidität und Mortalität (Barrett-Connor,1993; Wich und Carnes, 1995) und das Osteoporoserisiko (Barrett-Connor,1993; Wich und Carnes,1995; Bell,2003; Wronski et al.,1987). In einzelnen Studien sind ein erhöhtes Krebsrisiko im Bereich des Reproduktionstrakts (Barrett-Connor,1993) und ein steigender Körperfettanteil (Lovejoy,2003) beobachtet worden. 


\subsection{Hormone}

\subsubsection{Die Gruppe der Steroidhormone}

Die Gruppe der Steroide lässt sich in 7 Untergruppen einteilen. Östrogene, Gestagene und Androgene sind sexuale Steroide und haben ihren Hauptbildungsort in den Gonaden (Kuiper et al.,1997). Mineralokortikoide und Glukokortikoide, aus der Nebennierenrinde, sowie Vitamin D und die Gallensäuren bilden die restlichen 4 Fraktionen. Allen ist gemeinsam, dass innen Cholesterol als Ausgangsstruktur zugrunde liegt (Norman und Henry,2003). Alle lassen sich bezüglich ihres Aufbaus auf ein Steran-Gerüst zurückführen.

Der Einfluss der Gonadotropine (LH, FSH) bedingt, entsprechend deren Blutkonzentrationen, die Weitersynthese $z u$ den benötigten Sexualhormonen. Unter dem Einwirken des Hypophysenvorderlappenhormons LH (Luteinisierendes Hormon) kommt es zur Umwandlung von Cholesterol zu Gestagenen und weiter zu Androgenen. FSH (Follikelstimulierendes Hormon), gleichen Ursprungs wie LH, ist hingegen für den Umbau der Androgene zu Östrogenen verantwortlich. In beiden Geschlechtern finden sich sowohl die weiblichen Sexualhormone, die Östrogene, als auch die männlichen, die Androgene. Entscheidend ist hierbei, dass sie geschlechterspezifisch verschieden konzentriert vorkommen. Das häufigste und am stärksten wirksame Östrogen ist das Östradiol $\left(E_{2}\right)$. Für Testosteron gilt selbiges in der Gruppe der Androgene.

\subsubsection{Die Östrogene}

Die im Rahmen der Perimenopause stattfindenden hormonellen Veränderungen im Körper der Frau resultieren größtenteils aus dem Absinken des Östrogenspiegels. Östradiol $\left(E_{2}\right)$ gilt als wichtigstes und am stärksten wirksames weibliches Sexualhormon und erfährt seine Hauptproduktion in den Ovarien. Unter dem Prinzip der negativen Rückkopplung über Hypothalamus und Hypophyse setzt der HVL (Hypophysenvorderlappen) FSH in die Blutbahn frei, was wiederum die Bildung und Freisetzung von $E_{2}$ in den ovariellen Granulosazellen stimuliert. Es existieren des Weiteren die Östrogenmetabolite Östron $\left(E_{1}\right)$ und Östriol $\left(E_{3}\right)$, deren Wirksamkeit zurücksteht. Östrogene wirken über zwei spezifische Östrogenrezeptoren, ER $\alpha$ und ER $\beta$. 


\subsubsection{Aufbau, Funktionsweise und Verteilung der Östrogenrezeptoren $\alpha$ und $\beta$}

Im Jahr 1986 wurde im Uterusgewebe der Ratte ein östrogenselektiver Hormonrezeptor nachgewiesen. 1995 sorgte die Entdeckung eines weiteren Östrogenrezeptors in der Prostata der Ratte für Aufsehen (Kuiper et al.,1998b). Kurze Zeit später gelang auch der Nachweis in menschlichem Gewebe (Mosselman et al.,1996). Nachträglich wurde der bis dahin bekannt Rezeptor in ER $\alpha$ (Östrogenrezeptoer alpha) umbenannt und der neu entdeckte als ER $\beta$ (Östrogenrezeptor beta) definiert.

Beide gehören zur Familie der Kernrezeptoren (Kuiper et al.,1996), welche maßgeblichen Einfluss auf die Transkription bestimmter Gene ausüben und daher auch zur Gruppe der ligandenaktivierten Transkriptionsfaktoren zu zählen sind (Dahlman-Wright et al.,2003; Katzenellenbogen et al.,2000).

Trotz vieler Gemeinsamkeiten bestehen Unterschiede in der chromosomalen Lokalisation (Gustafsson,1999), der Aminosäurenanzahl und der molekularen Masse (ER $\alpha$ : 595 AS, 66 kDa; ERß: 485 AS, 54 kDa) (Bord et al.,2001). Beide bestehen aus fünf (Saunders, 1998) bzw. sechs (Nardulli,2003) Strukturdomänen, die mit A-F benannt sind. A und B werden meist als zusammengehöriger Komplex aufgeführt, woraus sich auch die abweichende Zahlenangabe, entsprechend der wissenschaftlicher Betrachtungsweise, ergibt. Die aminoterminale A/B-Domäne beinhaltet den transkriptionsfördernden Funktionskomplex AF1, welcher ligandenunabhängig arbeitet und nur durch voll wirksame ER-Antagonisten gehemmt wird. Für die Bindung des aktivierten Rezeptors an die DNS ist die C-Domäne, die DNS-Bindungsdomäne (DBD), verantwortlich. Als ,hinge'-Region, mit rein struktureller Bedeutung, wird der Abschnitt $D$ des ERs bezeichnet. Alle Liganden finden ihre Kontaktstelle in der Region E des Rezeptors, der Ligandenbindungsdomäne (LBD). Das carboxyterminale Rezeptorende $\mathrm{F}$ enthält die zweite Transkriptionsaktivierungseinheit AF-2 (Dechering et al.,2000).

Dem grundsätzlich gleichen Aufbau stehen strukturelle Abweichungen gegenüber. Hinsichtlich der DBD der beiden Subtypen erhält man, je nach Autor, Homogenitätsangaben zwischen >90\% (Kuiper et al.,1997) und 97\% (Gustafsson,1999). Die strukturelle Übereinstimmung im Bereich der LBD ist geringer und wird, auch autorenabhängig, mit 55\% (Kuiper et al., 1997) bis 60\% (Dechering et al.,2000) angegeben.

Die Varianz der LBD erlaubt die Schlussfolgerung, dass spezifische Liganden sowohl für $E R \alpha$ als auch für ER $\beta$ vorliegen müssen (Gustafsson, 1999).

ER-kompatible Substrate (Steroide und Analoga) haben die Fähigkeit, frei durch die Zellmembran der Zielzelle zu diffundieren. Erreichen sie die LBD und binden, so führt dies zur Aktivierung, gekennzeichnet durch Konformationsänderung des Rezeptors. Nun ist der 
Ligand-Rezeptor-Komplex in der Lage, über seine DBD an das „estrogen respons element", eine Struktur in der Promotorregion des Zielgens, zu binden und auf diesem Weg die spezifische Genexpression und nachfolgende Transkription (Bagchi,2003) zu steuern.

Zusätzliche Effekte haben auch die so genannten Co-Regulatoren, bei welchen man Aktivatoren und Repressoren unterscheidet (Nardulli,2003). Agonisten an der LBD des ERs ermöglichen die Bindung für Co-Aktivatoren. Diese wiederum ermöglicht die Transkription. Antagonisten ist dies nicht möglich (Dechering et al.,2000), wodurch der Kontakt zur DNS und somit die Transkription behindert wird.

Die Konzentration der hormonellen Liganden in der Zelle hat ebenfalls Einfluss auf die Wirkung des ERs. Beispielsweise benötigt ER $\beta$ das Östrogen $E_{2}$ in 10-fach höherer Konzentration, verglichen mit $\mathrm{ER} \alpha$, um eine vollständige Transkriptionsaktivität zu entfalten (Dahlman-Wright et al.,2003). Gleichzeitig ist eine höhere Affinität des Östradiols zu ER $\alpha$ gegenüber ERß bekannt (Saunders, 1998).

Als weiteres Kriterium der Wirkungsentfaltung kommt dem Verteilungsmuster der Östrogenrezeptoren eine bedeutende Rolle zu. Es bedingt den östrogenen Einfluss auf Haut, kardiovaskuläres System und Knochen, um nur einige zu nennen (Tapiero et al.,2002). Die Verteilung der Rezeptorsubtypen $\alpha$ und $\beta$ stellt hierbei eine zusätzliche Möglichkeit der Wirkungsmodulation dar (Kuiper et al., 1997).

$\mathrm{ER} \alpha$ ist der häufigste Östrogenrezeptor in der Leber (Fritzemeier et al.,2004; Kuiper et al.,1998b), der Hypophyse und im Uterus (Cowley et al.,1997; Dechering et al.,2000; Fritzemeier et al.,2004).

ER $\beta$ präsentiert seine Hauptvorkommen hingegen in den Granulosazellen der Ovarien, der Prostata (Dechering et al.,2000; Fritzemeier et al.,2004) und der Lunge (Cowley et al.,1997; Dahlman-Wright et al.,2003; Fritzemeier et al.,2004; Kuiper et al., 1998b).

In Harnblase und Harnröhre (Seidlová-Wuttke et al.,2004a), im Knochen, im ZNS und im Gefäßsystem (Kuiper et al.,1998b) kommen ebenso wie im Hypothalamus und im Thymus (Dechering et al.,2000) beide Östrogenrezeptortypen vor.

In Anbetracht dieses komplexen Verteilungsmusters scheint die Erfüllung verschiedener Funktionen durch den jeweiligen Subtyp als durchaus wahrscheinlich (Katzenellenbogen und Korach, 1997). 
$\underline{E R \alpha}$

$\underline{E R \alpha+E R \beta}$

- Hypophyse

- Leber

- Uterus

ER $\beta$

- Lunge

- Granulosazellen der Ovarien

- ZNS

- Hypothalamus

- Gefäßsystem

- Harnblase

- Harnröhre

- Knochen

Abb. 1.2. Übersicht über die Verteilung der Östrogenrezeptorsubtypen im Körper der geschlechtsreifen Frau

\subsubsection{Hormonumstellung im weiblichen Organismus in der Perimenopause}

Bereits Jahre vor dem merklichen Auftreten anovulatorischer Menstruationszyklen ist das Follikelwachstum gemindert und die Anzahl verfügbarer Follikel nimmt ab. Dadurch sinkt die Konzentration des aus den Ovarien stammenden Inhibins. Die GnRH (Gonadotropin Releasing Hormone) -Ausschüttung aus dem Hypothalamus steigt und somit auch die Freisetzung von LH und FSH aus dem Hypophysenvorderlappen (Nardulli,2003; Buckler,2005). Der prämenopausale Anstieg von FSH gilt als eines der ersten Zeichen der beginnenden Perimenopause (Wich und Carnes, 1995). Durch das Auftreten eisprungsfreier Menstruationszyklen reduziert sich die Menge des in den Granulosazellen produzierten Östrogens. Die erhöhte Konzentration von FSH, mit fehlendem Angriffspunkt an den Follikeln, stimuliert ab dieser Zeit mehr denn je die Androgenproduktion der ovariellen Stromazellen. Die Produktion der Testosteronvorstufe Androstendion in den Nebennieren bleibt unterdessen unangetastet (Wilson,2003), auch wird weiterhin der Großteil der Androgene in der Leber und im peripheren Fettgewebe zu Östrogenen umgewandelt (Breckwoldt,2001; Wüster und Ziegler,1999). Durch diesen extragonadalen Mechanismus besteht im weiblichen Organismus auch nach Ovarektomie ein geringer, konstanter Östrogenspiegel (Chakravarti et al.,1976, Sluijmer et al.,1995). Die Aromatisierung im 
Fettgewebe erklärt die höheren Östrogenkonzentrationen bei Frauen mit höherem BMI im Vergleich zu Frauen mit niedrigerem Körperfettanteil.

Der bisher unauffällige, physiologische Einfluss der männlichen Sexualhormone wird häufig durch den menopausalen Überschuss in Form von Haarausfall, einer tieferen Stimme und Seborrhoe sichtbar.

\subsection{Knochen}

Um das von uns untersuchte Krankheitsbild der postmenopausalen Osteoporose zu verstehen, ist es vorab sinnvoll, sich die grundsätzlichen Gegebenheiten des Knochens noch einmal zu vergegenwärtigen. Dies soll am Modell des langen Röhrenknochens geschehen, da dieser aufgrund des Vorhandenseins einer Metaphyse eine gute Demonstrierbarkeit der Knochenstoffwechselprozesse bietet und eben aus diesem Grund dieser Arbeit als Untersuchungsobjekt zugrunde liegt.

\subsubsection{Der Aufbau von Röhrenknochen}

Knochen besteht aus dem Verbund von Zellen, Kollagenfibrillen und Proteoglykanen. Die organische Matrix, auch als Osteoid oder Grundsubstanz bezeichnet, besteht zu 95\% aus Typ-I-Kollagen und zu 5\% aus Proteoglykanen sowie aus nicht kollagenösen Proteinen (Marks und Hermey,1996). Zur Verstärkung wird die neu gebildete extrazelluläre Matrix mit Hydroxylapatitkristallen mineralisiert, welche den Fibrillen angelagert werden. Geschieht dies in geordneter Lage, spricht man von lamellärem Knochen, bei ungerichteter Anordnung von Faser- bzw. Geflechtknochen.

Stellt man sich den lamellär aufgebauten Röhrenknochen wie ein Rohr vor, dann wird die äußere Struktur als Kortikalis bzw. als Kompakta bezeichnet. Ihre hohe Belastbarkeit entsteht durch die senkrecht zueinander verlaufenden Lamellen. Sie bedingt Form und Stabilität der langen Knochen. Als Osteone bezeichnet man die runden bis ovalen Grundstrukturen aus radiär angeordneten Lamellen, die in ihrer Vielzahl die Kortikalis bilden. In der Mitte eines jeden Osteons verläuft eine gefäßführende Aussparung, der Havers-Kanal. Die darüber sichergestellte Verbindung zum Blutkreislauf gewährleistet die Nährstoffversorgung des umgebenden Knochengewebes ebenso wie den Abtransport von Stoffwechselprodukten. 


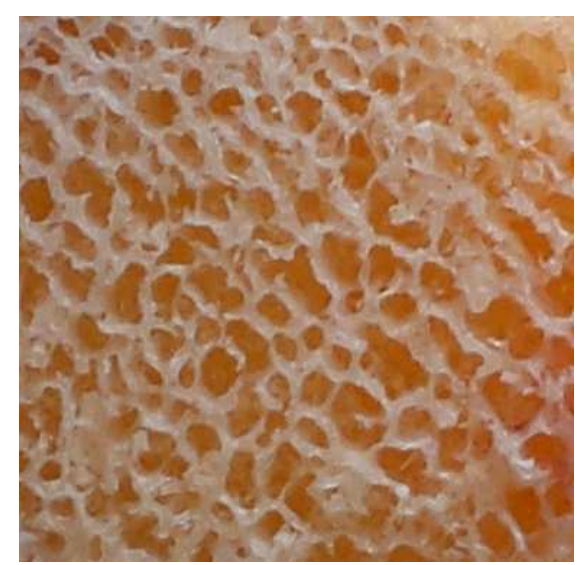

Das Innere der Röhre ist von einem Geflecht kleiner Bälkchen durchzogen, welches als Spongiosa bezeichnet wird. Jeden einzelnen der kleinen Balken bezeichnet man auch als Trabekel, weshalb der Begriff trabekulärer Knochen ebenso gebräuchlich ist. Die Zwischenräume werden von Fett, Stammzellen und Vorstufen der Erythro-, Granulo- und Thrombozyten sowie weiteren Zelltypen ausgefüllt.

Abb. 1.3. Spongiosaausschnitt aus dem Epiphysenbereich einer humanen Tibia (Foto A.Herbst; mit freundlicher Unterstützung durch Chefarzt PD Dr. med. F. Schulz, SHK Weimar)

Betrachtet man den Knochen in seiner Länge, dann werden die beiden Enden, die am Aufbau der angrenzenden Gelenke beteiligt sind, als Epiphysen bezeichnet. Der lange Schaft, das Mittelstück des Röhrenknochens, wird Diaphyse genannt. Zwischen diesen beiden Strukturen befindet sich die Metaphyse mit der Epiphysenfuge.

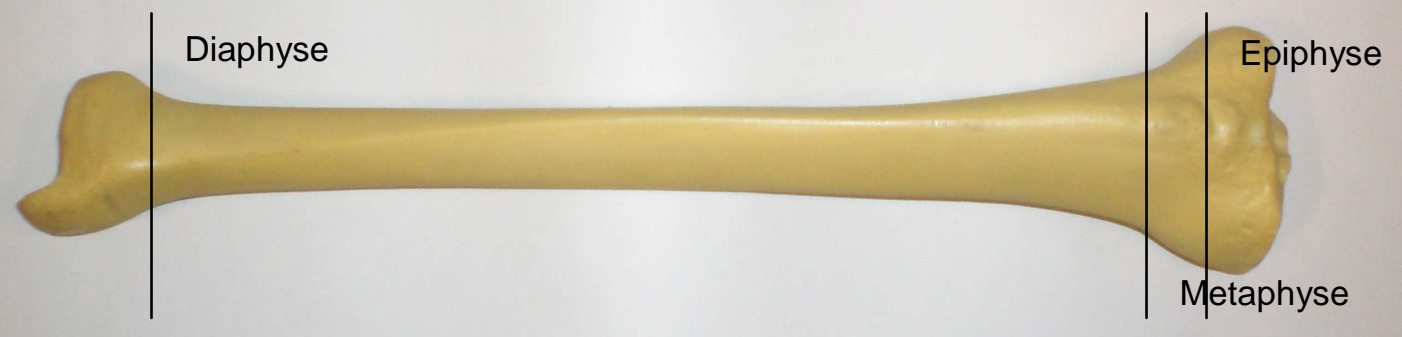

Abb. 1.4. Die Abschnitte eines Röhrenknochens am Modell der humanen Tibia (Foto A.Herbst; mit freundlicher Unterstützung durch Chefarzt PD Dr. med. F. Schulz, SHK Weimar)

\subsubsection{Die Östrogenrezeptorverteilung im Röhrenknochen}

Im unreifen Knochengewebe des wachsenden Tieres lassen sich sowohl ER $\alpha$ als auch ER $\beta$ nachweisen. Die Veränderung ergibt sich mit zunehmendem Alter, so dass bei der adulten Ratte das Vorkommen von ER $\alpha$ gegenüber ERß deutlich überwiegt (Onoe et al.,1997; Lim et al.,1999). Damit ist der Knochen als Zielorgan für Östrogene zu sehen (Seidlová-Wuttke et al.,2003). Die rezeptorvermittelten Wirkungen über ER $\alpha$ stehen aufgrund der vermehrten Konzentration im Blickpunkt. 


\subsubsection{Untersuchung der Metaphyse}

In der Humanmedizin gelten der proximale Femur und der Wirbelsäulenbereich L1-L4 als Referenzzonen für Knochenveränderungen bei Östrogenmangel (DVO-Leitlinien 2006). Die Metaphyse enthält im prozentualen Vergleich deutlich mehr Spongiosa als Kortikalis (Stürmer et al.,2006). Auswirkungen durch ein $\mathrm{E}_{2}$-Defizit zeigen sich hier somit besonders stark. Diese Bereiche konnten auch im Tiermodell bestätigt werden, da sie gleiche Reaktionen in Abhängigkeit von Östrogenen aufweisen.

Die Metaphyse ist bei der physiologischen Knochenentwicklung der Teil des Knochens, in dem bei beiden Geschlechtern das Längenwachstum stattfindet. Dies geschieht hauptsächlich durch Zellteilung in dieser umschriebenen Region. Durch den Anstieg der Plasmaöstrogenkonzentration in der Pubertät von Mädchen kommt es zum Schluss der Wachstumsfugen (Spelsberg et al.,1999; Vanderschueren et al.,2004). Dieses Phänomen ist beim männlichen Geschlecht nicht zu beobachten und erklärt so die Unterschiede in der durchschnittlichen Körpergröße.

\subsubsection{Der Knochenstoffwechsel und Stoffwechselmarker}

Knochen ist als lebendiges Gewebe zu verstehen. Während der Wachstumsphase des Menschen kommt es zur Vermehrung der Knochensubstanz, indem ihr Aufbau gegenüber inrem Abbau dominiert (Spelsberg et al.,1999). In der Altersspanne von durchschnittlich 20 bis 45 Jahren halten sich diese beiden Prozesse die Waage und man beobachtet ein stabiles Gleichgewicht im gesunden Knochen, der auch in dieser Zeit kein starres Konstrukt darstellt, sondern ständigem Umbau unterworfen ist. Bei beiden Geschlechtern ist die maximale BMD um das 30. Lebensjahr nachweisbar. Mit zunehmendem Alter kippt dieses Systems durch Hormonveränderungen und der Knochenabbau dominiert gegenüber dem -aufbau, woraus der Schwund von Knochenmasse resultiert (Lindberg et al.,2003). Dies geschieht zum einen durch die Aktivierung neuer Umbaueinheiten, zum anderen aber auch durch die Verlängerung der Lebenszeit der am Umbau beteiligten Zellen, insbesondere der Osteoklasten (Jilka,1998). Aufgrund dieses physiologischen Prozesses ist eine geminderte Mineraldichte des Knochens (BMD) im Alter regelrecht und wird als Altersosteopenie (primäre Osteoporose Typ II, siehe 1.5.5.) bezeichnet.

Auf zellulärer Ebene betrachtet, ist die aufbauende Wirkung am Skelett den Osteoblasten zuzuschreiben, der Abbau resultiert aus der Aktivität von deren Gegenspielern, den Osteoklasten. Beide beeinflussen sich gegenseitig mittels verschiedener Mediatoren, wobei 
dieses System in einem dynamischen Gleichgewicht stehen muss (Li et al.,2003). Der ständige Umbau von Knochensubstanz erfolgt in definierten Umbaueinheiten, in welchen die Osteoklasten den Knochen resorbieren und so kleine Hohlräume, Lakunen, schaffen. Diese werden dann durch neu synthetisierte Matrix, namentlich Osteoid, von den Osteoblasten aufgefüllt, was einem Austausch von alter gegen neue Knochenmasse entspricht (Oursler, 1998).

Aufschluss über die Aktivität der einzelnen Zellen gelingt durch den Nachweis von Stoffwechselprodukten im Urin oder im Serum des Probanden. Entsprechend der Forschungsergebnisse kann man heute die knochenspezifische alkalische Phosphatase (BAP) und das Osteokalzin den anabolen, durch Osteoblasten induzierten Prozessen zuordnen (Seidlová-Wuttke et al.,2004b; Seifert-Klauss et al.,2005). Pyridinolin, Desoxypyridinolin und Rat Laps (Cross Laps) sind Abbauprodukte kollagenösen Ursprungs. Sie entstehen durch Osteoklastenaktivität und weisen destruktive Prozesse nach (SeifertKlauss et al.,2005; Seidlová-Wuttke et al.,2004b; Vancata,2002).

Östrogene sind die entscheidenden Stoffe für den Erhalt der Knochensubstanz. Die Stimulation durch $E_{2}$ sorgt für eine Art Gleichgewicht, indem sie über beide Rezeptorsubtypen an den Osteoblasten (Bord et al.,2001; Monroe et al.,2003) und deren Vorstufen ihre stimulierende Wirkung entfaltet. Die Knochenmasse resultiert somit im besonderen Maße aus dem Einfluss der Östrogene (Pal et al.,2001) auf die aktivitäts- und wachstumsstimulierenden Prozesse, die bei physiologischer Stoffwechsellage beim adulten Menschen den osteoklastisch-katabolen überlegen sind. Der Substanzerhalt über weitere Mechanismen wie beispielsweise die mechanische Belastung (Lanyon et al.,2004) tritt in den Hintergrund der Hormonwirkung.

\subsection{Osteoporose}

Durch die Tatsache, dass sich die Wirkung der Östrogene positiv auf den Erhalt der Knochensubstanz auswirkt (Seidlová-Wuttke et al.,2003) ergibt sich, dass ihr Fehlen zu Veränderungen am Knochen führen muss. Dieser Zusammenhang wurde bereits in den 40er Jahren erkannt (Albright et al.,1941).

Der Dachverband Osteologie e.V. gibt in seinen Leitlinien (DVO-Leitlinien 2006) für das Krankheitsbild Osteoporose folgende Definition aus: „Die Osteoporose ist eine systemische Skeletterkrankung, die durch eine niedrige Knochenmasse und eine Verschlechterung der 
Mikroarchitektur des Knochengewebes charakterisiert ist, mit der Folge vermehrter Knochenbrüchigkeit.“.

Grundsätzlich unterscheidet man die Gruppe der idiopathischen Osteoporose, zu der sowohl die postmenopausale Form (Typ I) als auch die physiologische, senile Osteoporose (Typ II) gezählt werden, von der Gruppe der sekundären Osteoporosen, denen eine anders geartete Grunderkrankung zugrunde liegt. Die Zuordnung der postmenopausalen Osteoporose zu der idiopathisch induzierten Gruppe erklärt sich durch die Tatsache, dass alle Frauen die Hormonumstellung der Menopause erfahren, sich aber nur bei einigen das osteoporotische Krankheitsbild ausprägt.

\subsubsection{Pathophysiologie der Osteoporose}

Pathophysiologisch resultiert die Osteoporose der menopausalen Frau aus einem Östrogenmangel. $\mathrm{E}_{2}$ ist in der Lage, auf direkte Weise die Lebensspanne von Osteoklasten zu verkürzen, sowie deren Anzahl zu reduzieren. Dies geschieht durch Stimulation der Apoptose in diesen Zellen (Spelsberg et al.,1999). Östrogenmangel im Klimakterium oder durch Ovarektomie führt über fehlende Suppression zu einer vermehrten Aktivität und Anzahl von Osteoklasten (Riggs et al.,1998). Regulatorisch erhöht sich auch die Zahl der Osteoblasten und deren Tätigkeit, mit der Intention, den verstärkten Knochenabbau auszugleichen. Gelingt dies nicht, wie bei über $60 \%$ der postmenopausalen Frauen, kann eine Osteopenie nachgewiesen werden (da Paz et al.,2001).

Zum pathologischen Bild der Osteoporose kommt es, wenn die Homöostase der Knochenzellen sehr stark aus dem Gleichgewicht gerät.

Die spezifischen Veränderungen im Knochenumbau lassen sich in zwei Phasen einteilen. Der erste Abschnitt umfasst in etwa die ersten 8-10 Jahre nach der Menopause und ist durch einen überproportionalen Verlust an spongiösem Knochen im Vergleich zum Kompaktaverlust gekennzeichnet (Wronski und Yen,1991; Bonjour et al.,1997). Das Defizit beträgt 20-30\% von der Ausgangsmasse und wird in der Regel von den Betroffenen nicht bemerkt (Riggs et al.,1998). Die endostale Knochenfläche vergrößert sich durch die gesteigerte Stoffwechselaktivität, was sich ursächlich mit dem feinen Aufbau der Trabekel begründen lässt. Der ungleiche Knochenverlust resultiert aus den Unterschieden in der Masseverteilung am Röhrenknochen, wobei die Gesamtheit der Trabekel kleiner ist als die der Kortikalis. Eine komplette Erneuerung der Massen durch Ab- und Wiederaufbau benötigt im Bälkchenwerk rund 4 Jahre, in der Kompakta hingegen die doppelte Zeit. 
Substanzverluste in der Spongiosa zeigen eine Dezimierung der Knochenbälkchen, was die Struktur allein optisch verdünnt, den Knochen aber in jedem Falle stärker als bei Kortikalisverlusten in Bezug auf Stabilität und Funktion schädigt.

In der zweiten Phase verlangsamen sich die Umbauprozesse und der Knochenverlust der Spongiosa gleicht sich dem der Kompakta an. Sie werden proportional. Ursache hierfür ist der fehlende Einfluss von Östrogenen auf die extraskelettale Kalziumhomöostase, welche sich dadurch nicht mehr im erforderlichen Gleichgewicht befindet.

Durch die bereits erwähnte, regulatorisch erhöhte Aktivität der Osteoblasten produzieren diese vermehrt die Zytokine IL-1, IL-6 und TNF $\alpha$. Diese wirken zusätzlich, das Defizit an östrogenbedingter Inhibition verstärkend, stimulierend auf die Aktivität und die Reifung von Osteoklasten (Oursler, 1998). Die Zytokinproduktion und -freisetzung lässt sich nachweislich durch Östrogene unterdrücken (Horowitz,1993). Ein weiteres osteoblastäres Zytokin ist TGF$\beta$. Es wirkt, im Gegensatz zu den eben genannten, hemmend auf die Osteoklastenaktivität und steigert deren Apoptoserate. Östrogene wirken stimulierend auf seine Produktion und Freisetzung.

\subsubsection{Bedeutung von $E R \alpha$ und $E R \beta$}

Das erhaltene Wissen aus Untersuchungen von Östradiol, wirksam an beiden Östrogenrezeptoren, lässt keine Schlussfolgerung auf die Bedeutung der einzelnen Rezeptorsubtypen zu. Daher ist es nötig, deren Bedeutung durch spezifische Untersuchungen zu sichern.

Ein mögliches Verfahren hierfür stellt die Züchtung von Östrogen-Rezeptor- knock- outMäusen (ERKO) dar. Bei diesem genetischen Verfahren können selektiv Rezeptorsubtypen deaktiviert werden, so dass $\alpha$ ERKO- und $\beta$ ERKO-Tiere entstehen. Bei $\alpha$ ERKO sind alle $\alpha-$ Östrogenrezeptoren funktionsunfähig, bei $\beta E R K O$ alle $\beta$-Rezeptoren. Auch die Ausschaltung beider ER-Subtypen ist möglich.

In Untersuchungen konnte gezeigt werden, dass der östradiolinduzierte antiosteoporotische Effekt nur bei Tieren mit funktionsfähigem ER $\alpha$ zum Vorschein kam (Weihua et al.,2003; Lindberg et al.,2001). Bei $\alpha E R K O-T i e r e n$, bei denen ER $\beta$ unbeeinflusst vorliegt, war eine reduzierte BMD nachzuweisen. Dies erlaubt die Aussage, dass ER $\alpha$ für die Wirkung von Östradiol auf den Knochen von entscheidender Bedeutung ist. 
Eine andere Möglichkeit betrifft die Wahl der Liganden. Bei Einsatz von ER $\alpha$ - und ER $\beta-$ spezifischen Agonisten konnte durch die Untersuchung der Knochen vor und nach der Therapie ebenfalls der Substanzerhalt über ER $\alpha$ bestätigt werden.

\subsubsection{Diagnosemöglichkeiten}

Im Altag zeigt sich eine Osteoporose in den meisten Fällen durch stattgehabte pathologische Frakturen. Den Nachweis gilt es daher frühzeitig zu erbringen. Röntgenologisch diagnostizierbar wird das Krankheitsbild erst bei einem schon fortgeschrittenen Knochensubstanzverlust von etwa $30-40 \%$ an der Lendenwirbelsäule, ausgehend von der physiologischen Knochendichte (=100\%). Schon vorher lassen sich im Serum erhöhte Konzentrationen der Stoffwechselmarker Osteokalzin und Rat Laps (1.3.4.) nachweisen, was den Rückschluss auf eine gesteigerte Aktivität der Knochenzellen noch vor dem radiologischen Nachweis zulässt.

Derzeit wird die Reduktion der Knochenmasse durch quantitativen Ultraschall (QUS), quantitative Computertomographie (qCT) und Dual-Energy X-ray Absorptiometry (DXA) nachgewiesen. Zusammen mit der Serumanalyse sind sie die einzigen BMDDiagnostikmöglichkeiten, welche eine Beurteilung der gegebenenfalls bestehenden Osteoporosestufe zulassen.

\subsection{Therapieoptionen}

Bei allen in Betracht gezogenen Therapieoptionen bezüglich der postmenopausalen Frau strebt man nach der adäquaten Reduktion des Knochenstoffwechsels und somit nach der Erhaltung der Knochenmasse.

Da das Absinken der $E_{2}$-Konzentration sowohl vegetative als auch organisch-manifeste Auswirkungen hat, gilt es diesen vorzubeugen bzw. diese zu mildern. Wie bei jeder Behandlung müssen daher vorab individuelle Vorteile und Risiken gegeneinander abgewogen werden. Auch die Frage nach der Therapierelevanz sollte geklärt sein. 


\subsubsection{Die Hormonersatztherapie (HRT)}

Das Grundprinzip der HRT ist die Substitution der fehlenden Substanzen. Dies wird nach dem Verlust der ovariellen Funktion für Östrogene und Gestagene relevant, deren Rückgang somit ausgeglichen werden soll.

Indiziert ist die Gabe von Hormonen grundsätzlich gegen die vegetativen und organischen Folgen ihres Mangels, die zur Minderung der Lebensqualität führen oder Krankheiten nach sich ziehen. Eingesetzt wird die HRT häufig bei der Therapie von Stimmungsschwankungen, Hitzewallungen, Schlafstörungen, Unruhe und Abgeschlagenheit. Auch die Behandlung von urogenitalen Beschwerden hat Erfolg. Es besteht die Möglichkeit der Monotherapie mit Östrogenen, wegen kanzerogener Wirkung kontraindiziert bei Frauen mit Uterus (Endometriumkarzinom) (Barrett-Connor,1993), der Monotherapie mit Gestagenen, bei ausreichend hohem Östradiolspiegel (Fettgewebe) und Östradiol-Kontraindikationen und der Kombinationstherapie mit beiden Präparaten. Anwenden lässt sich die HRT den Symptomen entsprechend beispielsweise oral (Tabetten), transdermal (Cremes, Pflaster) oder als Reservoir (subkutane Applikatoren).

Therapieerfolge zeigen sich neben den oben genannten Indikationen in der Senkung der kardiovaskulären Morbidität, sowohl durch Verbesserung des Lipidhaushaltes (Hulley et al.,1998), als auch durch die antiatherosklerotische Wirkung der Östrogene (Warner et al.,1999). Auch ist ein reduzierter Verlust von Knochenmasse unter Substitution nachzuweisen. Der Knochen ist jedoch nur zur Zeit der frühen Menopause geschützt (Wronski et al., 1988). Daher ist ein früher Therapiebeginn entscheidend, auch wenn sich die hormonbedingte Minderung der Knochenmasse erst nach etwa 6 Monaten signifikant abzeichnet (Shiraishi et al.,2002). Bei der ossären Betrachtung gilt auch die Kombination mit Androgen als sinnvoll, da sich dessen anaboler Einfluss besonders an der Kortikalis (Furuya und Matsumoto,2003), der von $\mathrm{E}_{2}$ hingegen bevorzugt an der Spongiosa zeigt (Coxam et al.,1996). Dadurch wird die Knochenformation gesteigert und nicht nur, östrogengleich, der Knochenumbau gehemmt (Barrett-Connor, 1998).

Der künstliche Ersatz von Hormonen gilt bei der Therapie von Osteoporose als nicht ideal. Generell birgt die HRT, verglichen mit anderen Therapieformen, eine nicht unerhebliche Zahl an Nebenwirkungen. 


\subsubsection{Die Gruppe der SERMs}

Die SERMs umfassen eine Gruppe von Stoffen, die sowohl agonistisch als auch antagonistisch über den ER wirken können. Abhängig ist dies vom Zielorgan und der dort vorhandenen Rezeptorsubtyp-Verteilung. Diese Besonderheit von einzelnen Stoffen kann man sich in der Therapie bestimmter Krankheitsbilder oder Symptome zu Nutzen machen, da hier der ungewollte Einfluss auf andere Strukturen durch Antagonismus ausbleibt.

Am Beispiel von Raloxifen, einem SERM der ersten Generation, lässt sich dies gut beschreiben. Es bewirkt am Knochen eine Erhöhung der Knochendichte und wirkt teilweise auf den Cholesterinspiegel wie ein Östrogenagonist. Am Uterus und im Brustgewebe hingegen zeigt sich durch Raloxifen keinerlei östrogenagonistische Wirkung. Dies hat den Vorteil, dass sowohl die gefürchtete Brustkrebsstimulation, als auch der proliferative Einfluss auf das Endometrium von Anfang an nicht zu erwarten ist. Risiken birgt diese Substanz aufgrund ihrer Fähigkeit, die Blut-Hirn-Schranke zu überwinden und so Einfluss auf das vaskuläre Geschehen im ZNS auszuüben.

Tamoxifen ist ein weiterer Stoff der SERM-Gruppe, welcher heute erfolgreich als Antagonist bei der Therapie des Mammakarzinoms eingesetzt wird (Nardulli,2003). Den östrogensensiblen Krebszellen fehlt es an agonistischer Stimulation, was durch Wachstumshemmung Erfolge mit sich bringt. Die BMD profitiert durch den osteoprotektiven Effekt der Substanz. Nachteile ergeben sich aus der agonistischen, somit proliferativen Wirkung am Endometrium (McDonnell,2003).

Die Vorteile dieser Stoffgruppe sind deutlich, auch gegenüber der HRT. Ziel muss es jedoch sein, SERMs ohne unerwünschte Effekte zu entwickeln, welche ihre Wirkung ausschließlich gezielt entfalten.

\subsection{Tiermodell und Untersuchungsverfahren}

Die Ratte gilt seit Jahren als etabliertes Tiermodell bei der Betrachtung der Perimenopause (Wronski und Yen,1991; Frost und Jee,1992; Oursler,1998; da Paz et al.,2001; Vanderschueren et al.,2004; Seidlová-Wuttke et al.,2003). Sowohl Haltung als auch die Ovarektomie fordern keine abnormen Besonderheiten und zeichnen sich durch die geringe Zahl an Komplikation aus.

Unter Verweis auf die langjährigen Untersuchungserfahrungen kann das Tiermodell der ovarektomierten Ratte als Vergleichsstudie zur postmenopausalen Frau angesehen werden. 
Beide Individuengruppen zeigen nach dem Verlust der ovariellen Funktion, natürlich oder induziert, gleiche Erscheinungen bezüglich des Knochenaufbaus und des -stoffwechsels. Diesbezüglich untersuchten wir die Rattenknochen mittels qCT auf Dichte- und Flächenveränderungen, was in bisherigen Arbeiten, ebenso wie die durchgeführte Analyse der Serumparameter, als üblich und verifiziert gilt. Des Weiteren unterzogen wir die präparierten Tibiae einem standardisierten Bruchverfahren. Dies vor dem Hintergrund, dass die pathologische Fraktur bei Osteoporose eine der Hauptkomplikationen darstellt. Alle Untersuchungen betrachten gezielt die Metaphyse der Tibia, da sich hier ein Östrogendefizit deutlich und schnell auswirkt (Stürmer et al.,2005).

\subsection{Eingesetzte Substanzen}

\subsubsection{ER $\alpha$ - und ER $\beta$-Agonist}

Mit dem Wissen um die Gruppe der SERMs wurde für diese Studie ein selektiver ER $\alpha$ Agonist (ZK 281471) und ein selektiver ERß-Agonist (ZK 281738) verwendet. So konnte bei den ungleich substituierten Tiergruppen gezielt ein Rezeptorsubtyp angesprochen werden (Hillisch et al., 2004). Durch gleiche Ausgangs- (Alter, ovx) und Studienbedingungen (Applikationsdauer, Haltungsbedingungen, Ernährung, u.a.) war die vergleichende Betrachtung der Veränderungen in den Untersuchungseinheiten möglich. Der ausschließliche Agonismus erlaubt des Weiteren die Beurteilung der Bedeutung von ER $\alpha$ und ER $\beta$ für den Knochen im Zeitraum der Perimenopause.

\subsubsection{7ß-Östradiol}

$\mathrm{E}_{2}$ wird als Referenzgröße betrachtet. Es entspricht bei Substitution am ehesten der physiologischen Hormonwirkung. Dementsprechend macht es seinen Einfluss über beide Rezeptortypen, auch am Knochen, geltend (Kuiper et al.,1998a; Monroe et al.,2003). So bieten seine Resultate die zur Beurteilung der spezifischen Agonisten nötige Referenz. 


\subsubsection{Antiöstrogen ICI}

$\mathrm{ICI}$ ist ein erprobter, antiöstrogen wirksamer Steroidabkömmling. In früheren Studien an ovarektomierten Ratten wurden seine Wirkungen auf östrogene Erfolgsorgane untersucht (Knochen, Körpergewicht, Fettgehalt, u.a.) und seine ER-antagonistische Wirkung nachgewiesen (McDonnell et al.,2002; Wade et al., 1993). Es verfügt über eine dem Östradiol entsprechende Affinität zu beiden Östrogenrezeptoren und entfaltet seine Wirkung durch Blockade der Rezeptorbindungsstelle für ER-Agonisten.

\subsection{Ziel der vorliegenden Arbeit}

Anhand des Rattenmodells mit künstlich induzierter Menopause sollen abermals die knochenphysiologischen Grundlagen bezüglich der beiden Östrogenrezeptorsubtypen dargestellt werden. Dabei richtet sich unser Interesse auf die Herausstellung der Bedeutung von $E R \alpha$, der sich sowohl bei dem Studium von ERKO-Mäusen als auch in anderen Substitutionsstudien als entscheidender Rezeptor der Knochenprotektion dargestellt hat. Durch die Erweiterung der langjährig gängigen Untersuchungsverfahren (Körpergewicht, Knochendichte, -fläche, -umfang, Serumparameter) mittels der standardisierten metaphysären Tibiafraktur erhielten wir bei unseren Untersuchungen zwei weitere Werte, Bruchkraft und Maximalkraft, welche eine Aussage zur Elastizität und Stabilität der Metaphyse der untersuchten Knochen treffen.

Es wurde mit drei Dosierungen je Substanz gearbeitet, deren Wahl sich an bisherigen Erfahrungen orientiert. Die geringste Dosis ist als Schwelle für eine Resultatausbildung zu sehen, wobei sich die mittlere Dosis an der Optimaldosierung orientiert. Die Situation der beginnenden Überdosierung wird durch die jeweils höchste Dosis erreicht.

Eine Verknüpfung der Resultate aus den einzelnen Untersuchungen soll im günstigsten und ebenso erwarteten Fall die bekannten Grundsätze der Knochenphysiologie untermauern, die entscheidende Bedeutung von ER $\alpha$ bestätigen und zusätzlich die theoretischen Faktoren (Dichte, Fläche, Serumwerte) mit den praktischen Fakten (Fraktur) verknüpfen. Die Verwendung ER-Subtyp-spezifischer Agonisten lässt dies zu und ermöglicht durch den Vergleich mit $17 \beta$-Östradiol die Resultatbewertung. Ziel ist es, die Wirksamkeit der Knochenprotektion bei postmenopausalen Frauen durch Einsatz von selektiven ER $\alpha$ Agonisten zu bestätigen und zu zeigen, dass sich ihr Einfluss auch auf die Reduktion des osteoporosebedingten Frakturrisikos auswirkt. 


\section{Material und Methoden}

\subsection{Die Versuchstiere und ihre Haltung}

Die Genehmigung für alle durchgeführten Tierexperimente lag gemäß der gesetzlichen Bestimmung durch die Bezirksregierung Braunschweig vor (Az 509.42502/01-36.03).

Alle Versuche wurden unter Anleitung und Aufsicht von Dr. D. Seidlová-Wuttke in den Tierställen des Klinikums der Georg-August-Universität in Göttingen durchgeführt.

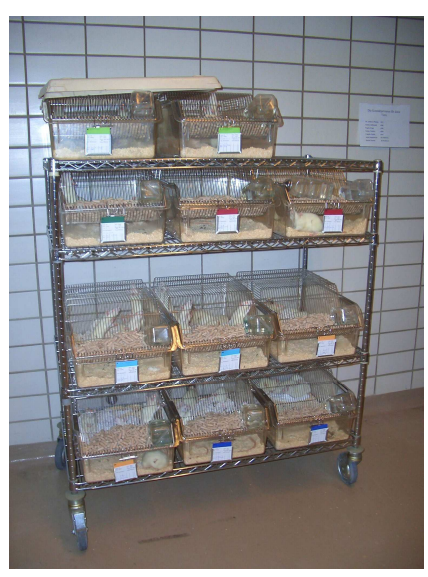

Abb. 2.1. Tierkäfige im Tierstall

Diese Arbeit basiert auf einem experimentellen Versuch, bei dem das Modell der weiblichen, ovarektomierten Ratte als geeignete Simulation für Frauen im postmenopausalen Stadium genutzt wird.

Hierfür wurden 151 adulte, weibliche Sprague-Dawley-Ratten (Firma Winkelmann) im Alter von 3 Monaten in den Tierstall des Universitätsklinikums Göttingen gebracht. Die Haltung erfolgte in Gruppen zu je fünf Tieren pro Käfig (Makrolonkäfig Typ 4, Firma Tecniplast Deutschland $\mathrm{GmbH}$ ).

Die Tiere waren in einem separaten Raum des Tierstalls untergebracht, in welchem durch eine Zeitschaltuhr während des gesamten Versuchszeitraums ein Hell-Dunkel-Rhythmus von je 12 Stunden geschaffen wurde. Es herrschte eine konstante Raumtemperatur von $20-22^{\circ} \mathrm{C}$. Die Betreuung und Versorgung der Tiere war durch einen festen Personenkreis mit Zugangserlaubnis sichergestellt, so dass unnötige Störungen unterblieben.

\subsection{Die Nahrung}

Die Fütterung der Tiere erfolgte über die Raufen der Käfige, welche alle regelmäßig mit der gleichen Sorte sojafreiem Pelletfutter (ssniff $^{\oplus}$ R-Z phytoöstrogenarm, V 1355, Soest, Germany) befüllt wurden. Somit hatten alle Tiere uneingeschränkten Zugang zur Nahrung. Auch frisches Trinkwasser aus den Wasserspendern stand ihnen zur freien Verfügung. 


\subsection{Die Identifizierung der Tiere}

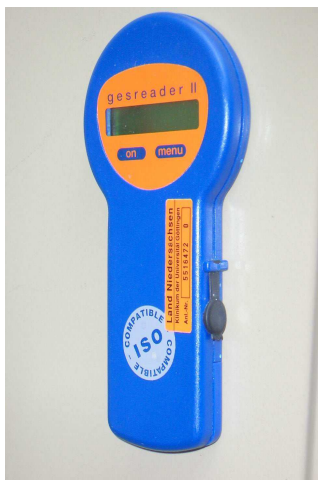

Abb. 2.2. Transponderchip-Lesegerät
Bei Ankunft wurde jedem Tier zur Identifizierung ein Transponderchip unter die Nackenhaut injiziert. Die Chipnummer wurde mit einem externen Lesegerät ermittelt und in den Aufzeichnungen festgehalten. Die Erkennung eines jeden Tieres war somit zu jeder Zeit zweifelsfrei möglich. Alle während der Versuchszeit evaluierten Daten wurden unter der jeweiligen Nummer gespeichert und ausgewertet.

\subsection{Die Gruppeneinteilung}

130 der 151 gelieferten Tiere wurden für die Zusammenstellung der geplanten Gruppen benötigt. Jeweils zwei Käfige wurden hierbei zu einer Einheit zusammengefasst und erhielten den gleichen Injektionsplan. Somit entstanden 13 Gruppen.

\begin{tabular}{|l|l|l|l|l|l|l|l|l|l|l|l|l|l|}
\hline Gruppe & 1 & 2 & 3 & 4 & 5 & 6 & 7 & 8 & 9 & 10 & 11 & 12 & 13 \\
\hline Käfige & $1+$ & $3+$ & $5+$ & $7+$ & $9+$ & $11+$ & $13+$ & $15+$ & $17+$ & $19+$ & $21+$ & $23+$ & $25+$ \\
& 2 & 4 & 6 & 8 & 10 & 12 & 14 & 16 & 18 & 20 & 22 & 24 & 26 \\
\hline Tiere & $1-$ & $11-$ & $21-$ & $31-$ & $41-$ & $51-$ & $61-$ & $71-$ & $81-$ & $91-$ & $101-$ & $111-$ & $121-$ \\
& 10 & 20 & 30 & 40 & 50 & 60 & 70 & 80 & 90 & 100 & 110 & 120 & 130 \\
\hline
\end{tabular}

Tab. 2.1. Einteilung der Tiere in 13 Versuchsgruppen 


\subsection{Die Gewichtsbestimmungen}

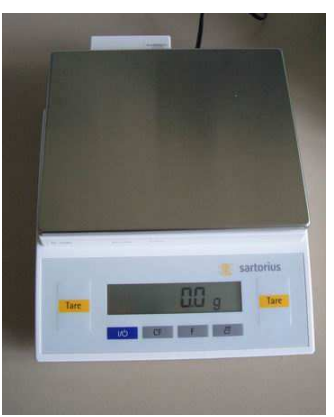

Nach 4 Tagen Akklimatisierungszeit wurden die Ratten erstmals gewogen. Das durchschnittliche Körpergewicht lag bei 229g. Weitere Messungen erfolgten bei Ovarektomie und jeweils 1 Woche, 3 Wochen und 4 Wochen danach.

(Waage basic lite BL3, Sartorius)

Abb. 2.3. Die Tierwaage

\subsection{Die Computertomographie}

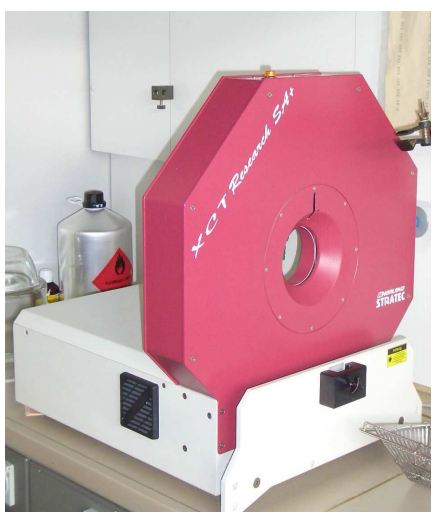

Abb. 2.4. Das CT-Gerät
Die Messung der Knochendichte und -fläche erfolgte mit einem CT-Gerät (XCT-Resaerch Bone Scanner, Firma Stratec). Dieses arbeitet mittels peripherer, quantitativer Computertomographie ( $\mathrm{qCT}$ ), einem Röntgenverfahren, bei dem die Röntgenröhre um das zu untersuchende Objekt rotiert. In seiner Größe ist es der Untersuchung von Kleintieren angepasst. Durch Kopplung mit PC und Monitor werden die gemessenen Strukturen graphisch und numerisch dargestellt.

Es wurden während des Versuches zwei Computertomogramme erstellt.

1. Vor Ovarektomie und Beginn der Injektionstherapie wurde zur Feststellung der Ausgangsknochenbeschaffenheit von allen Tieren ein CT erstellt (CT1). Die Tiere wurden per Zufallsprinzip in drei Gruppen aufgeteilt und an drei aufeinander folgenden Tagen untersucht. Dazu wurden sie einzeln in Narkose (2.7.) versetzt und rücklings auf dem Tisch des CT-Gerätes positioniert. Das jeweils linke Bein wurde in einer eigens dafür entwickelten Kunststoffhalterung so platziert, dass das Röntgen der tibialen Metaphyse bestmöglich durchzuführen war. Durch vorherige visuelle Positionsüberprüfung am zugehörigen PCMonitor konnte die Lage der zu messenden Knochenstelle exakt festgestellt werden und wurde, wenn nötig, korrigiert. Dadurch waren standardisierte Aufnahmen möglich. 
2. Das zweite Computertomogramm (CT2) wurde post mortem an den präparierten Tibiae der Tiere durchgeführt. Diese waren zur Aufbewahrung in Laborröhrchen tiefgefroren gelagert. Mittels einer speziellen Halterung für diese Aufbewahrungsbehältnisse wurden auch hier die Knochen in die gleiche Position wie bei CT1 gebracht und vermessen. Auch hier konnten, durch visuelle Kontrolle am PC, standardisierte Aufnahmen garantiert werden. Beide CT-Untersuchungen wurden mit der gleichen Mess-Maske erstellt und sind daher miteinander vergleichbar.

\subsection{Die Narkose}

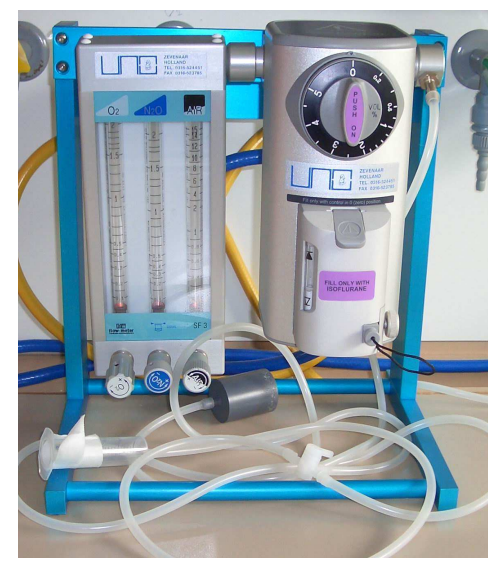

Abb. 2.5. Das Narkosegerät

Die Inhalationsnarkose wurde durch die Gabe von IsofluranGas (Forene ${ }^{\circledR}$, Firma Abbott) über eine Mund-Nasen-Maske herbeigeführt, wozu ein Kleintiernarkosegerät in Kombination mit einem Flow-Meter (beides Firma UNO, Zevenaar/Holland) verwendet wurde. Die Menge des Narkosegases konnte über das Narkosegerät reguliert und über das Flow-Meter einem beliebigen Sauerstoff- bzw. Luftzustrom beigemischt werden. Eine individuelle Narkoseanpassung war somit für jedes Tier gewährleistet.

Das ausströmende Gasgemisch wurde über einen Schlauch zur Mund-Nasen-Maske geleitet und dort vom Tier eingeatmet. Die Maske blieb jeweils während der gesamten Narkosezeit über die Atemöffnungen der Ratte gestülpt. Die Narkosetiefe konnte so angemessen reguliert werden. 


\subsection{Die Ovarektomie}

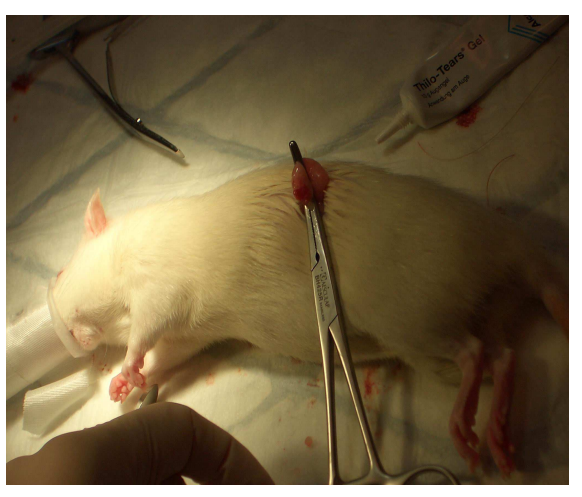

Abb. 2.6. Tier bei der Ovarektomie
Um das Tiermodell als Vergleich für die Gruppe der postmenopausalen Frauen annehmen zu können, müssen die Versuchstiere auf das ausschlaggebende niedrige Hormonniveau gebracht werden. Dies geschieht durch Ovarektomie. Durch die chirurgische Entfernung der Ovarien fehlt den weiblichen Tieren die hauptsächliche Östrogenquelle und es kommt künstlich zum Menopause.

Die Ovarektomie (ovx) wurde unter den oben beschriebenen Narkosebedingungen durchgeführt (2.7.). Es wurde die Bauchdecke an den Flanken eröffnet und die Ovarien freigelegt. Diese wurden unterhalb der Tuben mit resorbierbarem Nahtmaterial abgebunden und mit einem Skalpell entfernt. Die Wunde wurde mit sterilen Hauttackerklammern verschlossen.

\subsection{Die Injektionstherapie}

Die Tabelle 2.2. bietet einen Überblick über die Gruppen, die jeweils injizierte Substanz und den zugehörigen Injektionsplan. Der zur Injektionstherapie veranschlagte Versuchszeitraum von 4 Wochen begann am Tag 2 (Tag y) mit der ersten Applikation bei den Tieren, die am Tag zuvor (Tag 1) ovarektomiert wurden.

Die Substanzen ZK 281471 und ZK 281738 wurden von der Firma Bayer Schering Pharma $A G$, Berlin produziert.

Die Ovarektomie aller Ratten wurde auf 4 Tage verteilt durchgeführt. Folglich begannen auch die Injektionszeiträume an 4 aufeinander folgenden Tagen und endeten entsprechend. Alle Tiere erhielten somit die zugeordnete Applikation täglich und dies über den Zeitraum von 28 Tagen. 


\begin{tabular}{|c|c|c|c|c|c|c|}
\hline Gruppe & Tiere & $\begin{array}{l}\operatorname{Tag} x \\
\text { (ovx) }\end{array}$ & $\begin{array}{l}\text { Tag y } \\
\text { (1.Appl). }\end{array}$ & $\begin{array}{l}\text { Substanz }(\mu \mathrm{g}) / \text { Tag } \\
\text { und Tier }\end{array}$ & $\begin{array}{l}\text { Appl.Art+ } \\
\text { Interval }\end{array}$ & $\begin{array}{l}\text { Zeit- } \\
\text { raum }\end{array}$ \\
\hline 1 & $\begin{array}{l}1-5 \\
6-10\end{array}$ & $\begin{array}{l}1 \\
1\end{array}$ & $\begin{array}{l}2 \\
2\end{array}$ & $\mathrm{ovx}+0,2 \mathrm{ml} \mathrm{LM}$ & s.c. tgl. & $4 \mathrm{Wo}$ \\
\hline 2 & $\begin{array}{l}11-15 \\
16-20\end{array}$ & $\begin{array}{l}1 \\
1\end{array}$ & $\begin{array}{l}2 \\
2\end{array}$ & $o v x+E_{2}(0,1)$ & s.c. tgl. & $4 \mathrm{Wo}$ \\
\hline 3 & $\begin{array}{l}21-25 \\
26-30\end{array}$ & $\begin{array}{l}1 \\
2\end{array}$ & $\begin{array}{l}2 \\
3\end{array}$ & $o v x+E_{2}(1)$ & s.c. tgl. & $4 \mathrm{Wo}$ \\
\hline 4 & $\begin{array}{l}31-35 \\
36-40\end{array}$ & $\begin{array}{l}1 \\
2\end{array}$ & $\begin{array}{l}2 \\
3\end{array}$ & $\mathrm{ovx}+\mathrm{E}_{2}(10)$ & s.c. tgl. & $4 \mathrm{Wo}$ \\
\hline 5 & $\begin{array}{l}41-45 \\
46-50\end{array}$ & $\begin{array}{l}1 \\
2\end{array}$ & $\begin{array}{l}2 \\
3\end{array}$ & $\mathrm{ovx}+\mathrm{E}_{2}(1)+\mathrm{ICl}(1,53)$ & s.c. tgl. & $4 \mathrm{Wo}$ \\
\hline 6 & $\begin{array}{l}51-55 \\
56-60\end{array}$ & $\begin{array}{l}2 \\
3\end{array}$ & $\begin{array}{l}3 \\
4\end{array}$ & ovx + ZK281471 $(0,1)$ & s.c. tgl. & $4 \mathrm{Wo}$ \\
\hline 7 & $\begin{array}{l}61-65 \\
66-70\end{array}$ & $\begin{array}{l}2 \\
3\end{array}$ & $\begin{array}{l}3 \\
4\end{array}$ & ovx+ ZK281471(1) & s.c. tgl. & $4 \mathrm{Wo}$ \\
\hline 8 & $\begin{array}{l}71-75 \\
76-80\end{array}$ & $\begin{array}{l}2 \\
3\end{array}$ & $\begin{array}{l}3 \\
4\end{array}$ & ovx+ ZK281471(10) & s.c. tgl. & $4 \mathrm{Wo}$ \\
\hline 9 & $\begin{array}{l}81-85 \\
86-90\end{array}$ & $\begin{array}{l}2 \\
3\end{array}$ & $\begin{array}{l}3 \\
4\end{array}$ & $\begin{array}{l}\text { ovx+ ZK281471(1) } \\
+\mathrm{ICI}(1,53)\end{array}$ & s.c. tgl. & $4 \mathrm{Wo}$ \\
\hline 10 & $\begin{array}{l}91-95 \\
96-100\end{array}$ & $\begin{array}{l}2 \\
3\end{array}$ & $\begin{array}{l}3 \\
4\end{array}$ & ovx+ ZK281738(0,1) & s.c. tgl. & $4 \mathrm{Wo}$ \\
\hline 11 & $\begin{array}{l}101-105 \\
106-110\end{array}$ & $\begin{array}{l}3 \\
4\end{array}$ & $\begin{array}{l}4 \\
5\end{array}$ & ovx+ ZK281738(1) & s.c. tgl. & $4 \mathrm{Wo}$ \\
\hline 12 & $\begin{array}{l}111-115 \\
116-120\end{array}$ & $\begin{array}{l}3 \\
4\end{array}$ & $\begin{array}{l}4 \\
5\end{array}$ & ovx+ ZK281738(10) & s.c. tgl. & $4 \mathrm{Wo}$ \\
\hline 13 & $\begin{array}{l}121-125 \\
126-130\end{array}$ & $\begin{array}{l}3 \\
4\end{array}$ & $\begin{array}{l}4 \\
5\end{array}$ & $\begin{array}{l}\text { ovx+ ZK281738(1) } \\
+\operatorname{ICI}(1,53)\end{array}$ & s.c. tgl. & $4 \mathrm{Wo}$ \\
\hline
\end{tabular}

Tab. 2.2. Gruppeneinteilung und Injektionsplan (LM-Lösungsmittel; im Verhältnis 1:4 aus Benzylbenzoat und Rizinusöl) 
Die tägliche Injektion wurde während der gesamten Zeit des Versuches durch die gleichen Personen vorgenommen. Es wurden täglich neue, sterile Utensilien verwendet. Desweiteren wurde darauf geachtet, dass vor bzw. nach jeder Gruppe die Arbeitsfläche gereinigt und die Einweghandschuhe gewechselt wurden. Das war nötig, um eine mögliche transdermale Substanzaufnahme von Stoffen der jeweils anderen Gruppen zu verhindern.

\subsection{Die verabreichten Substanzen}

Die Injektionslösung der Tiere bestand, je nach Gruppe, aus unterschiedlichen Komponenten. $E_{2}$, ZK 281471 und ZK 281738 lagen in einem Lösungsmittelgemisch aus Benzylbenzoat (Firma Sigma) und Rizinusöl im Mischungsverhältnis 1:4 vor. Die Substanz ICI war in Erdnussöl gelöst.

Die Kurzform $E_{2}$ steht für $17 \beta$-Östradiol. Die mit ZK bezeichneten Substanzen stellen rezeptorspezifische Agonisten dar, wobei ZK 281471 als ER $\alpha$-Agonist wirkt und ZK 281738 als ERß-Agonist. ICI steht für ICI 182780 und fungiert als reiner ER-Antagonist.

Den Kontrolltieren wurde das reine Lösungsmittelgemisch aus Benzylbenzoat und Rizinusöl (1:4) appliziert.

\subsection{Die Tötung der Tiere und die Probengewinnung}

Nach vierwöchiger Substanzapplikation erfolgte die Tötung der Tiere. Dazu wurden diese erneut durch inhalative Gabe von Isofluran-Gas in Narkose (2.7.) versetzt und dann dekapitiert.

Die sofort nach der Tötung präparierten Organe wurden in flüssigem Stickstoff schockgefroren und somit für weitere Untersuchungen konserviert. Das für die Serumwertbestimmung benötigte Blut wurde beim Ausbluten der Tierkörper direkt nach der Dakapitation gewonnen. 


\subsection{Die standardisierte metaphysäre Tibiafraktur}

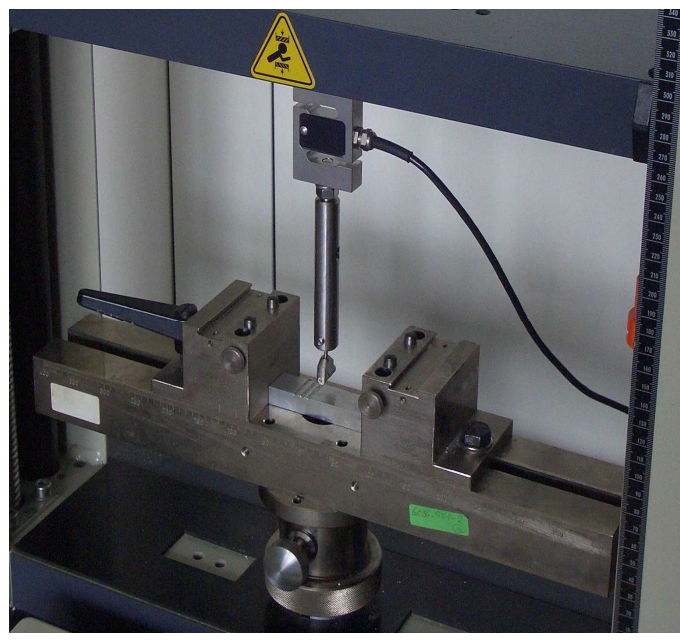

Abb. 2.7. Die Universalprüfmaschine Z020
Ein weiteres Verfahren, um die Elastizität und Stabilität der Tibiae zu bestimmen, ist die Messung der standardisierten Frakturierung der Metaphyse. Dazu werden die präparierten Knochen mit der Universalprüfmaschine Z020 (Typen-Nr. 145660 Z020, Firma Zwick) gebrochen. Zuerst erfolgt die Positionierung des Präparates auf dem 3-fach gekerbten Tisch. Je nach Größe des Knochens werden die beiden Chondylen der proximalen Diaphyse der Tibia in eine der Kerben gelegt. Damit ist einem Verrutschen unter Krafteinwirkung vorgebeugt.

Der Druckstempel des Universalprüfers wird metaphysär ausgerichtet. Nach dem Start der Messung bewegt sich dieser mit $1 \mathrm{~N}$ Vorkraft und $50 \mathrm{~mm} / \mathrm{sec}$ in senkrechter Achse von oben auf den Tisch zu. Erreicht der Stempel die Tibia, dann biegt er diese, je nach Elastizität entsprechend stark, bis zum Bruch des Knochens. Das Nachgeben des Materials wird in der Maschine als Abfall des Widerstands gegen die einwirkende Kraft registriert und stoppt die Abwärtsbewegung des Druckstempels. Die Bruchkurve aus Standardweg und Standardkraft wird zeitgleich dargestellt.

Die Abbildung 2.9. zeigt einen Ausschnitt aus einem Protokoll der standardisierten, metaphysären Tibiafraktur an der Universalprüfmaschine Z020.

Auf der X-Achse ist die Durchbiegung des Knochens in Millimetern aufgetragen, auf der YAchse die aufgewendete Kraft in Newton. Die Strecke AB stellt die Bruchkurve dar. Auf ihr sind verschiedene Punkte und Abschnitte eingezeichnet.

Die Strecke $\mathbf{A}$ bis $\mathbf{F}_{\text {Bruch }}$ zeigt die annähernd lineare Kurve der elastischen Knochenverformung.

$\mathbf{F}_{\text {Bruch }}$ markiert den Wendepunkt von elastischer zu plastischer Knochenverformung und markiert so das Maximum der getragenen Last ohne Schäden.

Der Kurvenabschnitt $\mathbf{F}_{\text {Bruch }}$ bis $\mathbf{F}_{\max }$ stellt die Phase der plastischen Verformung dar. Hier treten, zunehmend mit dem Kurvenverlauf, immer mehr Mikrofrakturen im Trabekelwerk auf. $\mathbf{F}_{\max }$ markiert die benötigte Kraft für den vollständigen Bruch des Knochens, der durch die Frakturierung der Kortikalis gekennzeichnet ist. 
Ergebnisse:

\begin{tabular}{c|c|c|c|c|c|c|c|c} 
Legende & $\mathrm{Nr}$ & Index & $\begin{array}{c}\text { F bei Weg1 } \\
\mathrm{N}\end{array}$ & $\begin{array}{c}\text { F bei Weg2 } \\
\text { F'eges }\end{array}$ & $\begin{array}{c}\text { Bruchkraft } \\
\mathrm{N}\end{array}$ & $\begin{array}{c}\text { Kraft bei Weg } 0,5 \\
\mathrm{~N}\end{array}$ & $\begin{array}{c}\text { Fmax } \\
\mathrm{N}\end{array}$ & $\mathrm{N}$ \\
\hline & 1 & & 46,33 & - & & 38,18 & 46,33 & 59,18
\end{tabular}

Seriengrafik:

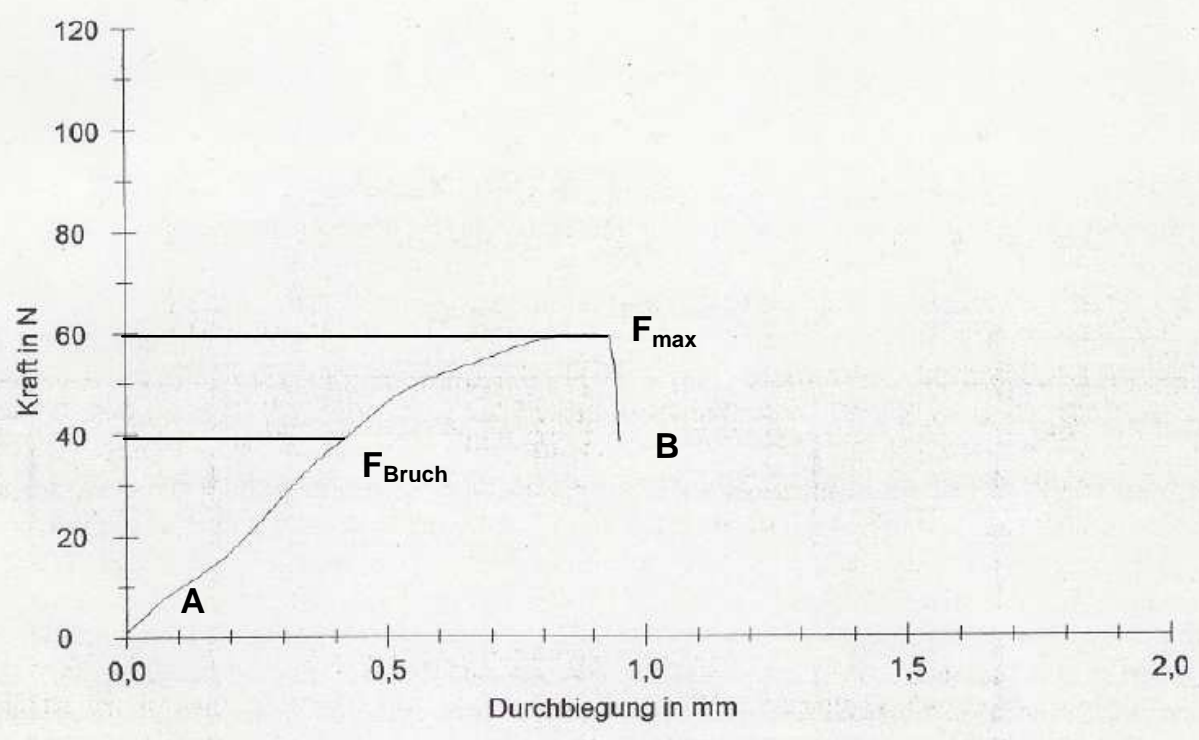

Abb. 2.9. Ausschnitt aus dem Protokoll einer standardisierten, metaphysären Tibiafraktur

\subsection{Die Serumanalyse}

Die beiden betrachteten Serumparameter Osteokalzin (OC) und Rat Laps wurden durch die Methode des RIAs (Radio-Immuno-Assay) aus dem Dekapitationsblut der einzelnen Tiere ermittelt. Durch sie kann man eine Aussage zur Zellaktivität im Knochen treffen. Bauen die destruierenden Osteoklasten ossäres Kollagen ab, so entsteht unter anderem der im Blut nachweisbare Parameter Rat Laps.

Die Aktivität der Osteoblasten kann indirekt durch den Osteokalzinspiegel nachgewiesen werden. Je höher die Zellaktivität ist, umso höher sind auch die Werte der beiden Stoffe im Serum. 


\subsection{Die statistischen Methoden}

Die Werte für die Statistik wurden mit dem Computerprogramm Graph Pad Prism $4{ }^{\circledR}$ berechnet. Das Signifikanzniveau wurde auf $p<0,05$ festgelegt. Die statistische Auswertung erfolgte durch Anwendung einer Varianzanalyse für wiederholte Messungen eines Faktors (ANOVA) und durch anschließenden multiplen t-Test nach Dunett. 


\section{Ergebnisse}

\subsection{Futtermenge}

Abb. 3.1.

Durchschnittlicher Tagesfutterverbrauch der ovarektomierten Ratte nach 4wöchiger s.c. Substitutionstherapie unter dem jeweiligen Einfluss von $E_{2}$, dem $E R \alpha$ - oder ER $\beta$-Agonisten $p<0,05$ versus ovx

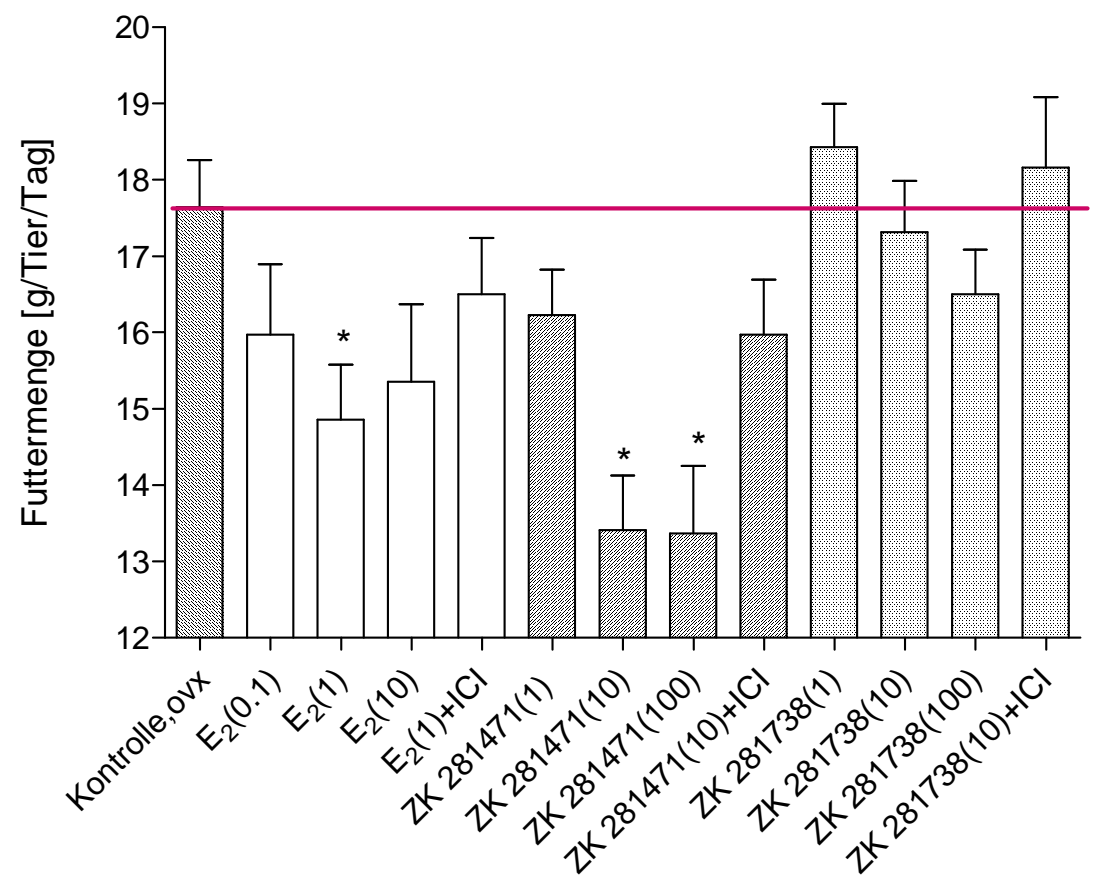

\begin{tabular}{|l|l|l|l|l|l|l|l|l|l|l|l|l|l|}
\hline $\begin{array}{l}\text { Substanz in } \\
\mu \mathrm{g} / \text { Tier/Tag }\end{array}$ & $\begin{array}{l}\text { Kon- } \\
\text { trolle } \\
\text { ovx }\end{array}$ & $\begin{array}{l}\mathrm{E}_{2} \\
0,1\end{array}$ & $\begin{array}{l}\mathrm{E}_{2} \\
1\end{array}$ & $\begin{array}{l}\mathrm{E}_{2} \\
10\end{array}$ & $\begin{array}{l}\mathrm{E}_{2} \\
1+ \\
\mathrm{ICl}\end{array}$ & $\begin{array}{l}\alpha \\
1\end{array}$ & $\begin{array}{l}\alpha \\
10\end{array}$ & $\begin{array}{l}\alpha \\
100\end{array}$ & $\begin{array}{l}\alpha \\
10+ \\
\mathrm{ICl}\end{array}$ & $\begin{array}{l}\beta \\
1\end{array}$ & $\begin{array}{l}\beta \\
10\end{array}$ & $\begin{array}{l}\beta \\
100\end{array}$ & $\begin{array}{l}\beta \\
10+ \\
\mathrm{ICl}\end{array}$ \\
\hline $\begin{array}{l}\varnothing \\
\begin{array}{l}\text { Futtermenge } \\
\text { in g/Tier/Tag }\end{array}\end{array}$ & 17,6 & 15,9 & 14,9 & 15,4 & 16,5 & 16,2 & 13,4 & 13,4 & 16,0 & 18,4 & 17,3 & 16,5 & 18,2 \\
\hline$\% \sim$ & 100 & 90,3 & 84,7 & 87,5 & 93,8 & 92,0 & 76,1 & 76,1 & 90,9 & 104,5 & 98,3 & 93,8 & 103,4 \\
\hline
\end{tabular}

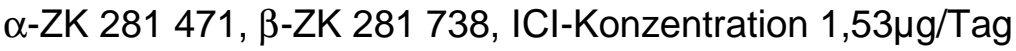

Die Futteraufnahme wurde unter Einfluss der verschiedenen Substanzen beobachtet. Es zeigt sich eine signifikante Reduktion der Futteraufnahme in der mitteldosierten $E_{2}$-Gruppe und unter mittel- und hochdosiertem ER $\alpha$-Agonisten ZK 281471. Der ER $\beta$-Agonist ZK 281738 zeigt keine signifikanten Auswirkungen bezüglich dem Futteraufnahmeverhalten. Unter ICl-Substitution erhöht sich die Futtermenge mäßig. 


\subsection{Körpergewicht}

Der Östrogeneinfluss auf das Körpergewicht, besonders auf den Körperfettanteil, ist bekannt. Hier wird nun der Einfluss der unterschiedlichen Substanzen auf die Gewichtsentwicklung dargestellt.

Abb. 3.2.

Durchschnittliches Körpergewicht der ovarektomierten Ratte nach 4wöchiger s.c.

Substitutionstherapie unter dem jeweiligen Einfluss von $\mathrm{E}_{2}$, dem $E R \alpha$ - oder

ER $\beta$-Agonisten

${ }^{*} p<0,05$ versus prea ovx, alle

$+p<0,05$ versus Kontrolle, ov $x$

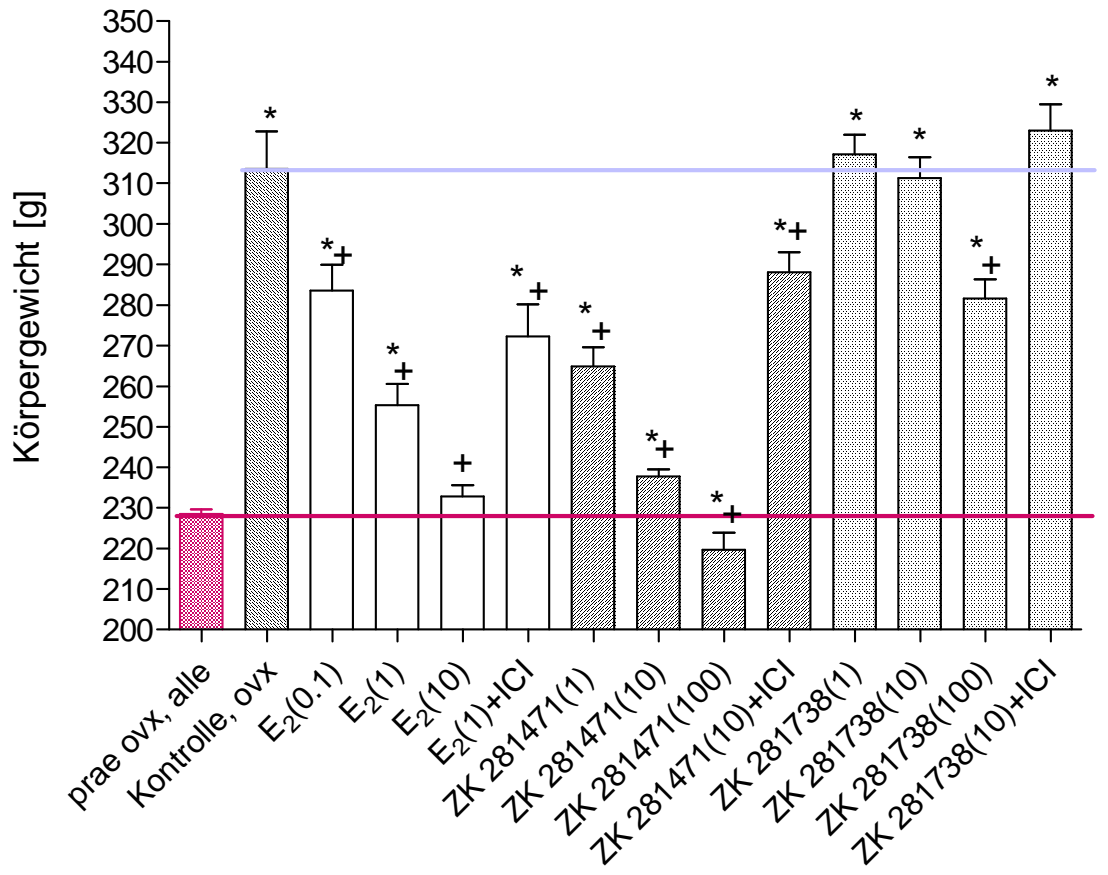

\begin{tabular}{|l|l|l|l|l|l|l|l|l|l|l|l|l|l|l|}
\hline $\begin{array}{l}\text { Substanz } \\
\text { in } \\
\mu \mathrm{g} / \text { Tier/Tag }\end{array}$ & $\begin{array}{l}\text { prae } \\
\text { ovx, } \\
\text { alle }\end{array}$ & $\begin{array}{l}\text { Kon- } \\
\text { trolle } \\
\text { ovx }\end{array}$ & $\begin{array}{l}\mathrm{E}_{2} \\
0,1\end{array}$ & $\begin{array}{l}\mathrm{E}_{2} \\
1\end{array}$ & $\begin{array}{l}\mathrm{E}_{2} \\
10\end{array}$ & $\begin{array}{l}\mathrm{E}_{2} \\
1+ \\
\mathrm{ICl}\end{array}$ & $\begin{array}{l}\alpha \\
1\end{array}$ & $\begin{array}{l}\alpha \\
10\end{array}$ & $\begin{array}{l}\alpha \\
100\end{array}$ & $\begin{array}{l}\alpha \\
10+ \\
\mathrm{ICl}\end{array}$ & $\begin{array}{l}\beta \\
1\end{array}$ & $\begin{array}{l}\beta \\
10\end{array}$ & $\begin{array}{l}\beta \\
100\end{array}$ & $\begin{array}{l}\beta \\
10+ \\
\mathrm{ICI}\end{array}$ \\
\hline $\begin{array}{l}\varnothing \text { Gewicht } \\
\text { in g }\end{array}$ & 229 & 314 & 284 & 255 & 233 & 272 & 265 & 238 & 220 & 288 & 317 & 311 & 282 & 323 \\
\hline$\% \sim$ & & 100 & 90 & 81 & 74 & 87 & 84 & 76 & 70 & 92 & 101 & 99 & 90 & 103 \\
\hline
\end{tabular}

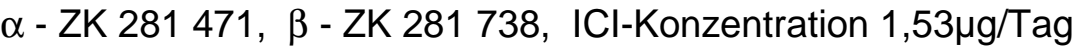

Die Substitution von $\mathrm{E}_{2}$ und dem ER $\alpha$-Agonisten ZK 281471 führt unter Dosissteigerung zur signifikant geringeren Gewichtszunahme in allen Substitutionsgruppen im Vergleich zu den Kontrolltieren. Dem ERß-Agonisten ZK 281738 gelingt dies nur unter der höchsten Dosis mit Signifikanz. Unter zusätzlicher ICl-Gabe tritt der Gewichtsverlust reduziert auf. 


\subsection{Ergebnisse der Knochendichtemessung in der Metaphyse der Tibia}

Es wurden die Auswirkungen der eingesetzten Substanzen auf den Erhalt der Knochendichte nach der Ovarektomie getestet. Hierbei wurden Spongiosa und Kortikalis getrennt voneinander betrachtet. Die Untersuchungen wurden an den Metaphysen der Tibiae durchgeführt. 


\subsubsection{Spongiosadichte in der Metaphyse der Tibia}

Abb. 3.3.1.

Durchschnittliche metaphysäre Spongiosadichte der ovarektomierten Ratte nach 4wöchiger s.c. Substitutionstherapie unter dem jeweiligen Einfluss von

$\mathrm{E}_{2}$, dem ER $\alpha$ - oder ER $\beta$-Agonisten

${ }^{*} p<0,05$ versus prae ovx, alle

$+p<0,05$ versus Kontrolle, ovx

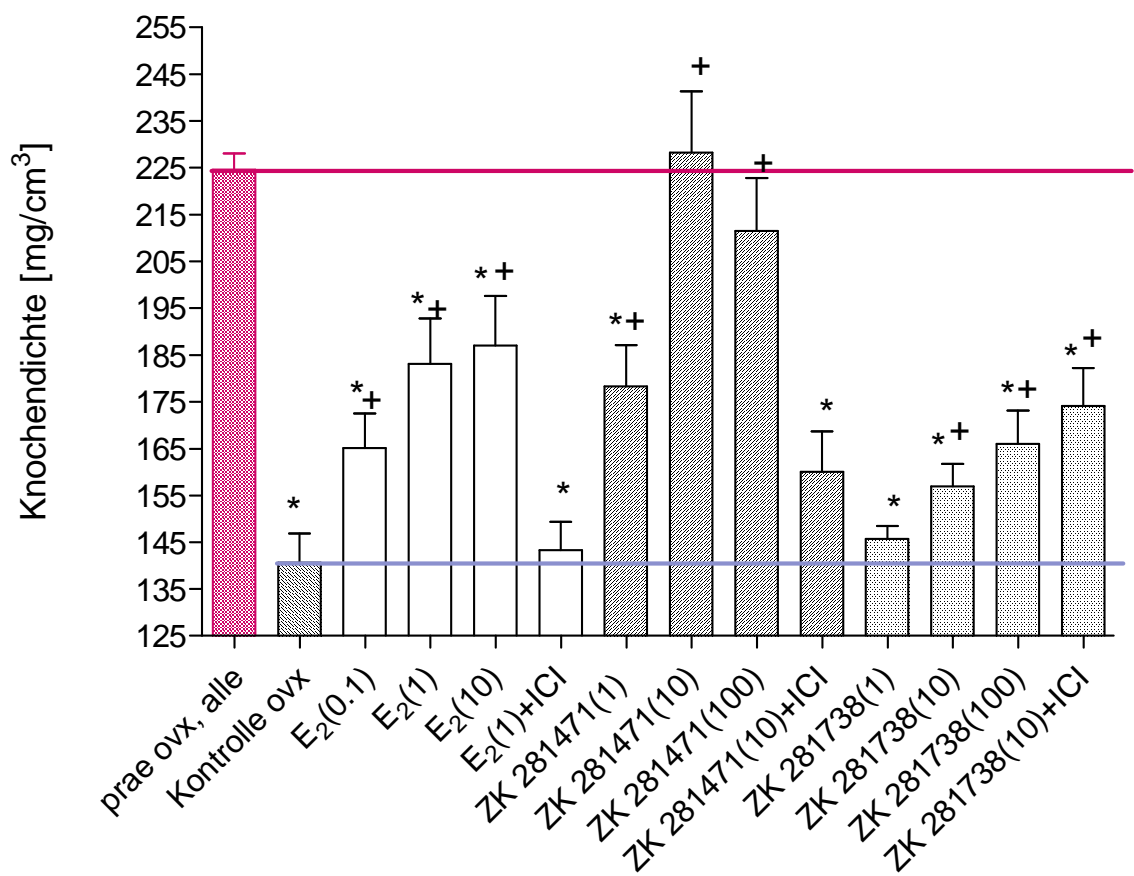

\begin{tabular}{|l|l|l|l|l|l|l|l|l|l|l|l|l|l|l|}
\hline $\begin{array}{l}\text { Substanz } \\
\text { in } \\
\mu \mathrm{\mu g} / \text { Tier/Tag }\end{array}$ & $\begin{array}{l}\text { prae } \\
\text { ovx, } \\
\text { alle }\end{array}$ & $\begin{array}{l}\text { Kon- } \\
\text { trolle } \\
\text {,ovx }\end{array}$ & $\begin{array}{l}\mathrm{E}_{2} \\
0,1\end{array}$ & $\begin{array}{l}\mathrm{E}_{2} \\
1\end{array}$ & $\begin{array}{l}\mathrm{E}_{2} \\
10\end{array}$ & $\begin{array}{l}\mathrm{E}_{2} \\
1+ \\
\mathrm{ICl}\end{array}$ & $\begin{array}{l}\alpha \\
1\end{array}$ & $\begin{array}{l}\alpha \\
10\end{array}$ & $\begin{array}{l}\alpha \\
100\end{array}$ & $\begin{array}{l}\alpha \\
10+ \\
\mathrm{ICl}\end{array}$ & $\begin{array}{l}\beta \\
1\end{array}$ & $\begin{array}{l}\beta \\
10\end{array}$ & $\begin{array}{l}\beta \\
100\end{array}$ & $\begin{array}{l}\beta \\
10+ \\
\mathrm{ICl}\end{array}$ \\
\hline $\begin{array}{l}\text { Ø Knochen } \\
\text {-dichte in } \\
\mathrm{mg} / \mathrm{cm}^{3}\end{array}$ & 225 & 141 & 165 & 183 & 187 & 143 & 178 & 228 & 211 & 160 & 146 & 157 & 166 & 174 \\
\hline$\% \sim$ & & 100 & 117 & 130 & 133 & 101 & 126 & 162 & 150 & 113 & 104 & 111 & 118 & 123 \\
\hline
\end{tabular}

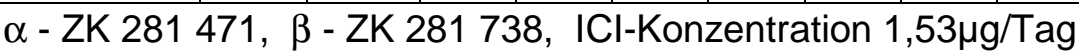

$E_{2}$ und der ER $\alpha$-Agonist ZK 281471 zeigen in allen Reinkonzentrationen einen signifikanten Erhalt der Spongiosadichte verglichen mit den Kontrolltieren. Dem ERß-Agonisten gelingt dies nur in seiner mittleren und hohen Konzentration. ICI reduziert die Spongiosadichte signifikant. 


\subsubsection{Kortikalisdichte in der Metaphyse der Tibia}

Abb. 3.3.2.

Durchschnittliche metaphysäre Kortikalisdichte der ovarektomierten Ratte nach 4wöchiger s.c. Substitutionstherapie unter dem jeweiligen Einfluss von

$\mathrm{E}_{2}$, dem $\mathrm{ER} \alpha$ - oder $\mathrm{ER} \beta$-Agonisten

${ }^{*} p<0,05$ versus prae ov $x$, alle

$+p<0,05$ versus Kontrolle, ovx

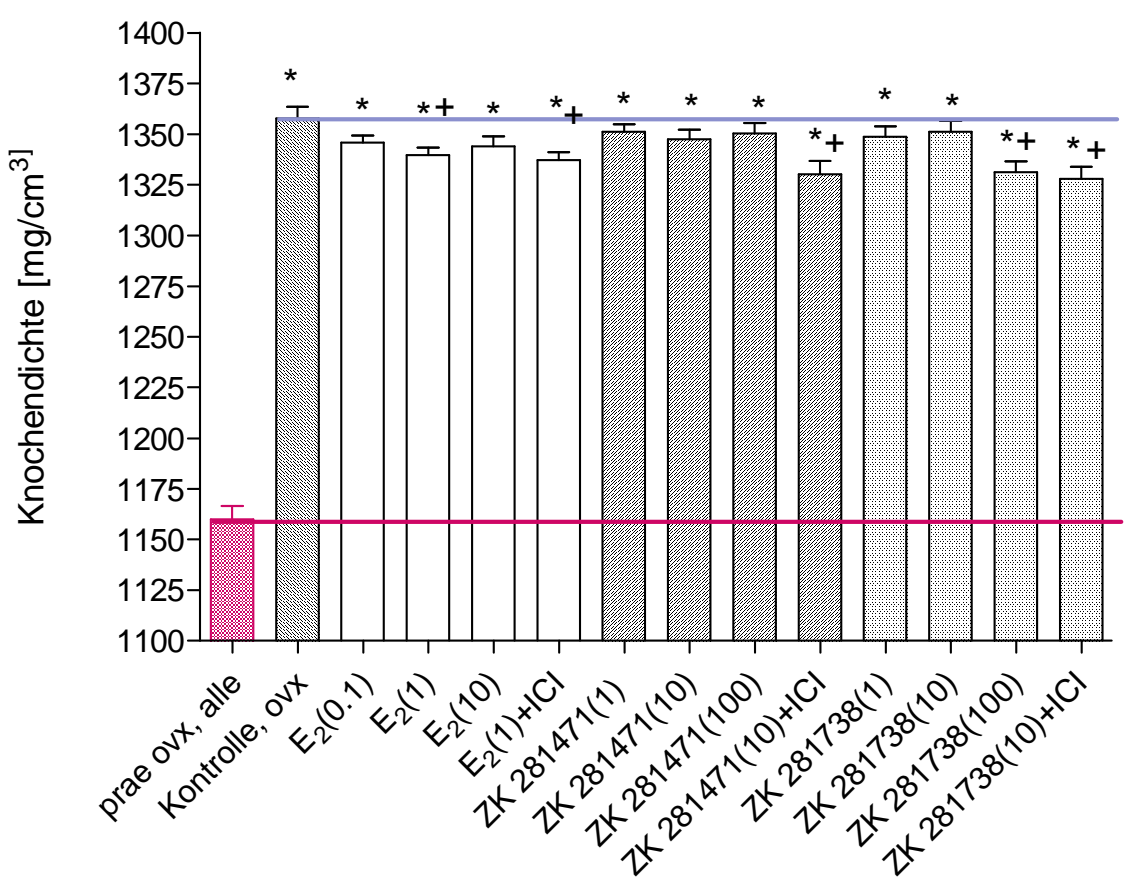

\begin{tabular}{|l|l|l|l|l|l|l|l|l|l|l|l|l|l|l|}
\hline $\begin{array}{l}\text { Substanz } \\
\text { in } \\
\mu \mathrm{g} / \text { Tier/Tag }\end{array}$ & $\begin{array}{l}\text { prae } \\
\text { ovx, } \\
\text { alle }\end{array}$ & $\begin{array}{l}\text { Kon- } \\
\text { trolle } \\
\text { ovx }\end{array}$ & $\begin{array}{l}\mathrm{E}_{2} \\
0,1\end{array}$ & $\begin{array}{l}\mathrm{E}_{2} \\
1\end{array}$ & $\begin{array}{l}\mathrm{E}_{2} \\
10\end{array}$ & $\begin{array}{l}\mathrm{E}_{2} \\
1+ \\
\mathrm{ICl}\end{array}$ & $\begin{array}{l}\alpha \\
1\end{array}$ & $\begin{array}{l}\alpha \\
10\end{array}$ & $\begin{array}{l}\alpha \\
100\end{array}$ & $\begin{array}{l}\alpha \\
10+ \\
\mathrm{ICl}\end{array}$ & $\begin{array}{l}\beta \\
1\end{array}$ & $\begin{array}{l}\beta \\
10\end{array}$ & $\begin{array}{l}\beta \\
100\end{array}$ & $\begin{array}{l}\beta \\
10+ \\
\mathrm{ICl}\end{array}$ \\
\hline $\begin{array}{l}\varnothing \text { Knochen } \\
\text {-dichte in } \\
\mathrm{mg} / \mathrm{cm}^{3}\end{array}$ & 1160 & 1358 & 1346 & 1340 & 1344 & 1337 & 1351 & 1348 & 1350 & 1330 & 1349 & 1351 & 1331 & 1328 \\
\hline$\%$ & 100 & 99,1 & 98,7 & 99,0 & 98,5 & 99,5 & 99,3 & 99,4 & 97,9 & 99,3 & 99,5 & 98,0 & 97,8 \\
\hline
\end{tabular}

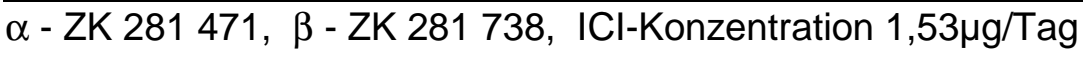

Einzig die mittlere Reindosis von $\mathrm{E}_{2}$ sowie die höchste Reindosis des ERß-Agonisten ZK 281738 zeigen einen signifikanten Substanzverlust. Die anderen Dosierungen dieser Gruppen weisen ebenso wie alle Substitutionseinheiten des ER $\alpha$-Agonisten ZK 281471 keine signifikanten Veränderungen auf. $\mathrm{ICl}$ verursacht einen nicht signifikanten Substanzrückgang. 


\subsection{Ergebnisse der Querschnittsflächenmessung in der Metaphyse der Tibia}

Es wurden die Auswirkungen der eingesetzten Substanzen auf den Erhalt der Knochenquerschnittsfläche nach der Ovarektomie getestet. Hierbei wurden Spongiosa und Kortikalis getrennt voneinander betrachtet. Die Untersuchungen wurden an den Metaphysen der Tibiae durchgeführt. 


\subsubsection{Endostale Fläche in der Metaphyse der Tibia}

Abb. 3.4.1.

Durchschnittliche endostale Fläche in der Metaphyse der ovarektomierten Ratte nach 4wöchiger s.c. Substitutionstherapie unter dem jeweiligen Einfluss von

$\mathrm{E}_{2}$, dem ER $\alpha$ - oder ER $\beta$-Agonisten

${ }^{*} p<0,05$ versus prae ov $x$, alle

$+p<0,05$ versus Kontrolle, ov $x$

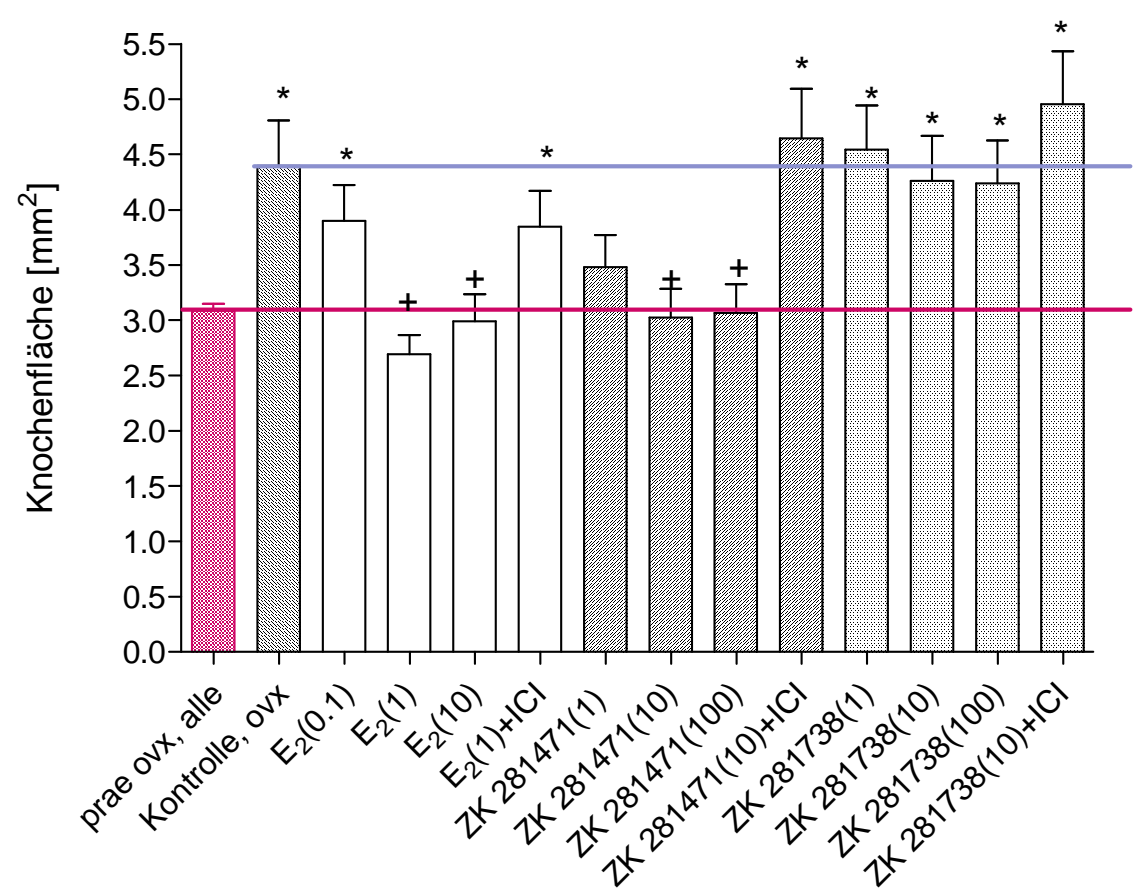

\begin{tabular}{|l|l|l|l|l|l|l|l|l|l|l|l|l|l|l|}
\hline $\begin{array}{l}\text { Substanz } \\
\text { in } \\
\mu \mathrm{g} / \text { Tier/Tag }\end{array}$ & $\begin{array}{l}\text { prae } \\
\text { ovx, } \\
\text { alle }\end{array}$ & $\begin{array}{l}\text { Kon- } \\
\text { trolle } \\
, \mathrm{ovx}\end{array}$ & $\begin{array}{l}\mathrm{E}_{2} \\
0,1\end{array}$ & $\begin{array}{l}\mathrm{E}_{2} \\
\mathrm{E}_{2}\end{array}$ & $\begin{array}{l}\mathrm{E}_{2} \\
10\end{array}$ & $\begin{array}{l}\alpha \\
1+ \\
\mathrm{ICl}\end{array}$ & $\begin{array}{l}\alpha \\
10\end{array}$ & $\begin{array}{l}\alpha \\
100\end{array}$ & $\begin{array}{l}\alpha \\
10+ \\
\mathrm{ICl}\end{array}$ & $\begin{array}{l}\beta \\
1\end{array}$ & $\begin{array}{l}\beta \\
10\end{array}$ & $\begin{array}{l}\beta \\
100\end{array}$ & $\begin{array}{l}\beta \\
10+ \\
\mathrm{ICl}\end{array}$ \\
\hline $\begin{array}{l}\emptyset \text { Knochen } \\
\text { fläche in } \\
\mathrm{mm}^{2}\end{array}$ & 3,1 & 4,4 & 3,9 & 2,7 & 3,0 & 3,8 & 3,5 & 3,0 & 3,1 & 4,6 & 4,5 & 4,3 & 4,2 & 5,0 \\
\hline$\% \sim$ & & 100 & 88,6 & 61,4 & 68,2 & 86,4 & 79,5 & 68,2 & 70,5 & 104,5 & 102,3 & 97,7 & 95,5 & 113,6 \\
\hline
\end{tabular}

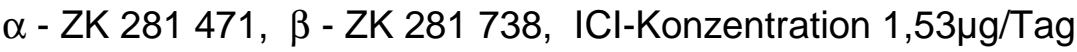

Eine signifikante Reduktion der endostalen Fläche lässt sich mittels Substitution von $E_{2}$ und dem ER $\alpha$-Agonisten ZK 281471 in mittlerer und hoher Dosis erreichen. Der ERß-Agonist ZK 281738 bewirkt keine signifikanten Veränderungen in Relation zu den Kontrolltieren. Die Applikation von ICl führt zu einer signifikanten endostalen Flächenzunahme. 


\subsubsection{Kortikalisquerschnittsfläche in der Metaphyse der Tibia}

Abb. 3.4.2.

Durchschnittliche metaphysäre Kortikalisquerschnittsfläche der ovarektomierten Ratte nach 4wöchiger s.c. Substitutionstherapie unter dem jeweiligen Einfluss von

$E_{2}$, dem ER $\alpha$ - oder ER $\beta$-Agonisten

${ }^{*} p<0,05$ versus prae ovx, alle

$+p<0,05$ versus Kontrolle, ovx

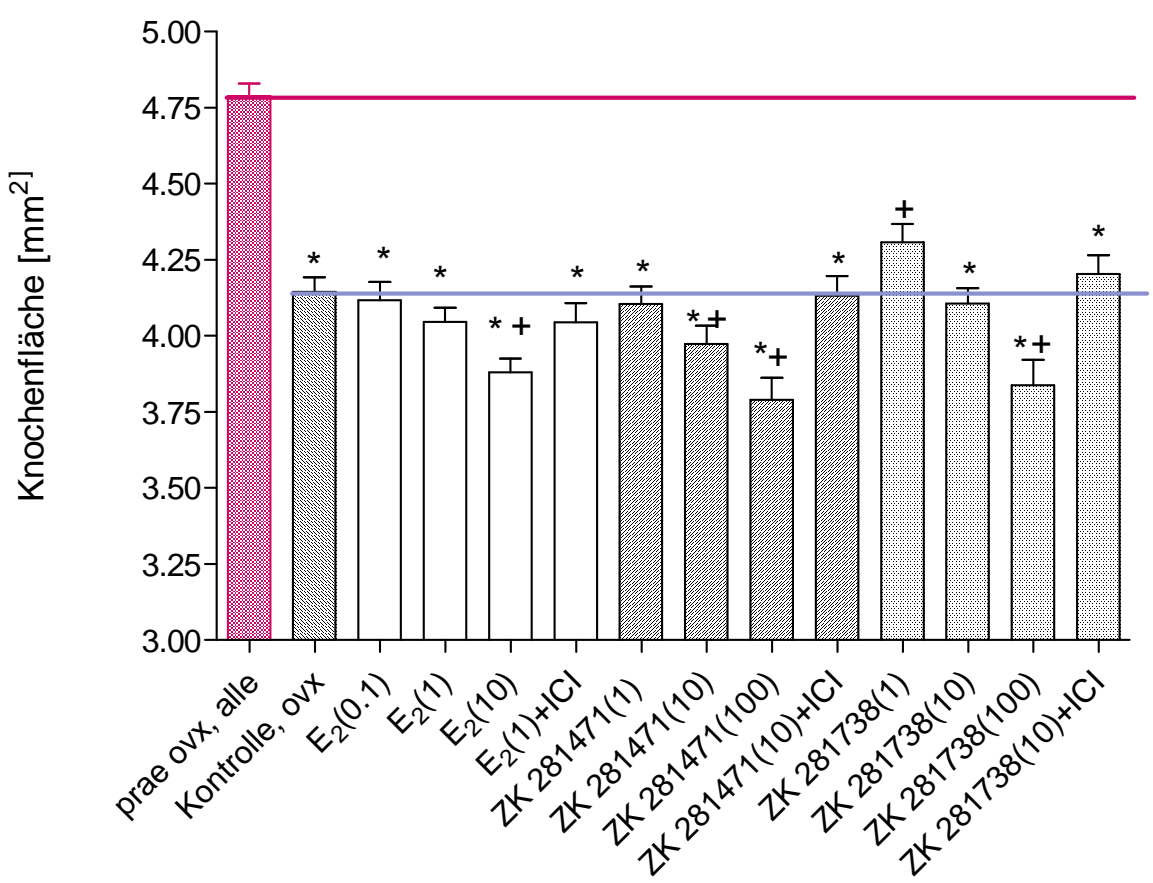

\begin{tabular}{|l|l|l|l|l|l|l|l|l|l|l|l|l|l|l|}
\hline $\begin{array}{l}\text { Substanz } \\
\text { in } \\
\mu \mathrm{g} / \text { Tier/Tag }\end{array}$ & $\begin{array}{l}\text { prae } \\
\text { ovx, } \\
\text { alle }\end{array}$ & $\begin{array}{l}\text { Kon- } \\
\text { trolle } \\
\text { ovx }\end{array}$ & $\begin{array}{l}\mathrm{E}_{2} \\
0,1\end{array}$ & $\begin{array}{l}\mathrm{E}_{2} \\
1\end{array}$ & $\begin{array}{l}\mathrm{E}_{2} \\
10\end{array}$ & $\begin{array}{l}\mathrm{E}_{2} \\
1+ \\
\mathrm{ICl}\end{array}$ & $\begin{array}{l}\alpha \\
1\end{array}$ & $\begin{array}{l}\alpha \\
10\end{array}$ & $\begin{array}{l}\alpha \\
100\end{array}$ & $\begin{array}{l}\alpha \\
10+ \\
\mathrm{ICl}\end{array}$ & $\begin{array}{l}\beta \\
1\end{array}$ & $\begin{array}{l}\beta \\
10\end{array}$ & $\begin{array}{l}\beta \\
100\end{array}$ & $\begin{array}{l}\beta \\
10+ \\
\mathrm{ICl}\end{array}$ \\
\hline $\begin{array}{l}\text { Ø Knochen } \\
\text { fläche in } \\
\mathrm{mm}^{2}\end{array}$ & 4,79 & 4,15 & 4,12 & 4,05 & 3,98 & 4,04 & 4,10 & 3,97 & 3,79 & 4,13 & 4,31 & 4,11 & 3,84 & 4,20 \\
\hline$\% \sim$ & & 100 & 99,3 & 97,6 & 95,9 & 97,3 & 98,8 & 95,7 & 91,3 & 99,5 & 103,9 & 99,0 & 92,5 & 101,2 \\
\hline
\end{tabular}

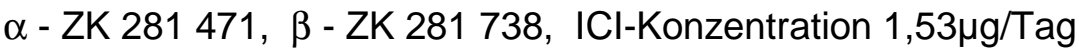

Eine signifikante Reduktion der Kortikalisfläche kann durch die Substitution der höchsten $\mathrm{E}_{2^{-}}$ Dosis, durch die mittlere und hohe Dosis des ER $\alpha$-Agonisten ZK 281471 und durch die höchste Dosis des ERß-Agonisten ZK 281738 erreicht werden. Unter der kleinsten Dosis des ERß-Agonisten tritt eine signifikante Flächenzunahme auf. $\mathrm{ICl}$ erreicht nur in Kombination mit dem ER $\alpha$-Agonisten eine signifikante Flächenvergrößerung. 


\subsection{Periostaler Umfang an der Metaphyse der Tibia}

Abb. 3.5.

Durchschnittlicher periostaler Umfang der Metaphyse der ovarektomierten Ratte nach 4wöchiger s.c. Substitutionstherapie unter dem jeweiligen

Einfluss von $E_{2}$, dem $E R \alpha$ - oder ER $\beta$-Agonisten

${ }^{*} p<0,05$ versus Kontrolle, $C T 1$, alle

$+p<0,05$ versus ov $x$

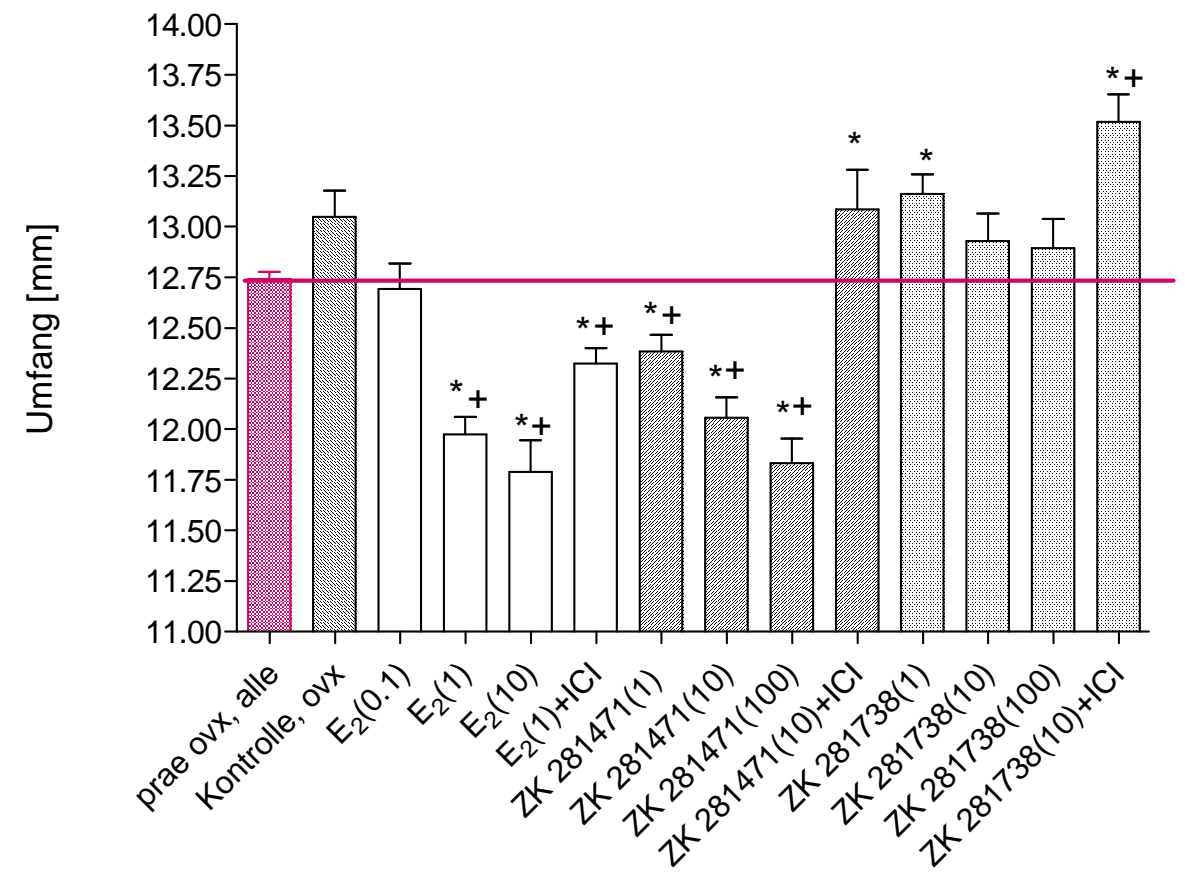

\begin{tabular}{|l|l|l|l|l|l|l|l|l|l|l|l|l|l|l|}
\hline $\begin{array}{l}\text { Substanz } \\
\text { in } \\
\mu \mathrm{\mu} / \text { Tier/Tag }\end{array}$ & $\begin{array}{l}\text { prae } \\
\text { ovx, } \\
\text { alle }\end{array}$ & $\begin{array}{l}\text { Kon- } \\
\text { trolle } \\
\text { ovx }\end{array}$ & $\begin{array}{l}\mathrm{E}_{2} \\
0,1\end{array}$ & $\begin{array}{l}\mathrm{E}_{2} \\
1\end{array}$ & $\begin{array}{l}\mathrm{E}_{2} \\
10\end{array}$ & $\begin{array}{l}\mathrm{E}_{2} \\
1+ \\
\mathrm{ICl}\end{array}$ & $\begin{array}{l}\alpha \\
1\end{array}$ & $\begin{array}{l}\alpha \\
10\end{array}$ & $\begin{array}{l}\alpha \\
100\end{array}$ & $\begin{array}{l}\alpha \\
10+ \\
\mathrm{ICl}\end{array}$ & $\begin{array}{l}\beta \\
1\end{array}$ & $\begin{array}{l}\beta \\
10\end{array}$ & $\begin{array}{l}\beta \\
100\end{array}$ & $\begin{array}{l}\beta \\
10+ \\
\mathrm{ICl}\end{array}$ \\
\hline $\begin{array}{l}\varnothing \text { Umfang } \\
\text { in } \mathrm{mm}\end{array}$ & 12,7 & 13,0 & 12,7 & 12,0 & 11,8 & 12,3 & 12,4 & 12,1 & 11,8 & 13,1 & 13,2 & 12,9 & 12,9 & 12,8 \\
\hline$\% \sim$ & & 100 & 97,7 & 92,3 & 90,8 & 94,6 & 95,4 & 93,1 & 90,8 & 100,8 & 101,5 & 99,2 & 99,2 & 98,5 \\
\hline
\end{tabular}

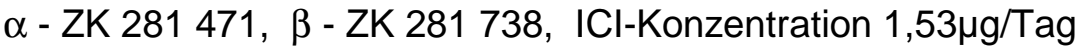

Allen drei reinen Dosierungen von $E_{2}$ und dem ER $\alpha$-Agonisten ZK 281471 gelingt die signifikante Reduktion des periostalen Umfangs verglichen mit der Kontrollgruppe. Dabei steigt die Effizienz mit Erhöhung der Dosis. Der ERß-Agonist ZK 281738 zeigt keinen signifikanten Einfluss auf diesen Parameter. Die Kombination des ERß-Agonisten mit ICI verursacht eine signifikante Umfangszunahme. 


\subsection{Standardisierte metaphysäre Tibiafraktur}

Die standardisierte metaphysäre Tibiafraktur wurde zur Ermittlung zweier Werte durchgeführt. Die Bruchkraft spiegelt den Wendepunkt zwischen elastischer und plastischer Verformung des untersuchten Knochens wider. Die ermittelte Maximalkraft trifft eine Aussage über die Kraft, bei der der Knochen vollständig bricht. Die Untersuchung wurde vor dem Hintergrund des steigenden Frakturrisikos bei Osteoporose durchgeführt. 


\subsubsection{Bruchkraft}

Abb. 3.6.1.

Durchschnittliche Bruchkraft bei der Tibiafraktur der ovarektomierten Ratte nach 4wöchiger s.c. Substitutionstherapie unter dem jeweiligen Einfluss von $\mathrm{E}_{2}$, dem $\mathrm{ER} \alpha$ - oder $\mathrm{ER} \beta$-Agonisten

${ }^{*} p<0,05$ versus Kontrolle, ovx

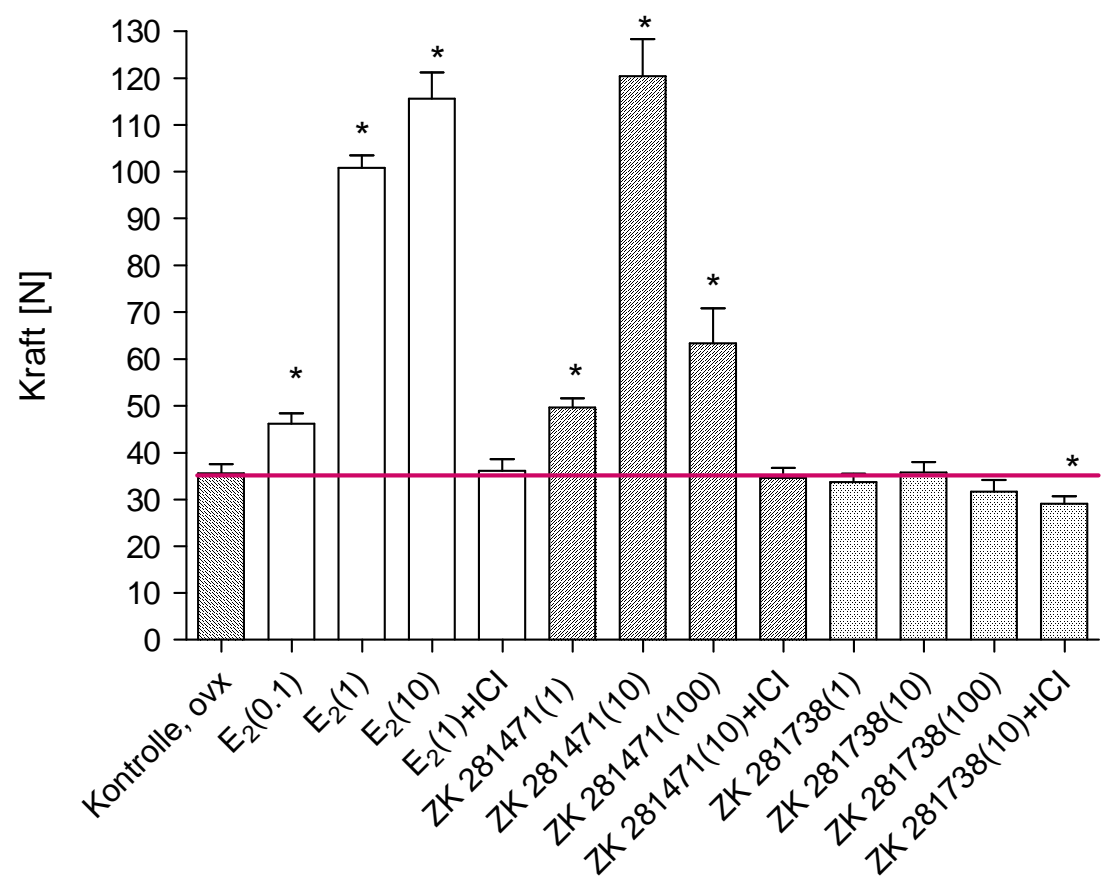

\begin{tabular}{|l|l|l|l|l|l|l|l|l|l|l|l|l|l|}
\hline $\begin{array}{l}\text { Substanz } \\
\text { in } \\
\mu \mathrm{g} / \text { Tier/Tag }\end{array}$ & $\begin{array}{l}\text { Kon- } \\
\text { trolle } \\
\text { ovx }\end{array}$ & $\begin{array}{l}\mathrm{E}_{2} \\
0,1\end{array}$ & $\begin{array}{l}\mathrm{E}_{2} \\
1\end{array}$ & $\begin{array}{l}\mathrm{E}_{2} \\
10\end{array}$ & $\begin{array}{l}\mathrm{E}_{2} \\
1+ \\
\mathrm{ICl}\end{array}$ & $\begin{array}{l}\alpha \\
1\end{array}$ & $\begin{array}{l}\alpha \\
10\end{array}$ & $\begin{array}{l}\alpha \\
100\end{array}$ & $\begin{array}{l}\alpha \\
10+ \\
\mathrm{ICl}\end{array}$ & $\begin{array}{l}\beta \\
1\end{array}$ & $\begin{array}{l}\beta \\
10\end{array}$ & $\begin{array}{l}\beta \\
100\end{array}$ & $\begin{array}{l}\beta \\
10+ \\
\mathrm{ICl}\end{array}$ \\
\hline $\begin{array}{l}\varnothing \text { Bruch- } \\
\mathrm{kraft} \text { in N }\end{array}$ & 36 & 46 & 101 & 116 & 36 & 50 & 120 & 57 & 35 & 34 & 36 & 32 & 29 \\
\hline$\% \sim ~$ & 100 & 128 & 281 & 322 & 100 & 139 & 333 & 158 & 97 & 94 & 100 & 89 & 81 \\
\hline
\end{tabular}

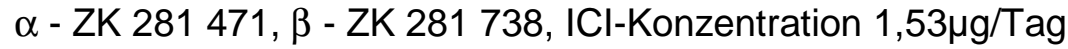

Durch Substitution von $\mathrm{E}_{2}$ und dem ER $\alpha$-Agonisten ZK 281471 tritt in allen Dosierungen eine signifikante Erhöhung der Bruchkraft auf. Unter Gabe des ERß-Agonisten ZK 281738 können keine signifikanten Veränderungen beobachtet werden. Der Einfluss von $\mathrm{ICl}$ auf diesen Parameter fällt gering aus und erreicht in Kombination mit dem ERß-Agonisten einen negativ signifikanten Wert. 


\subsubsection{Maximalkraft}

Abb. 3.6.2.

Durchschnittliche Maximalkraft bei der Tibiafraktur der ovarektomierten Ratte nach 4wöchiger s.c. Substitutionstherapie unter dem jeweiligen

Einfluss von $\mathrm{E}_{2}$, dem $\mathrm{ER} \alpha$ - oder $\mathrm{ER} \beta$-Agonisten

${ }^{*} p<0,05$ versus Kontrolle, ov $x$

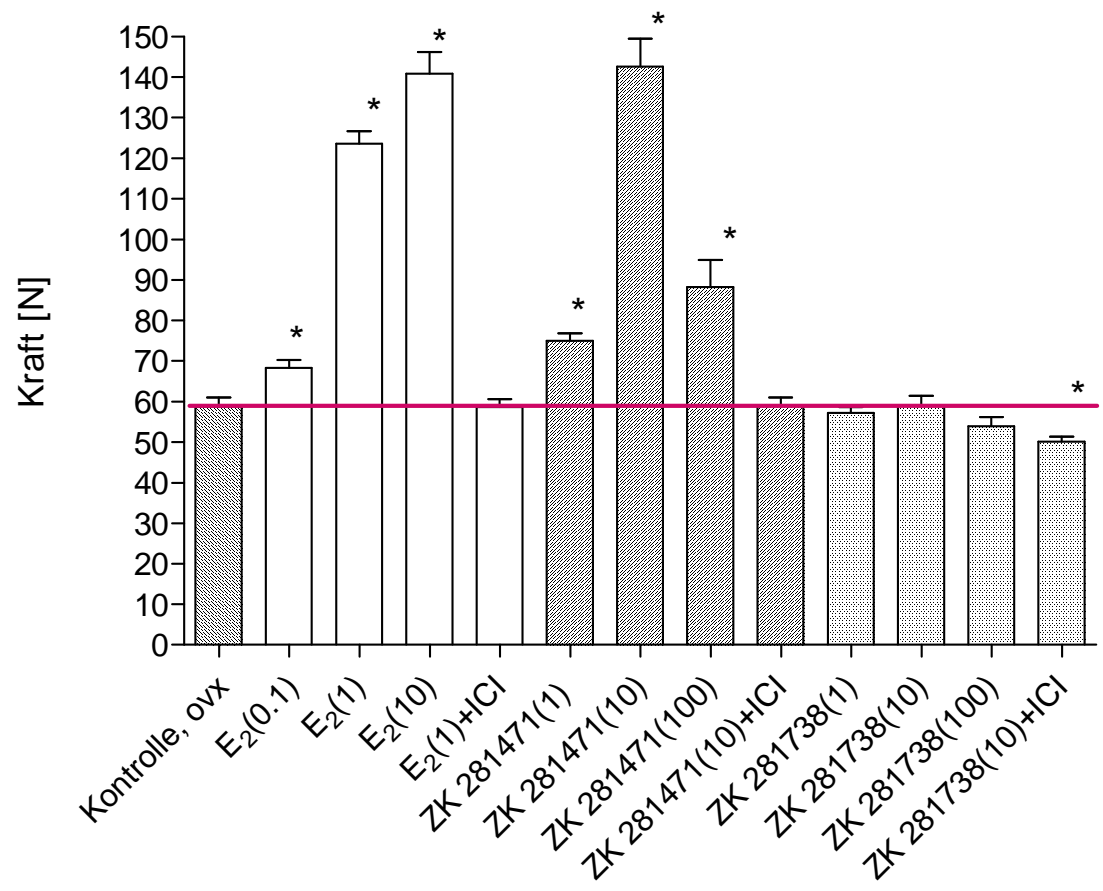

\begin{tabular}{|l|l|l|l|l|l|l|l|l|l|l|l|l|l|}
\hline $\begin{array}{l}\text { Substanz } \\
\text { in } \\
\mu \mathrm{g} / \text { Tier/Tag }\end{array}$ & $\begin{array}{l}\text { Kon- } \\
\text { trolle } \\
\text { ovx }\end{array}$ & $\begin{array}{l}\mathrm{E}_{2} \\
0,1\end{array}$ & $\begin{array}{l}\mathrm{E}_{2} \\
1\end{array}$ & $\begin{array}{l}\mathrm{E}_{2} \\
10\end{array}$ & $\begin{array}{l}\mathrm{E}_{2} \\
1+ \\
\mathrm{ICl}\end{array}$ & $\begin{array}{l}\alpha \\
1\end{array}$ & $\begin{array}{l}\alpha \\
10\end{array}$ & $\begin{array}{l}\alpha \\
100\end{array}$ & $\begin{array}{l}\alpha \\
10+ \\
\mathrm{ICl}\end{array}$ & $\begin{array}{l}\beta \\
1\end{array}$ & $\begin{array}{l}\beta \\
10\end{array}$ & $\begin{array}{l}\beta \\
100\end{array}$ & $\begin{array}{l}\beta \\
10+ \\
\mathrm{ICl}\end{array}$ \\
\hline $\begin{array}{l}\varnothing \text { Maximal- } \\
\text { kraft in N }\end{array}$ & 59 & 68 & 124 & 141 & 59 & 75 & 143 & 79 & 59 & 57 & 59 & 54 & 50 \\
\hline$\% \sim$ & 100 & 115 & 210 & 239 & 100 & 127 & 242 & 134 & 100 & 97 & 100 & 92 & 85 \\
\hline
\end{tabular}

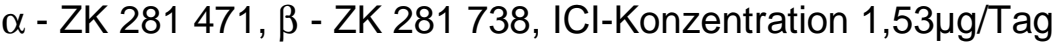

Durch Substitution von $\mathrm{E}_{2}$ und dem $\mathrm{ER} \alpha$-Agonisten ZK 281471 tritt in allen Dosierungen eine signifikante Erhöhung der Bruchkraft auf. Unter Gabe des ERß-Agonisten ZK 281738 können keine signifikanten Veränderungen beobachtet werden. Der Einfluss von $\mathrm{ICl}$ auf diesen Parameter fällt gering aus und erreicht in Kombination mit dem ERß-Agonisten einen negativ signifikanten Wert. 


\subsection{Serumanalyse der Knochenstoffwechselmarker}

Es wurde der Einfluss von $E_{2}$, dem ER $\alpha$-Agonisten und dem ER $\beta$-Agonisten auf die Serumwerte Rat Laps und Osteokalzin untersucht. Beides sind Stoffwechselmarker, wobei Rat Laps als spezifisch für Osteoklasten und Osteokalzin als spezifisch für Osteoblasten nachgewiesen wird. Dies stellt eine nicht invasive Analyse der Umbauprozesse im Knochen dar. 


\subsubsection{Rat Laps}

Abb. 3.7.1.

Durchschnittlicher Rat-Laps-Serumwert der ovarektomierten Ratte nach 4wöchiger S.c. Substitutionstherapie unter dem jeweiligen Einfluss von $\mathrm{E}_{2}$, dem $\mathrm{ER} \alpha$ - oder $\mathrm{ER} \beta$-Agonisten

${ }^{*} p<0,05$ versus Kontrolle, ov $x$

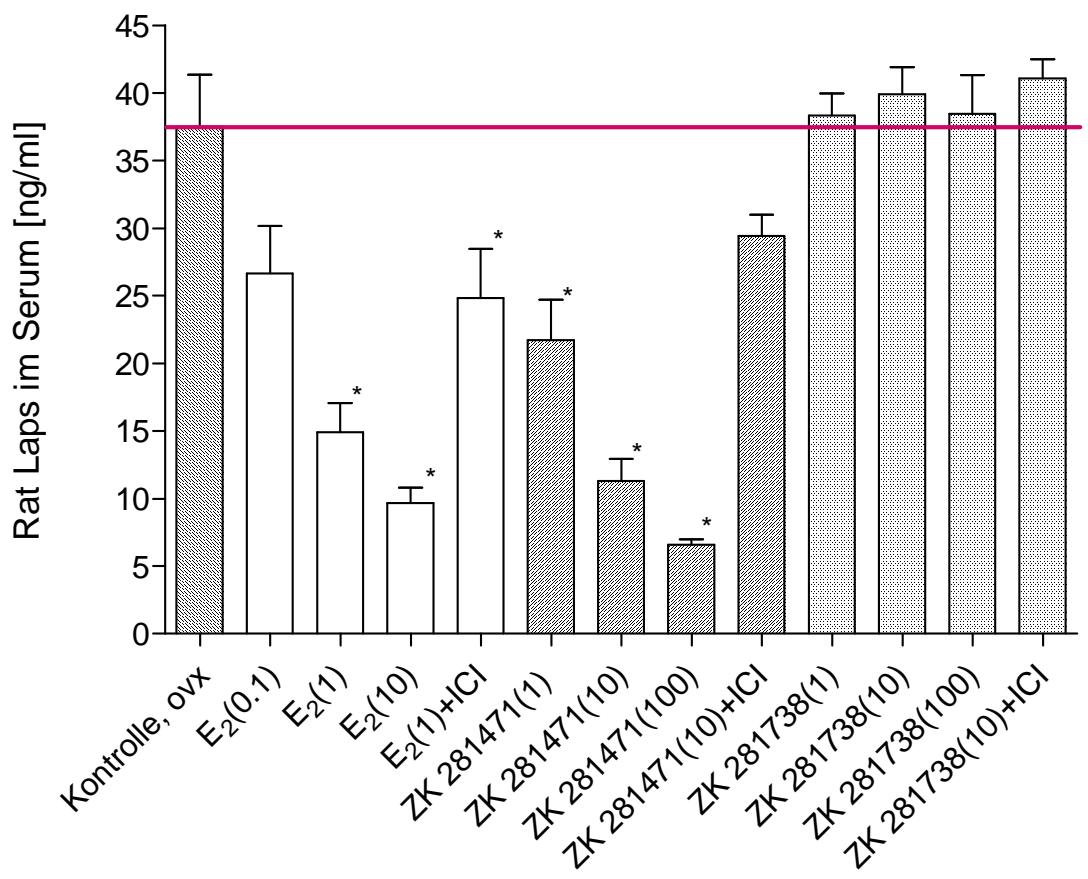

\begin{tabular}{|l|l|l|l|l|l|l|l|l|l|l|l|l|l|}
\hline $\begin{array}{l}\text { Substanz } \\
\text { in } \\
\mu \mathrm{\mu} / \text { Tier/Tag }\end{array}$ & $\begin{array}{l}\text { Kon- } \\
\text { trolle } \\
, \mathrm{ovx}\end{array}$ & $\begin{array}{l}\mathrm{E}_{2} \\
0,1\end{array}$ & $\begin{array}{l}\mathrm{E}_{2} \\
1\end{array}$ & $\begin{array}{l}\mathrm{E}_{2} \\
10\end{array}$ & $\begin{array}{l}\mathrm{E}_{2} \\
1+ \\
\mathrm{ICl}\end{array}$ & $\begin{array}{l}\alpha \\
1\end{array}$ & $\begin{array}{l}\alpha \\
10\end{array}$ & $\begin{array}{l}\alpha \\
100\end{array}$ & $\begin{array}{l}\alpha \\
10+ \\
\mathrm{ICl}\end{array}$ & $\begin{array}{l}\beta \\
1\end{array}$ & $\begin{array}{l}\beta \\
10\end{array}$ & $\begin{array}{l}\beta \\
100\end{array}$ & $\begin{array}{l}\beta \\
10+ \\
\mathrm{ICl}\end{array}$ \\
\hline $\begin{array}{l}\text { Ø Serum- } \\
\text { konz. in } \\
\mathrm{ng} / \mathrm{ml}\end{array}$ & 37,5 & 26,7 & 14,9 & 9,7 & 24,8 & 21,7 & 11,3 & 6,6 & 29,4 & 38,3 & 39,9 & 38,5 & 41,1 \\
\hline$\% \sim$ & 100 & 71,2 & 39,7 & 25,9 & 66,1 & 57,9 & 30,1 & 17,6 & 78,4 & 102,1 & 106,4 & 102,7 & 109,6 \\
\hline
\end{tabular}

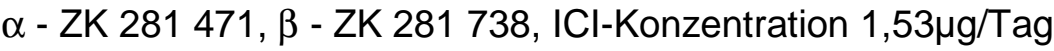

Eine signifikante Reduktion des Serummarkers im Vergleich zur Kontrolle gelingt unter mittlerer und hoher Konzentration von $\mathrm{E}_{2}$ und in allen Einheiten des $\mathrm{ER} \alpha$-Agonisten ZK 281471. Der ERß-Agonist ZK 281738 erzielt keinerlei signifikante Veränderungen. Auch durch $\mathrm{ICl}$ treten keine Signifikanzen auf. 


\subsubsection{Osteokalzin}

Abb. 3.7.2.

Durchschnittlicher Osteokalzin-Serumwert der ovarektomierten Ratte nach 4wöchiger s.c. Substitutionstherapie unter dem jeweiligen

Einfluss von $E_{2}$, dem $E R \alpha$ - oder $E R \beta$-Agonisten

${ }^{*} p<0,05$ versus ov $x$

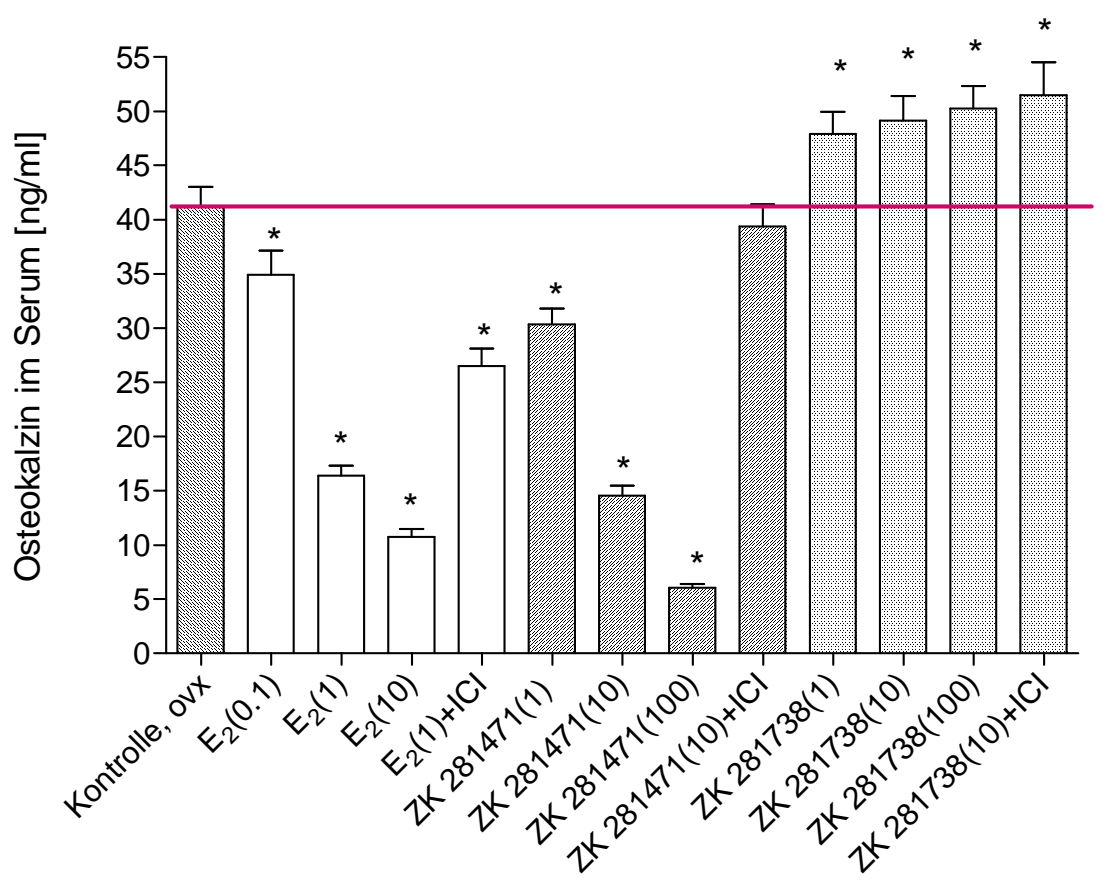

\begin{tabular}{|l|l|l|l|l|l|l|l|l|l|l|l|l|l|}
\hline $\begin{array}{l}\text { Substanz } \\
\text { in } \\
\mu \mathrm{g} / \text { Tier/Tag }\end{array}$ & $\begin{array}{l}\text { Kon- } \\
\text { trolle } \\
, \mathrm{ovx}\end{array}$ & $\begin{array}{l}\mathrm{E}_{2} \\
0,1\end{array}$ & $\begin{array}{l}\mathrm{E}_{2} \\
1\end{array}$ & $\begin{array}{l}\mathrm{E}_{2} \\
10\end{array}$ & $\begin{array}{l}\mathrm{E}_{2} \\
1+ \\
\mathrm{ICl}\end{array}$ & $\begin{array}{l}\alpha \\
1\end{array}$ & $\begin{array}{l}\alpha \\
10\end{array}$ & $\begin{array}{l}\alpha \\
100\end{array}$ & $\begin{array}{l}\alpha \\
10+ \\
\mathrm{ICl}\end{array}$ & $\begin{array}{l}\beta \\
1\end{array}$ & $\begin{array}{l}\beta \\
10\end{array}$ & $\begin{array}{l}\beta \\
100\end{array}$ & $\begin{array}{l}\beta \\
10+ \\
\mathrm{ICl}\end{array}$ \\
\hline $\begin{array}{l}\varnothing \text { Serum- } \\
\text { konz. in } \\
\mathrm{ng} / \mathrm{ml}\end{array}$ & 41,3 & 34,9 & 16,4 & 10,8 & 25,5 & 30,3 & 14,5 & 6,0 & 39,4 & 47,9 & 49,1 & 50,2 & 51,5 \\
\hline$\% \sim$ & 100 & 84,5 & 39,7 & 26,2 & 61,7 & 73,4 & 35,1 & 14,5 & 95,4 & 115,9 & 118,9 & 121,5 & 124,7 \\
\hline
\end{tabular}

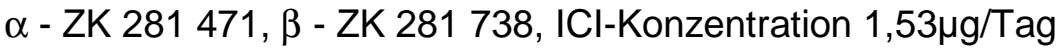

$\mathrm{E}_{2}$ bewirkt ebenso wie der ER $\alpha$-Agonist ZK 281471 eine signifikante Reduktion des Serumparameters Osteokalzin. Dabei sinkt der Wert umso mehr, je höher die Dosierung gewählt wurde. Die Gruppen des ERß-Agonisten ZK 281738 zeigen durchweg eine signifikante Konzentrationserhöhung. ICI zeigt seine einzige Signifikanz in Kombination mit dem ER $\alpha$-Agonisten. 


\section{Diskussion}

In dieser Arbeit steht die Untersuchung der osteoprotektiven Wirkung von $\mathrm{E}_{2}$ (17ß-Östradiol), dem reinen ER $\alpha$-Agonisten ZK 281471 und dem reinen ER $\beta$-Agonisten ZK 281738, sowie vom Antiöstrogen ICl am Knochen der ovarektomierten Ratte im Mittelpunkt. Dieses Modell bietet die Möglichkeit, Veränderungen am Knochen während der weiblichen Menopause zu simulieren. Durch die Substitutionstherapie können die Auswirkungen der verschiedenen applizierten Substanzen und deren Dosierung auf Osteoporoseparameter an der Metaphyse analysiert werden. Ziel ist hierbei die Ermittlung der Bedeutung der beiden ER-Subtypen für den Knochenstoffwechsel und die daraus resultierenden Therapiekonsequenzen. Um unsere Ergebnisse mit dem Hauptrisikoereignis der Osteoporose, der pathologischen Knochenfraktur (Stürmer et al.,2005), verbinden zu können, untersuchten wir die Knocheneigenschaften mittels eines standardisierten Tibia-Bruch-Verfahrens. Diese Untersuchung wurde in bisherigen Studien kaum durchgeführt und bietet daher kaum Vergleichsergebnisse, auf die zurückgegriffen werden kann. Die kombinierte Analyse der Mikroarchitekturresultate aus dem qCT und der Ergebnisse der metaphysären Tibiafraktur sollen so realitätsnahe Aussagen zum Frakturrisiko ermöglichen. Die ebenfalls ermittelten Stoffwechselparameter des Knochens sollen die qCT-Ergebnisse auf serologischer Ebene bestätigen und die Vernetzung mit den Knochenbruchwerten erleichtern.

\subsection{Futteraufnahme und Körpergewichte}

Die Veränderung des Hormonhaushaltes kann zu einer Veränderung des Körpergewichts führen. Ein Beispiel dafür ist die häufig beobachtete Gewichtszunahme der menopausalen Frau (Lovejoy,2003, Wronski et al.,1987), bei der durch den Abfall des Östrogenspiegels eine Vermehrung der Fettmasse (Lovejoy,2003, Seidlová-Wuttke et al.,2006) zu beobachten ist. Gleiches ist in der Gruppe der ovarektomierten, nicht substituierten Kontrolltiere festzustellen.

Dementsprechend ist unter der Substitution von $\mathrm{E}_{2}$ und dem $\mathrm{ER} \alpha$-Agonisten eine signifikante Reduktion der Gewichtszunahme zu verfolgen, was die Bedeutung der weiblichen Sexualhormone bestätigt. Die deutlich höhere Effizienz des ER $\alpha$-Agonisten hierbei deckt sich mit dem Wissen, dass ER $\alpha$ gegenüber ER $\beta$ der dominante Rezeptor im Fettgewebe ist (Naaz et al.,2002). Dies bestätigt auch der Vergleich der Resultate von $E_{2}$ mit denen des 
ER $\alpha$-Agonisten. Die rezeptorselektive Substanz hält das Gewicht geringer als Östradiol, welches über beide Rezeptorsubtypen wirkt.

Der Futterverbrauch weist Parallelen zum Gewichtsverhalten der einzelnen Tiere auf, was auf die Beeinflussung des metabolischen Geschehens schlussfolgern lässt. So fressen die Tiere etwa den gleichen Anteil gemessen an ihrem Körpergewicht. Die Kontrolltiere nehmen dabei entsprechend schneller an Gewicht zu und fressen so mehr und mehr, abhängig von ihrer steigenden Körpermasse. Bei den substituierten Gruppen unter $E_{2}$ und dem $E R \alpha-$ Agonisten tritt diese Gewichterhöhung so nicht auf und so bleibt auch der Futterverbrauch auf einem niedrigeren Niveau. Die Tiere nehmen also grundsätzlich nicht so schnell an Gewicht zu. Der lipolytisch-metabolische Effekt von Östrogenen wurde bereits beschrieben (Seidlová-Wuttke et al. 2006). So zeigen die hoch dosierten Tiere unter dem Einfluss des ER $\alpha$-Agonisten das geringste Körpergewicht der Studie, was mit der ER $\alpha$-Präsenz im Fettgewebe und dem Einfluss von Östrogenen auf den Stoffwechsel korreliert. Es sind auch Beobachtungen gemacht worden, die zeigen, dass Tiere unter Östrogensubstitution eine vermehrte Aktivität aufweisen und so auch mehr Energie verbrauchen, was eine weitere Erklärungsmöglichkeit für das geringere Gewicht darstellt (Lobo et al., 1993).

Entsprechend der Erwartungen zeigt der ERß-Agonist einen schwächren Einfluss. Ihm ist es nur unter der höchsten Dosis möglich die Gewichtszunahme signifikant zu verhindern. Auch hier zeigen sich die bereits beschriebenen Zusammenhänge zur Nahrungsaufnahme, da mit steigender Dosis das Gewicht und die Futtermenge weniger stark zunehmen.

Das Antiöstrogen ICl verhält sich erwartungsgemäß und fördert die Gewichtszunahme. Es blockiert die Rezeptorbindungsstellen für ER-Agonisten und schwächt so deren Wirkung ab (Wade et al.,1993). So sind die Tiere mit der Kombination aus ERß-Agonist und ICI durchschnittlich die schwersten der Studie.

\subsection{Knochenarchitektur, Knocheneigenschaften und Knochenstoffwechsel}

Wir haben es uns in dieser Studie zur Aufgabe gemacht, die Auswirkungen der postmenopausal fehlenden Östrogene auf den Knochen zu untersuchen. Diesen Veränderungen haben wir parallel unter Zuhilfenahme von ausgewählten Substanzen entgegen gewirkt und auch die daraus resultierenden Veränderungen dokumentiert und analysiert, um sie mit den untherapierten Auswirkungen des Hormondefizits zu vergleichen. Unbehandelt führt diese endokrine Umstellung häufig als erstes zur Osteopenie und weiter zum Krankheitsbild der Osteoporose. 
Die ersten Anzeichen des Östrogenmangels zeigen sich bereits deutlich nach 4 Wochen in der Metaphyse der Tibia (Yamauchi et al.,2001). Dieser Bereich gilt wegen seinem großen Spongiosaanteil (Stürmer et al.,2005) als besonders geeignet, da das Trabekelwerk den gesteigerten Knochenstoffwechsel als erstes reflektiert. Diese Stoffwechselsteigerung resultiert aus dem fehlenden Östrogeneinfluss (Pal et al.,2001), wodurch die Aktivität der Knochenzellen und die damit verbundene Rate der Umbauprozesse im Knochen steigt (Seidlová-Wuttke et al.,2003). Daraus resultieren Veränderungen in Dichte und Fläche der Metaphyse, welche wir mit Hilfe von 2 qCT-Untersuchungen, vor Ovarektomie und nach Ende der 4wöchigen Substitutionszeit, dargestellt haben. In diesem Zeitraum wurden den Tieren gruppenspezifisch die ausgewählten Testsubstanzen in den entsprechenden Konzentrationen appliziert. Die gewählten Dosierungen erwiesen sich als sinnvoll, da die mittleren Konzentrationen oft bessere oder ähnliche Resultate wie die hohen Dosen erbrachten. So können wir zeigen, dass es nicht nötig ist, die Dosierung im Bereich der toxischen Grenze zu wählen.

Wie erwartet zeigten sich nach 4 Wochen deutliche Merkmale der gesteigerten Umbauprozesse. In der Kontrollgruppe wurde eine signifikante Abnahme der Spongiosadichte $(-37,3 \%)$ und eine signifikante Zunahme der endostalen Fläche $(+41,9 \%)$ verzeichnet. Der vollständige Erhalt der Spongiosadichte ließ sich durch Substitution des ER $\alpha$-Agonisten in mittlerer Dosis erzielen. Auch zeigte sich in dieser Gruppe kein Zuwachs der endostalen Fläche. Diese Resultate bestätigen das Potential des ER $\alpha$-Agonisten am Knochen und untermauern die Annahme, dass ER $\alpha$ als dominanter Rezeptor im Knochen auftritt (Onoe et al., 1997; Lim et al., 1999).

Die Empfindlichkeit der Spongiosa für den Wegfall von Östrogenen (Wronski und Yen,1991; Bonjour et al.,1997) zeigt sich bei der gegenüberstellenden Betrachtung mit den Auswirkungen auf die Kortikalis. Bei Analyse der metaphysären Knochendichte und -fläche, sowohl der ovarektomierten Kontrolltiere als auch der substituierten Gruppen, zeigen sich im Vergleich zu den Ausgangswerten wachstumsabhängige Veränderungen am Knochen die alle Tiere gleichermaßen betreffen. Diese sind nicht therapieinduziert und stehen damit nicht im Blickfeld der Betrachtung. Beim Vergleich der verschieden behandelten Tiergruppen mit der Kontrollgruppe kann man erkennen, dass die hormonbedingten Veränderungen deutlich geringer als am spongiösen Knochen ausfallen. Wie auch an der Spongiosa gelingt es dem ER $\alpha$-Agonisten am besten, dicht gefolgt von 17ß-Östradiol, die Knochenstruktur kompakt und somit stabil zu halten. Dieses Resultat bestätigt unsere Erwartungen und deckt sich mit Erkenntnissen aus früheren Untersuchungen (Bonjour et al., 1997; da Paz et al., 2001; Riggs et al., 1998), bei denen ebenfalls in der postmenopausalen Phase der spongiöse Knochenverlust dominiert. 
Abschließend wird für diese Studie die Aussage getroffen, dass die Kortikalis unter dem Verlust des Östrogeneinflusses weniger starken Veränderungen unterworfen ist und so zur Beurteilung des $\mathrm{E}_{2}$-Defizits die sensitive Spongiosa betrachtet werden muss.

Zur Untersuchung des periostalen Umfangs wurde ebenfalls der Bereich der tibialen Metaphyse herangezogen. Die ermittelten Werte scheinen mit der Flächenzunahme der Kortikalis zu korrelieren und zeigen, dass diese sich (auch) nach außen erweitert. Um eine Flächenvergrößerung auf Kosten des Spongiosabereichs auszuschließen ist die zusätzliche Betrachtung des endostalen Umfangs von Nöten. Dies kann hier somit nicht vollständig ausgeschlossen werden, aber eine kortikale Flächenvermehrung einzig auf Kosten der Spongiosaareale wird widerlegt.

Das Antiöstrogen ICI zeigt bezüglich der Dichten, Flächen und des periostalen Umfangs in der tibialen Metaphyse in allen behandelten Gruppen den erwarteten Effekt und reduziert durch Rezeptorblockade die knochenprotektive Wirkung des jeweiligen ER-Agonisten. Daraus resultiert eine Steigerung des Knochenstoffwechsels und eine entsprechende Knochenumgestaltung in Vergleich zur Substitutionsgruppe mit entsprechender Agonistkonzentration aber ohne ICI.

Unsere Ergebnisse bestätigen somit das Wissen aus vorangegangenen Studien (Weihua et al., 2003; Fritzemeier et al.,2004; Lanyon et al., 2004; Seidlová-Wuttke et al., 2004b) bezüglich der Effektivität der ER $\alpha$-Stimulation am Knochen.Ebenso konnte die geringere Effizienz von $E_{2}$ und dem ERß-Agonisten, sowie die gegenläufige Wirkung von Antiöstrogenen nachweisen werden. Den 4 Wochen nach Ovarektomie manifesten Veränderungen, besonders an der Spongiosa, konnten durch Substitution des ER $\alpha$ Agonisten signifikant entgegen gewirkt werden. Das aus Studien mit ER $\alpha$ - und ER $\beta$ - knockout- Mäusen ( $\alpha \mathrm{ERKO} / \beta \mathrm{ERKO}$ ) stammende Wissen (Weihua et al.,2003; Lindberg et al.,2001; Dahlman-Wright et al.,2003) (siehe 1.4.2.) um die Bedeutung des $\alpha$-Rezeptors beim Erhalt der Knochenmasse unter Östrogeneinfluss bestätigt ebenfalls unsere Untersuchungsergebnisse und ermöglicht so abermals die Verifizierung der Bedeutung von $\mathrm{ER} \alpha$ für den postmenopausalen Knochenerhalt.

Die Untersuchungen im Rahmen der Tibiafraktur wurden an den post mortem präparierten Tibiae der Tiere durchgeführt. Unter standardisierten Bedingungen wurde der gezielte Bruch der proximalen Metaphyse initiiert. Dies erbrachte für unsere Studie 2 neue Werte, die bisher in weinigen Arbeiten betrachtet wurden (Stürmer et al.,2005). Die hierbei ermittelten Daten bezüglich der Bruchkraft lassen eine Aussage über die Elastizität des Knochens zu, denn sie definieren den Punkt des Übergangs von elastischer zu plastischer Verformung. Die fortan 
auftretenden Mikrofrakturierungen finden sich gehäuft im Trabekelwerk des Knochens und führen beim Auftreten der jeweils knochenspezifischen Maximalkraft zum endgültigen Knochenbruch. Dieser ist durch die Zerstörung der kortikalen Struktur gekennzeichnet. Zu erwarten ist eine Steigerung beider Kraftwerte über $\mathrm{ER} \alpha$, da diese Gruppen bereits in den Untersuchungen der Mikroarchitektur osteoprotektive Wirkungen aufzeigen.

Erfreulicherweise treten eben diese Resultate in signifikanter Weise in den Ergebnissen unserer Studie auf. Die mittlere Dosis des ER $\alpha$-Agonisten erweist sich bezüglich beider Werte als am effektivsten. $E_{2}$ gelingt annähernd Gleiches, aber erst in seiner höchsten Dosierung. Durch beide Substanzen ist so eine Elastizitätssteigerung um mehr als das 3fache und eine mehr als doppelte Bruchfestigkeit erreicht worden. Zur Vermeidung der Dosierung im toxischen Grenzbereich gilt es, die Präferenz des ER $\alpha$-Agonisten zu erwägen. Deutlich wird die Bedeutung von ER $\alpha$ bei der Begutachtung der Resultate des ER $\beta$ Agonisten. Diesem ist es nicht möglich bedeutenden Einfluss auf die Brucheigenschaften der Tibia zu nehmen. Das Antiöstrogen ICl zeigt seinen signifikanten Effekt durch vollständiges Aufheben des östrogenen Einflusses der Agonisten und beweist so die große Bedeutung von Veränderungen in der Spongiosa des Knochens. Bei vergleichender Betrachtung der Ergebnisse aus dem Bruchversuch mit denen der qCT-Untersuchungen stellt man fest, dass der Spongiosadichte, gefolgt von der Spongiosafläche, der bedeutendste Einfluss auf Elastizität und Stabilität zugeschrieben werden muss. Der gegenläufige Einfluss von ICI auf die agonistische Substanz fällt hier am deutlichsten aus und ist bei den Flächeuntersuchungen der Spongiosa und besonders bei den Dichte- und Flächeuntersuchungen der Kortikalis nicht in gleicher Eindrücklichkeit festzustellen. Dies bestätigt die Bedeutung der Spongiosadichte für die Knochendichte (BMD) (Matsubara et al.,1999; Stürmer et al.,2005) und somit die Bedeutung der BMD für die Beurteilung des Frakturrisikos (Bonjour et al., 1997).

Zum Verständnis der Veränderungen der Serumparameter ist das Wissen um die pathophysiologischen Veränderungen des Knochenstoffwechsels essentiell. Wir ermittelten die Serumwerte Rat Laps und Osteokalzin unter Analyse des nach der Tötung durch Dekapitation austretenden Blutes, vornehmlich aus den großen Halsgefäßen des Tierkörpers. Rat Laps entspricht beim Menschen dem Parameter Cross Laps und ist zur Beurteilung der katabol wirkenden Osteoklastenaktivität nutzbar. Es entsteht beim Abbau von kollagenösen Strukturen im Knochen und ermöglicht daher die Beurteilung der ossären Abbauprozesse auf serologischer Ebene. Osteokalzin hingegen ist ein Stoffwechselprodukt der Osteoblasten und spiegelt somit deren Aktivität wieder (Seidlová-Wuttke et al.,2004b; 
Seifert-Klauss et al.,2005). Bei beiden Werten korreliert die Zellaktivität mit dem Anstieg der Serummarker (Vancata,2002; Seidlová-Wuttke et al.,2004b; Seifert-Klauss et al.,2005), was eine Beurteilung der Gesamtsituation des Knochenstoffwechsels zulässt. Des Weiteren ist bekannt, das der Wegfall des hemmenden Östrogeneinflusses zuerst eine Steigerung der Osteoklastenaktivität provoziert und deren Lebensspanne durch Reduktion der Apoptoserate verlängert (Jilka,1998). Reflektorisch steigen die Osteoblastenzahlen und somit die Zeichen der Osteoblastenaktiviät (Riggs et al., 1998; Vanderschueren et al., 2004). Das unter dem physiologischen Hormoneinfluss ausgeglichene System erfährt unter Verlust des Einflusses der Östrogene eine Verschiebung zu Gunsten der katabolen Seite. Daraus resultiert die Entstehung der postmenopausalen Osteoporose. Diese Tatsachen sind das Fundament für die im qCT und bei der Tibiafraktur ermittelten Veränderungen am Knochen durch dessen gesteigerten Stoffwechsel.

Die Wirkung von Östrogenen über $E R \alpha$ und dessen Bedeutung am Knochen wurde in vorangehenden Abschnitten bereits erklärt. Beide Serummarker können durch die Gabe von ER $\alpha$-Agonisten gesenkt werden. Diese Tatsache ermöglicht die Behauptung, dass beide Serummarker in den intakten Tieren in geringerer Konzentration als in den ovarektomierten Kontrolltieren zu Versuchsende vorlagen. Dies wiederum bestätigt die Aussage, dass der Knochenstoffwechsel durch natürliche Östrogene unterdrückt wird (Pal et al.,2001) und dass durch ihren Abfall eine Stoffwechselsteigerung im Knochen auftritt. Gleiches gelingt uns durch die Substitution künstlicher, am ER $\alpha$ agonistisch wirkender Substanzen. Da die Werte der Serummarker die Gesamtsituation des Knochenstoffwechsels des Tieres widerspiegeln, kann aufgezeigt werden, dass der ER $\alpha$-Agonist am besten in der Lage ist die Aktivität der Knochenzellen gering zu halten. $E_{2}$ folgt mit seinen Resultaten dicht dahinter.

Unter dem Einfluss des ERß-Agonisten erfährt der Knochenstoffwechsel eine Steigerung. Dies zeigt sich deutlich bei der Betrachtung der beiden Serumparameter. Dieses Ergebnis sympathisiert mit den Resultaten der anderen Untersuchungen und belegt ein weiters Mal die Ineffizienz des ERß-Agonisten bezüglich der Knochenprotektion und somit die mangelnde Bedeutung des ER $\beta$ am Knochen. 
Alle in dieser Studie ermittelten Werte scheinen miteinander zu korrelieren. Die Betrachtung der Pathophysiologie des Knochenstoffwechsels unter dem Einfluss von Östrogenen ist der Ausgangspunkt für die Entstehung der postmenopausalen Osteoporose und spiegelt sich in den Serumparametern der Knochenzellen wieder. Gerät dieses System durch ein $\mathrm{E}_{2}$-Defizit zu Gunsten der katabolen Seite in Schräglage, so resultieren daraus die bei den Kontrolltieren 4 Wochen nach Ovarektomie beobachteten Veränderungen der ossären Mikroarchitektur. Dies führt zu einer Minderung der Stabilität des Knochens und so zu einer erhöhten Anfälligkeit für Frakturereignisse.

Die Therapie ist mit am ER $\alpha$ agonistisch wirkenden Substanzen am effektivsten, da ER $\alpha$ der vornehmlich vorkommende Rezeptorsubtyp am adulten Knochen ist. Dies erklärt ebenfalls den mangelnden Therapieerfolg bei rein ERß-agonistischer Substitution. $E_{2}$ wirkt nicht selektiv über einen ER- Subtyp und kann so gute Ergebnisse erzielen, welche aber lediglich an die $E R \alpha$-selektiven Therapieerfolge heranreichen. ICl zeigt seinen antiöstrogenen Effekt durch Minderung der östrogenagonistischen Wirkung. 


\subsection{Kritische Beurteilung des Studienaufbaus}

Die Studie ist in ihrem Aufbau sehr ausgeglichen und gut durchdacht. Es wurde eine Vielzahl von Werten ermittelt, die aufgrund bisheriger wissenschaftlicher Forschungsarbeiten miteinander zu korrelieren scheinen. Der Einsatz vieler verschiedener Verfahren zur Erhebung der Daten dient der Messfehlerdezimierung.

Anhand der zitierten Quellen kann ebenfalls gezeigt werden, dass die Ergebnisse mit anderen wissenschaftlichen Arbeiten übereinstimmen und durch diese bestätigt werden.

Die Auswahl der Substitutionsdosen erwies sich bei retrospektiver Betrachtung als geeignet. Auch bieten die Stoffauswahl und die damit erzielten Erfolge bei der Therapie weiteren Anreiz zur detaillierteren Erforschung.

Vor dem rein mathematischen Hintergrund betrachtet wäre eine höhere Individuenzahl pro Gruppe anzustreben, da erst dann Aussagen bezüglich der Signifikanz rechnerisch bestätigt werden würden. Wir haben durch den weitläufigen Vergleich unserer Ergebnisse mit denen anderer Forschungsgruppen eine andere Möglichkeit der Steigerung der Aussagekraft geschaffen.

Zur erweiterten Beurteilbarkeit der ovarektomierten Kontrollgruppe würde ich die Haltung einer scheinovarektomierten Kontrollgruppe befürworten. Dies bietet die Möglichkeit, die physiologische Entwicklung der untersuchten Individuen unter gleichen Umgebungsbedingen zu studieren. 


\section{Zusammenfassung}

In dieser Arbeit stand die Untersuchung der osteoprotektiven Wirkung von $E_{2}$ (17ßÖstradiol), dem reinen ER $\alpha$-Agonisten ZK 281471 und dem reinen ERß-Agonisten ZK 281738, sowie vom Antiöstrogen ICI am Knochen der ovarektomierten Ratte im Mittelpunkt. Dieses Modell bietet die Möglichkeit, Veränderungen am Knochen während der weiblichen Menopause zu simulieren. Als zentrale Aufgaben ergaben sich die Analyse der sichtbaren Veränderungen der tibialen Metaphyse, die Stabilitätsprüfung dieses Knochenabschnittes im standardisierten Bruchversuch und die Betrachtung der serologisch relevanten Veränderungen. Mit Hilfe der durchgeführten Substitutionsversuche konnte eine Aussage zu Erfolg versprechenden Therapiegrundlagen erarbeitet werden.

Das gewählte Versuchsmodell der ovarektomierten Ratte erwies sich als geeignet für die Untersuchung der Knochenveränderungen der menopausalen Frau aufgrund gleicher physiologischer Hormon- und Knochenstoffwechselprozesse. So trat nach Ovarektomie bei den nicht therapierten Kontrolltieren eine Östrogen- MangelOsteoporose, vergleichbar mit der der postmenopausalen Frau, auf. Das entstandene Krankheitsbild beim untersuchten Tier entspricht ebenso wie das des Menschen der DVO-Definition: „Die Osteoporose ist eine systemische Skeletterkrankung, die durch eine niedrige Knochenmasse und eine Verschlechterung der Mikroarchitektur des Knochengewebes charakterisiert ist, mit der Folge vermehrter Knochenbrüchigkeit."(DVO-Leitlinien,2006)

In allen Untersuchungen zeigten die ovarektomierten Kontrolltiere den erwarteten Effekt. Der Wegfall der natürlichen Östrogene aus den Ovarien spiegelte sich so in der Zunahme des Körpergewichts, der Vergrößerung der metaphysären Knochenfläche und Verminderung der metaphysären Knochendichte, einer Stabilitätsminderung des Knochens und dem Anstieg der knochenspezifischen Serumparameter wider.

Diese erfolgreich induzierten Veränderungen und deren Beobachtung waren die Grundlage der durchgeführten Substitutionstherapie, welche es damit zu verhindern galt. Die Substanzen ZK 281471 als selektiver ER $\alpha$-Agonist und ZK 281738 als selektiver ERß-Agonist wurden unter dem Gesichtspunkt der Rezeptorselektivität ausgewählt. $\mathrm{E}_{2}$ (17ß-Östradiol) simuliert die physiologische Hormonsituation mittels Wirkungsentfaltung über beide Rezeptorsubtypen, $\mathrm{ICl}$ hingegen soll als Antiöstrogen die Effekte der 3 genannten Substanzen antagonisieren. Bezüglich der untersuchten Dosierungen erwies sich die gewählte Minimalkonzentration erwartungsgemäß als generell zu niedrig. Die mittleren und hohen Konzentrationen, besonders von den für 
uns relevanten Substanzen ( $E_{2}$, ER $\alpha$-Agonist), zeigten oft gemeinsam eine signifikante Veränderung. Dies ermöglicht den Ausschluss der am toxischen Maximum liegenden, hohen Dosierung.

Aufgrund der Rezeptorverteilung im Knochen, bei der das Vorkommen von ER $\alpha$ dem von $E R \beta$ deutlich überlegen ist, ist grundsätzlich mit einer höheren osteoprotektiven Wirkung über einen ER $\alpha$-Agonisten zu rechnen. Dies bestätigt sich in unserer Studie.

Futterverbrauch und die Veränderung der Körpergewichte über den Versuchszeitraum spielen in dieser Studie eine untergeordnete Rolle. Die Ergebnisse bestätigen die Wirksamkeit der Substanzen und zeigen die Sensitivität der Tiere für selbige. Eine deutliche Zunahme des Körpergewichts wurde durch Ovarektomie erreicht. Die Verhinderung der Gewichtszunahme gelang am effizientesten durch die Substitution des rezeptorspezifischen $E R \alpha$-Agonisten, dann durch die von $E_{2}$. Dieses Ergebnis stimmt mit dem Wissen um die Präsenz von ER $\alpha$ im Fettgewebe und der Wirkung der natürlichen Östrogene im weiblichen Organismus überein. Die Wirkung des ER $\beta$ Agonisten erwies sich diesbezüglich als wenig bedeutsam. Der östrogenantagonistische Effekt von ICI wurde durch eine Zunahme des Gewichts deutlich.

Im Rahmen der beiden qCT- Untersuchungen wurden die spongiöse und kortikale Dichte und Fläche sowie der periostale Umfang ermittelt. Typisch für den Wegfall des physiologischen Östrogenspiegels ist die Reduktion der Knochendichte, eine Vergrößerung der Knochenfläche und die Zunahme des Umfangs. Die Spongiosa ist hierbei die aussagekräftigere Struktur, da sie schneller die stattfindenden Veränderungen präsentiert. Ihr kommt eine große Bedeutung für die $B M D \mathrm{zu}$. Diesbezüglich zeigten die Kontrolltiere die typischen Veränderungen. Diese wurden am besten durch die Substitution des ER $\alpha$-Agonisten beherrscht. Die Substitution von $\mathrm{E}_{2}$ erwies sich als ebenfalls effizient, bezüglich der Reduktion der Spongiosaquerschnittsfläche als effizienter. Dem ER $\beta$-Agonisten gelang weder ein bedeutsamer Erhalt der Knochendichte noch die Verhinderung der Flächenzunahme. Auch die Auswirkungen der ICl-Applikation entsprechen der erwarteten antiöstrogenen Wirkung.

Die bei der standardisierten metaphysären Tibiafraktur ermittelten Werte machen Angaben über die Elastizität des Knochens und die benötigte Kraft für den vollständigen Bruch. Mit diesen Werten ist es möglich eine Aussage zur Stabilität des Knochens zu treffen. Dies ist nötig, um eine effektive Prävention bezüglich der osteoporosebedingten Fraktur zu leisten. Die Ergebnisse harmonieren besonders gut mit den qCTResultaten der Spongiosadichte und zeigen so die Verknüpfung von BMD mit dem Frakturrisiko. Ebenfalls untermauern sie die durch die qCT-Ergebnisse als effizient 
eingeschätzte Wirkung des ER $\alpha$-Agonisten, gefolgt von $E_{2}$. Hier bestätigt sich deutlich die Ineffizienz des ER $\beta$-Agonisten, dessen Werte sehr nah bei denen der Kontrollgruppe liegen. Auch zeigt sich, dass durch den Einfluss von $\mathrm{ICl}$ sämtlicher, durch Therapie erreichter, osteoprotektiver Benefit in Bezug auf das Frakturrisiko verloren geht.

Sowohl die qCT-Untersuchungen als auch der standardisierte Knochenbruch wurden an der Metaphyse der Tibia durchgeführt. Grundlage dafür ist das Verteilungsverhältnis von Spongiosa und Kortikalis. Durch viel Trabekelwerk werden in dieser Region östrogenbedingte Veränderungen in der ossären Mikroarchitektur frühzeitig deutlich.

Die Serumparameter Rat Laps und Osteokalzin spiegeln die strukturellen Veränderungen auf serologischer Ebene wider. Sie sind beweisend für die Knochenstoffwechsellage im gesamten Organismus. Dies können die regional begrenzten Ergebnisse aus qCT und Knochenbruch nicht leisten. Rat Laps spiegelt als knochenspezifisches kollagenöses Abbauprodukt durch seine Serumkonzentration proportional die Tätigkeit der Osteoklasten wider. Für die Messung der anabolen Aktivität der Osteoblasten nutzten wir ihr ebenfalls proportional anfallendes Stoffwechselprodukt Osteokalzin. Es zeigt sich die erwartete Zunahme des ossären Stoffwechsels bei fehlendem Östrogeneinfluss an den Kontrolltieren. Dies wird ein weiteres Mal am effektivsten durch den $E R \alpha$-Agonisten verhindert. Auch $E_{2}$ zeigt annähernd gleiche und somit signifikante Resultate. Die paradox erscheinenden Auswirkungen unter dem ERß-Agonisten werden anderen Einflussgrößen zugesprochen. Seine Auswirkung auf die Knochenzellaktivität ist somit mäßig. ICI ist durch seine antiöstrogene Wirkung in der Lage, dem östrogenen Effekt der Agonisten entgegenzuwirken. 
Zusammenfassend kann gesagt werden, dass sich die durch Östrogenmangel bedingten Veränderungen bereits 4 Wochen nach Ovarektomie deutlich an der Metaphyse der Tibia darstellen. Als am sensitivsten ist die Dichte der Spongiosa zu bewerten.

Um diesen Veränderungen entgegen zu wirken erwies sich der ER $\alpha$-Agonist ZK 281471 als am effektivsten. Dies bestätigt bisheriges Wissen um die beachtliche Bedeutung von ER $\alpha$ am Knochen. Der Ausgleich des physiologischen Östrogendefizits durch 17ß-Östradiol $\left(E_{2}\right)$ ist ebenfalls effizient, reicht aber nicht an die Resultate des ER $\alpha$-Agonisten heran. Aufgrund der Rezeptorverteilung ist es dem ERß-Agonisten nicht möglich, eine signifikante Knochenprotektion zu erzielen. ICI war als ER-Antagonist in der Lage, den Wirkungen der ER-Agonisten entgegen zu wirken.

Zur Verhinderung der durch Östrogendefizit verursachten postmenopausalen Osteoporose erweist sich der Einsatz eines ER $\alpha$ - spezifischen SERMs als am geeignetsten. 


\section{Literaturverzeichnis}

Albright F, Smith PH, Richardson AM (1941):

Postmenopausal osteoporosis.

JAMA $\underline{116}$, 2465-2474

Bagchi MK:

Steroid Hormone Receptor Family: Mechanisms of Action;

in: Encyclopedia of Hormones, Volume 3; hrsg. v. Henry H L, Norman A W; Elsevier Inc., San Diego/USA 2003, 403-410

Barrett-Connor E (1993):

Epidemiology and the Menopause: A Global Overview.

Int J Fertil Menopausal Stud 38(1), 6-14

Barrett-Connor E (1998):

Efficacy and Safety of Estrogen/Androgen Therapy. Menopausal symptoms, bone and cardiovascular parameters.

J Reprod Med 43 (8), 746-752

Bell NH:

Osteoporosis: Hormonal Treatment;

in: Encyclopedia of Hormones, Volume 3; hrsg. v. Henry H L, Norman A W; Elsevier Inc., San Diego/USA 2003, 86-88

Bonjour JP, Burckhardt P, Dambacher M, Kraenzlin ME, Wimpfheimer C (1997):

Epidemiology of osteoporosis.

Schweiz Med Wochenschr 127(16), 659-667

Bord S, Horner A, Beaven S, Compston J (2001):

Estrogen Receptors $\alpha$ and $\beta$ are Differentially Expressed in Developing Human Bone.

J Clin Endocrinol Metab 86(5), 2309-2314

Breckwoldt M :

Geschlechtsspezifische Funktionen und ihre Störungen;

in: Gynäkologie und Geburtshilfe, hrsg. v. Pfleiderer A, Breckwoldt M, Martius G, 4. Auflage,

Georg Thieme Verlag Stuttgart 2001, 47-77

Buckler H (2005):

The menopause transition: endocrine changes and clinical symptoms.

J Br Menopause Soc 11, 61-65

Chakravarti S, Collins WP, Forecast JD, Newton JR, Oram DH, Studd JWW (1976):

Hormonal profiles after the menopause.

BMJ 1976,2, 784-787

Cowley SM, Hoare S, Mosselman S, Parker MG (1997):

Estrogen Receptors $\alpha$ and $\beta$ Form Heterodimers on DNA.

J Biol Chem 272(37), 19858-19862 
Coxam V, Bowman BM, Mecham M, Roth CM, Miller MA, Miller SC (1996):

Effects of Dihydrotestosterone Alone and Combined with Estrogen on Bone Mineral Density, Bone Growth, and Formation Rates in Ovariectomized Rats.

Bone 19(2), 107-114

Dahlman-Wright K, Koehler K, Gustafsson JA:

Estrogen Receptor- $\beta$ Structure and Function;

in: Encyclopedia of Hormones, Volume 1; hrsg. v. Henry H L, Norman A W; Elsevier Inc., San Diego/USA 2003, 599-608

da Paz LHBC, de Falco V, Teng NC, dos Reis LM, Pereira RMR, Jorgetti V (2001):

Effect of $17 \beta$-estradiol or alendronate on the bone densitometry, bone histomorphometry and bone metabolism of ovariectomized rats.

Braz J Med Biol Res $\underline{34}(8), 1015-1022$

Dechering K, Boersma C, Mosselman S (2000):

Estrogen Receptors $\alpha$ and $\beta$ : Two Receptors of a Kind? .

Curr Med Chem $\underline{7}(5), 561-576$

DVO-Leitlinien 2006 zur Prophylaxe, Diagnostik und Therapie der Osteoporose bei Frauen ab der Menopause, bei Männern ab dem 60. Lebensjahr, Dachverband Osteologie e.V., www.lutherhaus.de/dvo-leitlinien

Fritzemeier $\mathrm{KH}$, Hillisch A, Elger W, Kaufmann U, Kollenkirchen U, Kosemund D, Lindenthal B, Müller G, Muhn P, Nubbemeyer R, Peters O, Siebel P, Hegele-Hartung C (2004):

Biological Effects of ER $\alpha$ - and ER $\beta$-Selective Estrogens.

Ernst Schering Res Found Workshop 46, 127-150

Frost HM, Jee WSS (1992):

On the rat model of human osteopenias and osteoporoses.

Bone Miner 18(3), 227-236

Furuya K, Matsumoto T (2003):

The effect of androgen on bone metabolism.

Clin Calcium 13(11), 1412-1418

Gustafsson JA (1999):

Estrogen receptor $\beta$ - a new dimension in estrogen mechanism of action.

J Endocr 163, 379-383

Hillisch A, Peters O, Kosemund D, Müller G, Walter A, Schneider B, Reddersen G, Elger W, Fritzemeier KH (2004):

Dissecting Physiological Roles of Estrogen Receptor $\alpha$ and $\beta$ with Potent Selective Ligands from Structure-Based Design.

Mol Endocrinol 18(7), 1599-1609

Horowitz MC (1993):

Cytokines and estrogen in bone: anti-osteoporotic effects.

Science 260(5108), 626-627 
Hulley S, Grady D, Bush T, Furberg C, Herrington D, Riggs B, Vittinghoff E (1998):

Randomized trial of estrogen plus progestin for secondary prevention of coronary heart disease in postmenopausal women.

JAMA $\underline{280}(7), 605-613$

Jilka RL (1998):

Cytokines, Bone Remodeling, and Estrogen Deficiency: A 1998 Update.

Bone 23(2), 75-81

Katzenellenbogen BS, Korach KS (1997):

Editorial: A New Actor in the Estrogen Receptor Drama -- Enter ER- $\beta$.

Endocrinology 138(3), 861-862

Katzenellenbogen BS, Montano MM, Ediger TR, Sun J, Ekena K, Lazennec G, Martini PGV, McInerney E, Delage-Mourroux R, Weis K, Katzenellenbogen JA (2000):

Estrogen Receptors: Selective Ligands, Partners, and Distinctive Pharmacology.

Recent Prog Horm Res $\underline{55}$, 163-195

Kuiper GGJM, Enmark E, Pelto-Huikko M, Nilsson S, Gustafsson JA (1996):

Cloning of a novel estrogen receptor expressed in rat prostate and ovary.

Proc Natl Acad Sci USA 93(12), 5925-5930

Kuiper GGJM, Carlsson B, Grandien K, Enmark E, Häggblad J, Nilsson S, Gustafsson JA (1997):

Comparison of the Ligand Binding Specificity and Transcript Tissue Distribution of Estrogen

Receptors $\alpha$ and $\beta$.

Endocrinology 138(3), 863-870

Kuiper GGJM, Shughrue PJ, Merchenthaler I, Gustafsson JA (1998a):

The Estrogen Receptor $\beta$ Subtype: A Novel Mediator of Estrogen Action in Neuroendocrine Systems.

Front Neuroendocrinol $\underline{19}(4), 253-286$

Kuiper GGJM, Carlquist M, Gustafsson JA (1998b):

Estrogen Is a Male and Female Hormone.

Sci Med $\underline{5}(4), 36-45$

Lanyon L, Armstrong V, Ong D, Zaman G, Price J (2004):

Is estrogen receptor $\alpha$ key to controlling bones' resistance to fracture?

J Endocrinol 182, 183-191

Li JK, Chang WH, Lin JC, Ruaan RC, Liu HC, Sun JS (2003):

Cytokine release from osteoblasts in response to ultrasound stimulation.

Biomaterials 24(13), 2379-2385

Lim SK, Won YJ, Lee HC, Huh KB, Park YS (1999):

A PCR analysis of ER $\alpha$ and ER $\beta$ mRNA abundance in rats and the effect of ovariectomy.

J Bone Miner Res 14(7), 1189-1196

Lindberg MK, Alatalo SL, Halleen JM, Mohan S, Gustafsson JA, Ohlsson C (2001):

Estrogen receptor specificity in the regulation of the skeleton of female mice.

J Endocr 171, 229-236 
Lindberg MK, Movérare S, Skrtic S, Gao H, Dahlman-Wright K, Gustafsson JA, Ohlsson C (2003):

Estrogen Receptor (ER)- $\beta$ Reduces ER $\alpha$-Regulated Gene Transcription, Supporting a "Ying Yang" Relationship between ER $\alpha$ and ER $\beta$ in Mice.

Mol Endocrinol 17(2), 203-208

Lobo MJ, Remesar X, Alemany M (1993):

Effects of chronic intravenous injection of steroid hormones on body weight and composition of female rats.

Biochem Mol Biol Int 29 $(2)$, 349-358

Lovejoy JC (2003):

The menopause and obesity.

Prim Care Clin Office Pract $\underline{30}$, 317-325

Marks SC, Jr. and Hermey DC:

The Structure and Development of Bone; in: Principles of Bone Biology; hrsg. v. Bilezikian J P, Raisz L G, Rodan G A; Academic

Press, San Diego/USA 1996, 3-14

Matsubara M, Nakamura K, Morita S, Kashima J (1999):

None-invasive assessement of bone quality.

J Med Dent Sci 46(4), 165-176

McDonnell DP, Wijayaratne A, Chang C, Norris JD (2002):

Elucidation of the Molecular Mechanism of Action of Selective Estrogen Receptor

Modulators.

Am J Cardiol $\underline{90}, 35 \mathrm{~F}-43 \mathrm{~F}$

McDonnell DP:

SERMs (Selective Estrogen Receptor Modulators);

in: Encyclopedia of Hormones, Volume 3; hrsg. v. Henry H L, Norman A W; Elsevier Inc., San Diego/USA 2003, 335-340

Monroe DG, Getz BJ, Johnsen SA, Riggs BL, Khosla S, Spelsberg TC (2003):

Estrogen Receptor Isoform-Specific Regulation of Endogenous Gene Expression in Human Osteoblastic Cell Lines Expressing Either ER $\alpha$ or ER $\beta$.

J Cell Biochem 90(2), 315-326

Mosselman S, Polman J, Dijkema R (1996):

ERß: identification and characterization of a novel human estrogen receptor.

FEBS Lett $\underline{392}, 49-53$

Naaz A, Zakroczymski M, Heine P, Taylor J, Saunders P, Lubahn D, Cooke PS (2002):

Effect of ovariectomy on adipose tissue of mice in the absence of estrogen receptor alpha (ERalpha): a potential role for estrogen receptor beta (ERbeta).

Horm Metab Res 34, 758-763

Nardulli AM:

Estrogen Receptor- $\alpha$ Structure and Function;

in: Encyclopedia of Hormones, Volume 1; hrsg. v. Henry H L, Norman A W; Elsevier Inc., San Diego/USA 2003, 594-599 
Norman AW, Henry HL:

Steroid Nomenclature;

in: Encyclopedia of Hormones, Volume 3; hrsg. v. Henry H L, Norman A W; Elsevier Inc., San Diego/USA 2003, 410-413

Onoe Y, Miyaura C, Ohta H, Nozawa S, Suda T (1997):

Expression of Estrogen Receptor $\beta$ in Rat Bone.

Endocrinology 138(10), 4509-4512

Oursler MJ (1998):

Estrogen Regulation of Gene Expression in Osteoblasts and Osteoclasts.

Crit Rev Eukaryot Gene Expr $\underline{8}(2), 125-140$

Pal R, Chaturvedi R, Kamboj KK, Chowdhury SR, Dwivedi A (2001):

Estrogen Receptors In Rat Bone: Their Interaction With Estrogen Receptor Modulators.

Endocr Res 27(3), 283-291

Riggs BL, Khosla S, Melton LJ (1998):

A Unitary Model for Involutional Osteoporosis: Estrogen Deficiency Causes Both Type I and Type II Osteoporosis in Postmenopausal Women and Contributes to Bone Loss in Aging Men.

J Bone Miner Res 13(5), 763-773

Saunders PTK (1998):

Oestrogen receptor beta $(E R \beta)$.

Rev Rep $\underline{3}, 164-171$

Seidlová-Wuttke D, Hesse O, Jarry H, Christoffel V, Spengler B, Becker T, Wuttke W (2003): Evidence for selective estrogen receptor modulator activity in a black cohosh (Cimicifuga racemosa) extract: comparison with estradiol-17ß.

Eur J Endocrinol 149(4), 351-362

Seidlová-Wuttke D, Schultens A, Jarry H, Wuttke W (2004a):

Urodynamic Effects of Estradiol $\left(E_{2}\right)$ in Ovariectomized (ovx) Rats.

Endocrine 23(1), 25-32

Seidlová-Wuttke D, Jarry $H$, Wuttke W (2004b):

Pure estrogenic effect of benzophenone-2 (BP2) but not of bisphenol A (BPA) and dibutylphtalate (DBP) in uterus, vagina and bone.

Toxicology 205(1-2), 103-112

Seidlová-Wuttke D, Stürmer KM, Stürmer EK, Sehmisch S, Wuttke W (2006):

Contrasting effects of estradiol, testosterone and of a black cohosh extract on density, mechanical properties and expression of several genes in the metaphysic of the tibia and on fat tissue of orchidectomized rats.

Maturitas $\underline{55}, 64-74$

Seifert-Klauss V, Laakmann J, Rattenhuber J, Höß C, Luppa P, Kiechle M (2005):

Bone Metabolism, Bone Density and Estrogen Levels in Perimenopause: A Prospektive 2-

Year-Study.

Z Gynecol 127(3), 132-139 
Shiraishi A, Higashi S, Masaki T, Saito M, Ito M, Ikeda S, Nakamura T (2002):

A Comparison of Alfacalcidol and Menatetrenone for the Treatment of Bone Loss in an Ovariectomized Rat Model of Osteoporosis.

Calcif Tissue Int $\underline{71}(1), 69-79$

Sluijmer AV, Heinemann MJ, Jong FH, Evers JLH (1995):

Endocrine Activity of the Postmenopausal Ovary: The Effects of Pituitary Down-Regulation and Oophoectomy.

$\mathrm{J}$ Clin Endocrinol Metab 42, 629-636

Spelsberg TC, Subramaniam M, Riggs BL, Khosla S (1999):

The Actions and Interactions of Sex Steroids and Growth Factors/Cytokines on the Skeleton.

Mol Endocrinol 13(6), 819-828

Stürmer EK, Seidlová-Wuttke D, Sehmisch S, Rack T, Wille J, Frosch KH, Wuttke W, Stürmer KM (2005):

Standardized Bending and Breaking Test for the Normal and Osteoporotic Metaphyseal Tibias of the Rat: Effect of Estradiol, Testosterone and Raloxifen.

J Bone Miner Res 20, 89-96

Tapiero H, Nguyen Ba G, Tew KD (2002):

Estrogens and environmental estrogens.

Biomed Pharmacother 56(1), 36-44

Vancata R (2002):

Knochen-Abbauprodukte und ihr Einsatz im Disease Management der Osteoporose : $\beta$ CrossLaps in der Ostoporose-Diagnostik.

J Miner Stoffwechs 1 , 42-43

Vanderschueren D, Vandenput L, Boonen S, Lindberg MK, Bouillon R, Ohlsson C (2004): Androgens and Bone.

Endocr Rev 25(3), 389-425

Wade GN, Blaustein JD, Gary JM, Meredith JM (1993):

ICI 182,780: a pure antiestrogen that affects behaviors and energy balance in rats without actingin the brain.

Am J Physiol 265, R1392-1398

Warner M, Nilsson S, Gustafsson JA (1999):

The estrogen receptor family.

Gynecology 11(3), 249-254

Weihua Z, Andersson S, Cheng G, Simpson ER, Warner M, Gustafsson JA (2003):

Update on estrogen signaling.

FEBS Lett $\underline{546}(1), 17-24$

Wich BK, Carnes M (1995):

Menopause And The Aging Female Reproductive System.

Endocrinol Metab Clin N Am 24(2), 273-295

Wilson EM:

Androgen Receptor Structure and Function;

in: Encyclopedia of Hormones, Volume 1; hrsg. v. Henry H L, Norman A W; Elsevier Inc.,

San Diego/USA 2003, 103-110 
Wronski TJ, Yen CF (1991):

The Ovariectomized Rat As An Animal Model For Postmenopausal Bone Loss.

Cells Mater $\underline{1}, 69-74$

Wronski TJ, Schenck PA, Cintrón M, Walsh CC (1987):

Effect of Body Weight on Osteopenia in Ovariectomiezed Rats.

Calcif Tissue Int $\underline{40}(3), 155-159$

Wronski TJ, Cintrón M, Doherty AL, Dann LM (1988):

Estrogen Treatment Prevents Osteopenia and Depresses Bone Turnover in Ovariectomized Rats.

Endocrinology 123, 681-686

Wüster C, Ziegler R: Metabolische Knochenerkrankungen,

in: Thiemes Innere Medizin, hrsg. v. Klaus K, Werner GD, Diener HC, Freund M, Köhler H, Matern S, Maurer HH, Michel BA, Nowak D, Risler T, Schaffner A, Scherbaum WA, Sybrecht GW, Wolfram G, Georg Thieme Verlag, Stuttgart 1999, 350-362

Yamauchi M, Sugimoto T, Yamaguchi T, Nakaoka D, Kanzawa M, Yano S, Ozuru R, Sugishita T, Chiara K (2001):

Plasma leptin concentrations are associated with bone mineral density and the presence of vertebral fractures in postmenopausal women.

Clin Endocrinol $\underline{55}, 241-247$ 


\section{Abbildungs- und Tabellenverzeichnis}

\section{Seite}

1. Einleitung

Abb. 1.1.

Übersicht über die physiologische Einteilung der

zweiten Lebenshälfte der Frau

Abb. 1.2.

Übersicht über die Verteilung der Östrogenrezeptorsubtypen

im Körper der geschlechtsreifen Frau

Abb. 1.3.

Spongiosaausschnitt aus dem Epiphysenbereich einer

humanen Tibia

Abb. 1.4.

Die Abschnitte eines Röhrenknochens am Modell der humanen Tibia

Abb. 2.2.

Transponderchip-Lesegerät

Tab. 2.1.

Einteilung der Tiere in 13 Versuchsgruppen

Abb. 2.3.

Die Tierwaage

Abb. 2.4 .

Das CT-Gerät

Abb. 2.5.

Das Narkosegerät

29

Abb. 2.6.

Tier bei der Ovarektomie

Tab. 2.2.

Gruppeneinteilung und Injektionsplan

Abb. 2.7.

Die Universalprüfmaschine Z020

(Quelle der Abbildungen 2.1.-2.7.: A.Herbst \& K.Stolze, Tierstall des Universitätsklinikums Göttingen)

Abb. 2.9.

Ausschnitt aus dem Protokoll einer standardisierten,

Ratte nach 4wöchiger s.c. Substitutionstherapie unter dem jeweiligen Einfluss von $E_{2}$, dem $E R \alpha$ - oder ER $\beta$-Agonisten

Abb. 3.2.

Durchschnittliches Körpergewicht der ovarektomierten

Ratte nach 4wöchiger s.c. Substitutionstherapie unter dem jeweiligen Einfluss von $E_{2}$, dem $E R \alpha$ - oder $E R \beta$-Agonisten 
Abb. 3.3.1. Durchschnittliche metaphysäre Spongiosadichte der

ovarektomierten Ratte nach 4wöchiger s.c.

Substitutionstherapie unter dem jeweiligen Einfluss

von $E_{2}$, dem $E R \alpha$ - oder $E R \beta$-Agonisten

Abb. 3.3.2. Durchschnittliche metaphysäre Kortikalisdichte der

ovarektomierten Ratte nach 4wöchiger s.c.

Substitutionstherapie unter dem jeweiligen Einfluss

von $E_{2}$, dem $E R \alpha$ - oder $E R \beta$-Agonisten

Abb. 3.4.1. Durchschnittliche endostale Fläche in der Metaphyse

der ovarektomierten Ratte nach 4wöchiger s.c.

Substitutionstherapie unter dem jeweiligen Einfluss

von $E_{2}$, dem $E R \alpha$ - oder ER $\beta$-Agonisten

Abb. 3.4.2.

Durchschnittliche metaphysäre Kortikalisquerschnittsfläche

der ovarektomierten Ratte nach 4wöchiger s.c.

Substitutionstherapie unter dem jeweiligen Einfluss

von $E_{2}$, dem $E R \alpha$ - oder ER $\beta$-Agonisten

Abb. 3.5.

Durchschnittlicher periostaler Umfang der Metaphyse der

ovarektomierten Ratte nach 4wöchiger s.c.

Substitutionstherapie unter dem jeweiligen Einfluss

von $E_{2}$, dem $E R \alpha$ - oder ER $\beta$-Agonisten

Abb.3.6.1. Durchschnittliche Bruchkraft bei der Tibiafraktur der

ovarektomierten Ratte nach 4wöchiger s.c.

Substitutionstherapie unter dem jeweiligen Einfluss

von $E_{2}$, dem $E R \alpha$ - oder $E R \beta$-Agonisten

Abb. 3.6.2. Durchschnittliche Maximalkraft bei der Tibiafraktur der

ovarektomierten Ratte nach 4wöchiger s.c.

Substitutionstherapie unter dem jeweiligen Einfluss

von $E_{2}$, dem $E R \alpha$ - oder ER $\beta$-Agonisten

Abb. 3.7.1. Durchschnittlicher Rat-Laps-Serumwert der

ovarektomierten Ratte nach 4wöchiger s.c.

Substitutionstherapie unter dem jeweiligen Einfluss

von $E_{2}$, dem $E R \alpha$ - oder ER $\beta$-Agonisten

Abb. 3.7.2. Durchschnittlicher Osteokalzin-Serumwert der

ovarektomierten Ratte nach 4wöchiger s.c.

Substitutionstherapie unter dem jeweiligen Einfluss

von $E_{2}$, dem $E R \alpha$ - oder $E R \beta$-Agonisten 


\section{Danksagung}

Ich danke Herrn Prof. Dr. W. Wuttke für die Anregung und Bereitstellung des Themas, durch welches ich diese experimentelle Arbeit im Department für Endokrinologie am Universitätsklinikum Göttingen anfertigen konnte. Seine produktive Kritik in der Phase der Fertigstellung hat mir sehr geholfen.

Ich danke Frau Dr. D. Seidlová-Wuttke für die Betreuung während der Zeit der Entstehung meiner Arbeit. Ihre Unterstützung und Erfahrung während der experimentellen Phase war unerlässlich.

Ich danke Herrn PD Dr. med. F. Schulz, Chefarzt der Klinik für Unfall- und Wiederherstellungschirurgie am Sophien- und Hufeland-Klinikum Weimar für die durch Ihn realisierte Möglichkeit, Bildmaterial für meine Arbeit zu erstellen. Es war eine sehr lehrreiche und menschlich wertvolle Zeit, die ich als PJ-lerin in seiner Abteilung verbringen konnte.

Darüber hinaus danke ich Katrin Stolze für unser gemeinsames Schaffen, im Besonderen während der experimentellen Phase dieser Arbeit. Wir haben dadurch eine wichtige Stufe in unserer Berufsausbildung gemeinsam genommen. Wenn ich an mein Studium in Göttingen denke, wird unsere gemeinsame Zeit dabei immer eine wichtige Rolle spielen. 


\section{Lebenslauf}

Mein Name ist Antje Herbst und ich wurde am 17.06.1982 in Weimar/Thüringen geboren. Meine Kindheit verbrachte ich in Süßenborn, einem kleinen Dorf bei Weimar, der Heimat meiner Familie. Während des Studiums meiner Mutter, Corona Herbst, zur diplomierten Sozialpädagogin in Berlin, übernahm meine Oma, Waltraud Herbst, einen großen Teil meiner Betreuung und Erziehung. Nach Abschluss der Hochschulausbildung meiner Mutter zog unsere Familie nach Weimar, meiner Heimatstadt, welche wir Ende der achtziger Jahre wieder verließen. Unser Wohnsitz verlagerte sich in die Nachbarstadt Apolda, in der ich ab 1989 die Grundschule besuchte. 1993 begann meine Ausbildung am „Staatlichen Gymnasium Bergschule Apolda“, an dem ich im Jahr 2001 mit dem Abitur meine Hochschulreife erwarb. Hier arbeitet meine Mutter als Amtsleiterin des ,Jugend- und Sportamtes' im Landratsamt Weimarer Land. Mein Vater, Johannes Zühlke, war viele Jahre im Bereich ,Brandschutz' des Kreises Weimarer Land tätig und wirkte im Amt des Kreisbrandinspektors und Kreisbrandmeisters.

Im Oktober 2001 begann ich in Bad Wildungen/Hessen die Ausbildung zur Krankenschwester, welche ich noch in der Probezeit aufgab, um Medizin zu studieren. Mein Studium begann ich im Sommersemester 2002 an meiner Wunschuniversität, der GeorgAugust-Universität in Göttingen.

Für die Absolvierung des Praktischen Jahres wechselte ich im Frühjahr 2007 an die Friedrich-Schiller-Universität Jena. Das Wahlfach belegte ich in der Abteilung Mund-, Kiefer-, Gesichtschirurgie am Universitätsklinikum Jena. Hier werde ich nach Abschluss meines Studiums eine Stelle als Assistenzärztin antreten. 